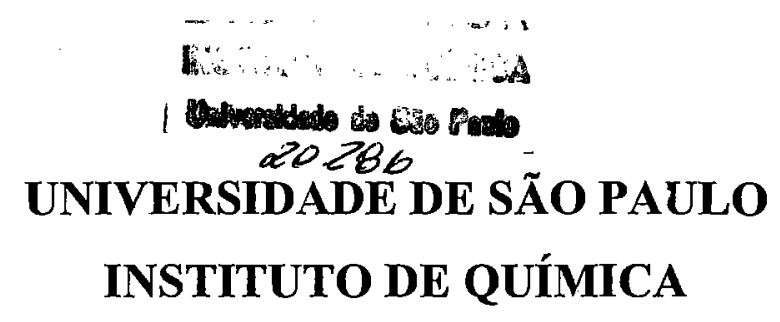

\title{
USO DE MICROFRASCOS DE DIGESTÃO EM FORNO DE MICROONDAS FOCALIZADAS COMO UMA ALTERNATIVA PARA A PREPARAÇÃo DE AMOSTRAS
}

Tan Chun Shan DISSERTAÇÃO DE MESTRADO

\author{
ORIENTADORA \\ PROFa. Dra. ELISABETH DE OLIVEIRA
}

SÃO PAULO

Janeiro de 2003

02 


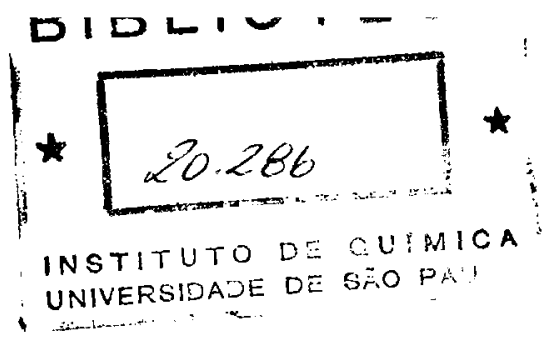

\section{DEDALUS - Acervo - CQ

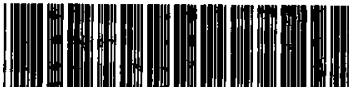 \\ 30100005149}

Ficha Catalográfica

Elaborada pela Divisão de Biblioteca e

Documentação do Conjunto das Químicas da USP.
S528u Uso de microfrascos de digestão em forno de microondas focalizadas como uma alternativa para a preparação de amostras
/ Tan Chun Shan. -- São Paulo, 2003. $83 \mathrm{p}$.

Dissertação (mestrado) - Instituto de Química da Universidade de São Paulo. Departamento de Química Fundamental.

Orientador: Oliveira, Elisabeth de

1. Amostra : Preparação: Química analítica 2. Absorção atômica I. T. II. Oliveira, Elisabeth de, orientador. 


\section{"Uso de Microfrascos de Digestão em Forno de Microondas Focalizadas como uma Alternativa para a Preparação de Amostras"}

\section{TAN CHUNSHAN}

Dissertação de Mestrado submetida ao Instituto de Química da Universidade de São Paulo como parte dos requisitos necessários à obtenção do grau de Mestre em Química - Área: Química Analítica.

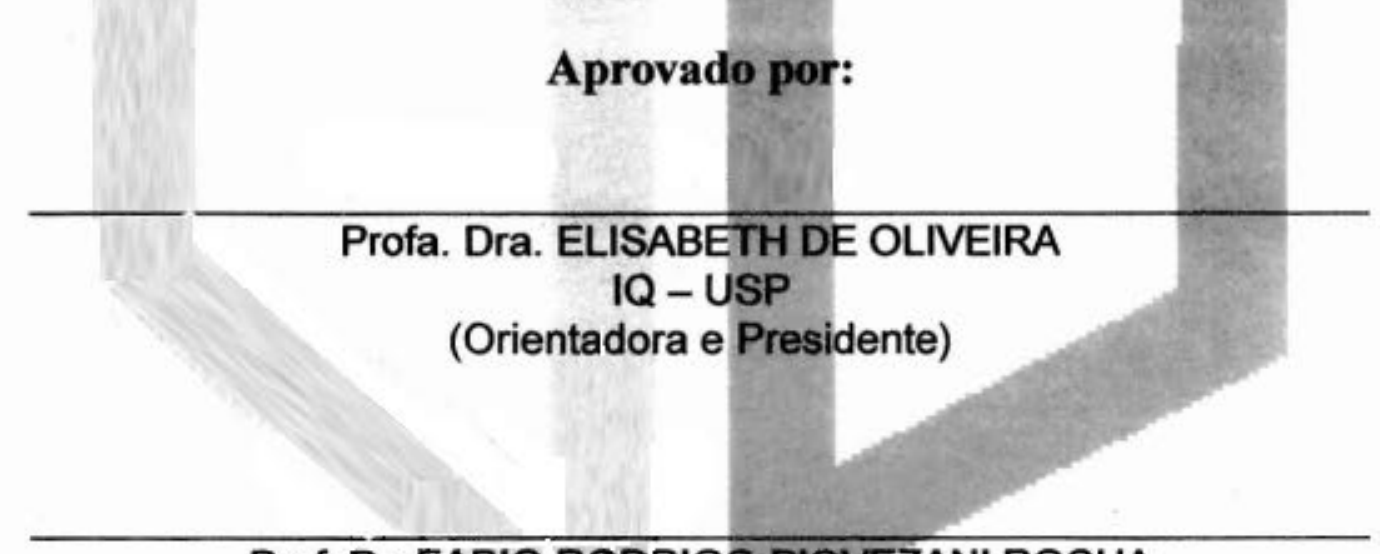

Prof. Dr. FABIO RODRIGO PIOVEZANI ROCHA

IQ - USP

Prof. Dr. FRANCISCO JOSÉ KRUG

CENA - USP - Piracicaba

SÃO PAULO

16 DE DEZEMBRO 2002. 
"Existe uma coisa que uma longa existência me ensinou: toda a nossa ciência, comparada à realidade, é primitiva e inocente; portanto, é o que temos de mais valioso."

Albert Einstein 
"Nunca pare de aprender e de se adaptar. O mundo está sempre mudando. Se você se limitar àquilo que sabia e com que você se sentia à vontade em outra época da vida, irá se isolando à medida que envelhecer e sentindo cada vez maior frustação com as circunstâncias à sua volta." 
Dedico este trabalho a minha mãe e ao meu irmão, que nos momentos bons e dificeis tanto lutaram pela minha formação e realização pessoal, e sem os quais, nada teria sido possível. 


\section{Agradecimentos}

À $\operatorname{Dr}^{\mathrm{a}}$ Elisabeth de Oliveira pela orientação, amizade, apoio e confiança em mim depositado durante o desenvolvimento do presente trabalho.

Ao Prof. Dr. Pedro Vitoriano de Oliveira pela co-orientação, amizade e respeito.

A assessoria científica da FAPESP, pelo apoio financeiro concedido para a realização do trabalho.

Ao Dr Francisco José Krug por fornecer o moinho criogênico para o desenvolvimento do trabalho.

À Dra Marina Vasconcellos do IPEN por fornecer uma amostra de referência de cabelo durante o desenvolvimento do trabalho.

À Pró-Reitoria de Pós-Graduação da USP pelo apoio financeiro que permitiu minha participação em um relevante encontro científico.

Ao Prof. José Anchieta Gomes Neto que despertou meu interesse pela Química Analítica.

À todos os docentes do IQ-UNESP de Araraquara pela sólida formação em Química, que me permitiu ingressar no programa de Pós-Graduação do IQ-USP.

À minha mãe pelo carinho e incentivo pelos estudos.

Ao meu querido irmão pela amizade e suporte financeiro ao longo dos quatro anos de graduação. 
À Melissa pela paciência, apoio e carinho durante todos os momentos

Ao Paulo, pela amizade e pelas discussões científicas que auxiliaram bastante no desenvolvimento do presente trabalho.

Aos amigos do LEEAA, pela agradável convivência ao longo desses anos de trabalho.

Aos amigos da secretaria de Pós-Graduação do IQ-USP, pelo atendimento cordial e eficiente oferecido durante o mestrado. 


\section{SUMÁRIO}

1 Introdução

2 Revisão Bibliográfica

2.1 Pré-tratamento de amostra 3

2.1.1 Decomposição de amostra - Procedimentos convencionais 5

2.1.1.1 Decomposição de amostras - Via seca 6

2.1.1.2 Decomposição de amostras - Via úmida 8

2.1.2 Decomposição de amostra - Procedimentos alternativos 14

2.1.2.1 Acoplamento do forno de microondas a sistemas de fluxo $\quad 14$

2.1.2.2 Decomposição de amostras em microfrascos 16

2.1.2.3 Decomposição de amostras em microfrascos com vapor ácido $\quad 17$

2.1.2.4 Decomposição de amostras através da hidrólise enzimática $\quad 18$

2.1.2.5 Decomposição a alta pressão com microondas focalizadas $\quad 19$

2.1.2.6 Decomposição assistida por radiação infravermelho 19

2.1.2.7 Associação do forno de microondas com radiação UV para 20 decomposição de amostras

2.2 Aspectos morfológicos do cabelo 21

2.2.1 Absorção de elementos pelo cabelo 22

2.2.2 Determinação elementar no cabelo 23

2.3 Importância nutricional dos elementos $\mathrm{Se}, \mathrm{Mn}, \mathrm{Fe}, \mathrm{Cu}$ e $\mathrm{Zn}$

3 Objetivo $\quad 28$

4 Experimental $\quad 29$ 
4.2 Reagentes e soluções

4.3 Procedimento 34

4.3.1 Construção de um sistema de decomposição com microfrascos 34

4.3.2 Calibração da potência total do forno de microondas focalizadas 36

4.3.3 Verificação da potência absorvida pelos microfrascos no forno de microondas focalizadas

4.3.4 Programa de aquecimento do forno de microondas focalizadas

4.3.5. Avaliação da quantidade de massa de amostra utilizada para decomposição nos microfrascos

4.3.6 Verificação da variação do volume do microfrasco de polipropileno após a decomposição

4.3.7 Avaliação da temperatura do sistema de decomposição proposto

4.3.8 Avaliação da eficiência de decomposição do sistema proposto

4.3.8.1 Decomposição de amostras de cabelo em forno de microondas fechado (FMfec)

4.3.8.2 Decomposição de amostras de cabelo em forno de microondas focalizadas - Método convencional (FMfoc)

4.3.8.3 Decomposição de amostras de cabelo pelo procedimento proposto

4.3.9 Otimização do programa de aquecimento para determinação de Mn em digeridos de cabelo por GFAAS

4.3.10 Otimização do programa de aquecimento para determinação de Se em digeridos de cabelo por GFAAS 
4.3.10.1 Verificação do comportamento térmico do Se frente a diferentes tipos de modificadores químicos

4.3.10.2 Avaliação da concentração dos modificadores químicos

4.3.10.3 Estudo da interferência de sulfato na determinação de Se por GFAAS

4.3.10.4 Programa de aquecimento na presença do melhor modificador químico

4.3.11 Avaliação de perda dos elementos utilizando o sistema de digestão proposto

4.3.12 Determinação dos elementos em amostras de referência certificada de cabelo e avaliação de adição e recuperação de analito

4.3.13 Decomposição de diferentes matrizes utilizando o sistema proposto

5 Resultados e discussão

5.1 Microfrascos de polipropileno e a escolha dos reagentes 54

5.2 Calibração do forno de microondas focalizadas 56

5.3 Verificação da potência absorvida pelos microfrascos no forno de microondas focalizadas

5.4 Programa de aquecimento do forno de microondas focalizadas

5.5 Avaliação da quantidade de massa de amostra utilizada para decomposição nos microfrascos

5.6 Verificação da variação do volume do microfrasco de polipropileno após a decomposição 
5.9 Programa de aquecimento para determinação de Mn em digeridos de cabelo por GFAAS

5.10 Programa de aquecimento para determinação de Se em digeridos de cabelo por GFAAS

5.10.1 Verificação do comportamento térmico do Se frente a diferentes tipos de modificadores químicos

5.10.2 Avaliação da concentração dos modificadores químicos

5.10.3 Interferência de sulfato na determinação de Se por GFAAS

5.10.4 Programa de aquecimento utilizando o melhor modificador químico

5.11 Avaliação de perda dos elementos utilizando o sistema de digestão proposto

5.12 Determinação dos elementos em amostras de referência certificada de cabelo e avaliação de adição e recuperação de analitos

5.13 Decomposição de diferentes matrizes utilizando o sistema proposto 


\section{LISTA DE FIGURAS}

BIBLIOTECA

INSTITUTO DE QUIMICA

Ualversiçade de São Prulc 


\section{Lista de figuras}

Figura 1. Sistema de decomposição com plasma de oxigênio (CPA) com agitador magnético.

Figura 2. Sistema de decomposição de alta pressão em autoclave.

Figura 3. Desenho esquemático de um forno de microondas

Figura 4. Esquema de guia de ondas de forno com microondas focalizadas equipado com um único magnetron.

Figura 5. Esquema de microondas focalizadas equipado com 6 frascos digestores.

Figura 6. Diagrama de blocos representando o sistema de fluxo acoplado a um forno de microondas para o preparo de amostras.

Figura 7. Representação dos folículos do cabelo.

Figura 8. Sistema de decomposição proposto.

Figura 9. Desenho esquemático do sistema de decomposição proposto.

Figura 10. Posições para o suporte 1.

Figura 11. Posições para o suporte 2.

Figura 12. Procedimento de digestão das amostras para avaliação de perdas de elementos por volatilidade.

Figura 13. Variação do volume dos microfrascos de $2,0 \mathrm{~mL}$, verificada após aquecimento com o programa de decomposição.

Figura 14. Variação do volume dos microfrascos de $4,0 \mathrm{~mL}$, verificada após aquecimento com o programa de decomposição.

Figura 15. Temperaturas atingidas no interior dos microfrascos.

Figura 16. Curvas de temperaturas de pirólise e atomização de manganês na presença dos modificadores químicos.

Figura 17. Curvas de temperatura de pirólise e atomização de selênio na ausência e presença de modificadores químicos.

Figura 18. Curvas de temperaturas de pirólise e atomização para a solução analítica de selênio e para a solução de digerido de cabelo com adição de padrão. 
Figura 19. Sinal analítico de $20 \mu \mathrm{g} / \mathrm{L}$ de Se utilizando modificares químicos $\mathrm{Pd}+$ $\mathrm{Mg}$ e Ir + Mg com as diferentes concentrações.

Figura 20. Sinal analítico e background de selênio utilizando modificador químico $\mathrm{Pd}+\mathrm{Mg}$ com diferentes concentrações.

Figura 21. Supressão do sinal analítico de selênio pela presença de $25 \mu \mathrm{g} \mathrm{de} \mathrm{SO}_{4}{ }^{2-}$

Figura 22. Comportamento térmico do selênio com a utilização do modificador químico $20 \mu \mathrm{g} P d+10 \mu \mathrm{g} \mathrm{Mg}$ na solução analítica de selênio e na solução de digerido de cabelo com adição de $20 \mu \mathrm{g} / \mathrm{L}$ Se. 


\section{Lista de tabelas}

Tabela 1. Parâmetros instrumentais para determinação dos elementos por FAAS e GFAAS.

Tabela 2. Parâmetros instrumentais do ICP-OES para determinação de carbono residual.

Tabela 3. Opções de aplicação de potência do forno de microondas focalizadas.

Tabela 4. Programa de aquecimento do forno de microondas focalizadas para a decomposição de amostras de cabelo utilizando os microfrascos.

Tabela 5. Programa de aquecimento do forno de microondas focalizadas para a digestão de amostras no procedimento convencional.

Tabela 6. Programa de aquecimento do forno de microondas focalizadas para a digestão de amostra no sistema proposto.

Tabela 7. Programa de aquecimento para estudar o comportamento térmico do manganês.

Tabela 8. Programa de aquecimento para a determinação de selênio por GFAAS.

Tabela 9. Modificadores químicos com diferentes concentrações.

Tabela 10. Parâmetros utilizados para avaliação de perda de elementos por volatilidade.

Tabela 11. Parâmetros analíticos para determinação dos elementos em cabelo.

Tabela 12. Parâmetros analíticos para determinação dos elementos em fígado bovino.

Tabela 13. Potência real calculada através da calibração do forno de microondas focalizadas.

Tabela 14. Potência estimada nas posições utilizando microfrascos de $2,0 \mathrm{~mL}$.

Tabela 15. Potência estimada nas posições utilizando microfrascos de $4,0 \mathrm{~mL}$.

Tabela 16. Teor de carbono residual de diferentes procedimentos de digestão.

Tabela 17. Teor de carbono residual de diferentes amostragens de cabelo. 
Tabela 18. Programa de aquecimento otimizado para a determinação de manganês.

Tabela 19. Programa de aquecimento para a determinação de selênio por GFAAS.

Tabela 20. Recuperação dos elementos após o procedimento de digestão.

Tabela 21. Parâmetros das calibrações para determinações dos elementos.

Tabela 22. Resultados obtidos em amostra de material de referência IAEA-086.

Tabela 23. Resultados obtidos em amostra de cabelo.

Tabela 24. Resultados obtidos nas análises dos elementos das amostras de cabelo.

Tabela 25. Recuperações dos elementos $\mathrm{Fe}, \mathrm{Cu}$ e $\mathrm{Zn}$ na amostra de fígado bovino. 
$\underline{\text { LISTA DE ABREVIATURAS E SÍMBOLOS }}$ 


\section{Lista de abreviaturas e símbolos}

01. CPA: Equipamento para decomposições via seca a baixas temperaturas, do inglês, Cool Plasma Asher.

02. DNA: Ácido desoxirribonucleico

03. EDL: Lâmpada de descarga sem eletrodo, do inglês, Electroless Discharge Lamp.

04. EDTA: Sal de sódio etilenodiaminotetracético.

05. ETAAS: Espectrometria de absorção atomica eletrotérmica, do inglês, Electrothermal Atomic Absorption Spectrometry.

06. FIA: Analise por Injeção em fluxo, do inglês, Flow Injection Analysis.

07. GFAAS: Espectrometria de absorção atômica em forno de grafite, do inglês, Graphite Furnace Atomic Absorption Spectrometry.

08. HCl: Lâmpada de catodo oco, do inglês, Hollow Cathode Lamp.

09. HPA: Sistema de decomposição a alta pressão em autoclave, do inglês, High Pressure Asher.

10. HPA-FMs: Sistema de decomposição a alta pressão com aquecimento por forno de microondas, do inglês: High-Pressure Asher Focused Microwave.

11. ICP-MS: Espectrometria de massa com plasma indutivamente acoplado, do inglês, Inductively Coupled Plasma - Mass Spectrometry.

12. ICP-OES: Espectrometria de emissão ótica com plasma indutivamente acoplado, do inglês, Inductively Coupled Plasma Atomic Emission Spectrometry.

13. OMC: Organização Mundial da Saúde.

14. PTFE: Politetrafluoretileno

15. PFA: Perfluoralcoxi.

16. RIA: Radioimunoensaio. 
17. TFM $^{\circledR}$ : Marca registrada da Hoechst para PTFE quimicamente modificado.

18. USDA: Departamento de agricultura dos Estados Unidos, do inglês U. S. Department of Agriculture.

19. UV: Ultra-Violeta.

20. UV-Vis: Espectrofotometria de absorção no ultra-violeta e visível. 


\section{RESUMO}

Este trabalho propõe o uso de microfrascos de polipropileno adaptados a um forno de microondas focalizadas como um procedimento alternativo para a preparação de amostras. $\mathrm{O}$ pré-tratamento de amostras em microfrascos digestores agrega algumas características importantes como aumento da freqüência analítica, pequena massa de amostra e baixo consumo de reagentes. A eficiência do sistema de digestão foi verificada com o desenvolvimento de metodologia para a determinação de cobre, ferro, manganês, selênio e zinco em cabelo por espectrometria de absorção atômica com atomização por chama ou eletrotérmica em forno de grafite. Os elementos selecionados são essenciais para os seres humanos e são indicadores nutricionais e do bom funcionamento enzimático.

O sistema de digestão é constituído de um forno de microondas focalizadas e um tubo de vidro com $30 \mathrm{~cm}$ de comprimento e $4 \mathrm{~cm}$ de largura, ao qual são colocados quatro ou cinco microfrascos de polipropileno com capacidade para respectivamente $4,0 \mathrm{~mL}$ e $2,0 \mathrm{~mL}$. Esses microfrascos foram adaptados a um suporte de Teflon $^{\circledR}$ e fixado a uma haste de vidro, facilitando a introdução e retirada do interior do tubo de vidro.

O sistema proposto possibilitou uma drástica redução no tempo de preparo de amostra e melhor eficiência de decomposição (menor teor de carbono residual) em comparação com os procedimentos convencionais. O sistema "quase fechado" associado a baixas temperaturas atingidas evitou perdas de elementos por volatilidade, além de apresentar uma ótima homogeneidade de aquecimento entre os microfrascos.

A exatidão da metodologia foi verificada através de ensaios de recuperação da análise de um material de referência certificado (IAEA-086) e da análise de amostra com adição e recuperação dos analitos apresentando recuperações de 90 a 103\%. 
In this work the use of polypropylene vials adapted at focused microwaves, as alternative method for sample preparation is proposed. The sample pre-treatment in digestion vials include some desirable characteristics like increase of analytical frequency, low sample mass and low reagents consumption. To check the efficiency of the digestion system the development of a methodology for copper, iron, manganese, selenium and zinc determination using graphite furnace or flame atomic absorption spectrometry was performed. The selected elements are essential for human individual, nutritional indicators and required for enzymatic working.

The digestion system is constituted of a focused microwave oven, a glass tube with $30 \mathrm{~cm}$ length and $4 \mathrm{~cm}$ width, where are setting four or five polypropylene vials with capacity for $4.0 \mathrm{~mL}$ and $2.0 \mathrm{~mL}$, respectively, through a Teflon ${ }^{\circledR}$ support assisted by glass haste.

The proposed system allowed a drastic reduction of sample preparation time and improved the decomposition efficiency (lower carbon residual content) comparing with conventional methods. The "almost closed" system associated with the low temperature avoids elements losses and improve heating homogeneity among the vials.

The accuracy of the methodology was ascertained through good recoveries for a certificate reference material (IAEA-086) analysis and good recovery of spiked sample analysis, presenting recovery 90 to $103 \%$. 


\section{INTRODUÇÃO}

A tendência atual da química analítica moderna é o desenvolvimento de métodos que apresentem como características principais simplicidade, rapidez, segurança, necessite de um mínimo de reagentes, apresente baixo nível de contaminações e que produza pequena quantidade de resíduos, gerando resultados precisos e exatos ao menor custo possível. Entretanto, do ponto de vista prático, os métodos atuais ainda não contemplam todas essas caraterísticas.

A grande maioria das técnicas analíticas utilizadas para determinações elementares requer que a amostra esteja na forma de uma solução aquosa e desta forma, na maioria das vezes, a frequência analítica fica comprometida. É conveniente observar que, entre as várias etapas envolvidas no processo analítico, o pré tratamento das amostras, necessário na maioria das vezes, é a que consome o maior tempo do analista e é aquela em que estão associados muitos erros cometidos durante a análise química ${ }^{1,2}$.

Os procedimentos convencionais de pré tratamento de amostra por via úmida, via seca ou fusão, utilizando chapas elétricas ou muflas, requerem um laborioso trabalho experimental, consumindo muito tempo e reagentes; alguns deles são potencialmente perigosos, podendo ainda estar sujeitos a perdas do analito ou contaminações ${ }^{2}$. Alternativamente, os procedimentos de pré tratamento de amostra com aquecimento assistido por microondas vem sendo utilizados cada vez mais, sobretudo devido às características favoráveis como rapidez e reduzido volume de reagente requerido ${ }^{3-5}$. As vantagens oferecidas pelo aquecimento assistido por microondas são amplamente demonstradas em muitos dos procedimentos disponíveis na literatura ${ }^{3,4}$. Entretanto, as condições de decomposição precisam ser estabelecidas para cada problema analítico individualmente, ou seja, tipo de amostra, elementos a serem determinados e o tipo de forno de microondas empregado ${ }^{6}$.

Uma das principais metas da química analítica atual é o aperfeiçoamento e a simplificação das operações envolvidas no pré-tratamento de amostra. A amostragem direta de suspensões ${ }^{7}$, a mecanização empregando sistemas de injeção em fluxo acoplados a fornos 
de microondas para digestão "on-line" de amostras ${ }^{8,9}$, o emprego de microfrascos de polipropileno para o pré-tratamento de amostras de materiais vegetais e biológicos em sistemas pressurizados $^{10-13}$, a solubilização de amostras de materiais vegetais por digestão ácida em fase vapor ${ }^{12,13}$ e a utilização de radiação do infravermelho como alternativa aos fornos de microondas ${ }^{14}$ reforçam essa tendência. Esses procedimentos de pré tratamento de amostras são adequados para as determinações elementares por espectrofotometria de absorção molecular ultravioleta-visível (UV-Vis), espectrometria de absorção atômica com chama (FAAS) e com atomização eletrotérmica (ETAAS), espectrometria de emissão ótica com plasma induzido em argônio (ICP-OES) e espectrometria de massas com fonte de plasma (ICP-MS). 


\section{REVISÃO BIBLIOGRÁFICA}

A revisão bibliográfica, aqui apresentada, encontra-se subdividida em três partes, carrespondendo aos principais assuntos abordados neste trabalho: pré-tratamento de amostras, análise de cabelo e a importância nutricional dos elementos analisados no cabelo. Na primeira parte da revisão, procurou-se descrever os métodos convencionais de pré-tratamento de amostras com ênfase especial aos procedimentos de decomposição de amostras por via seca e via úmida. Na segunda parte, abordaram-se assuntos envolvendo morfologia e determinações elementares em cabelo. Na ultima parte da revisão abordaram-se aspectos nutricionais do selênio, manganês, cobre, ferro e zinco no organismo humano.

\subsection{Pré-tratamento de Amostra}

Os avanços da eletro-eletrônica e da informática possibilitaram a rápida evolução da química analítica, em especial a instrumentação. Atualmente, existem equipamentos que permitem a determinação de elementos ao nível de $\mathrm{ng} \mathrm{g}^{-1}$ com grande precisão, equipamentos especiais para o processamento de líquidos, os quais fazem diluições em linha, adições de soluções de referências e de outros reagentes e pré-concentrações ${ }^{15}$. Apesar desse grande avanço instrumental, para muitas técnicas, especialmente as espectroanalíticas como FAAS, ETAAS, ICP-OES e ICP-MS, a maneira usual de introdução de amostra é na forma de solução aquosa. Sendo assim, muito freqüentemente, uma solubilização ou decomposição das amostras é uma tarefa necessária antes das determinações elementares. O pré-tratamento de amostra, o qual frequentemente inclui os procedimentos de decomposição, é uma etapa crítica, uma vez que, a maior parte do tempo gasto (61\% do tempo total de uma análise) e os maiores erros $(30 \%)$ de uma análise estão a ela associados ${ }^{16}$.

Em geral, os procedimentos de pré-tratamento das amostras envolvem não somente a digestão ou solubilização, e a maioria das amostras requer etapas preliminares como lavagem, secagem, moagem, armazenamento, liofilização, homogeneização, 
filtração e extração. Em todas essas etapas, os problemas inerentes do pré-tratamento podem surgir ${ }^{17}$.

A lavagem, para muitas amostras é uma etapa desnecessária, entretanto existem amostras que precisam sofrer o processo de lavagem para reduzir a variabilidade causada pela presença de poeira ou partículas de solo ${ }^{18}$. No caso da análise de cabelo, a etapa de lavagem é considerada imprescindível na análise elementar, para a eliminação de contaminação exógena ${ }^{19}$. Isto deve-se em parte às dificuldades e problemas que ocorrem nesta etapa e que normalmente implicam em erros sistemáticos ${ }^{20}$.

A operação de secagem é feita com dois objetivos: preservação de amostras ambientais e biológicas da ação microbiana durante o armazenamento (fungos podem aparecer após poucos dias de estocagem) e padronização do teor de umidade de um ou mais lotes de amostras. A secagem pode ser feita em dessecadores, estufas e fornos ou por liofïlização, processo no qual a amostra é inicialmente congelada e depois seca sob vácuo em temperaturas da ordem de $45^{\circ} \mathrm{C}^{21}$.

$\mathrm{O}$ armazenamento de amostras em condições adequadas evita a contaminação proveniente do ambiente. No armazenamento é importante considerar não somente o material do frasco, como também a temperatura. Em geral, os materiais mais usados são: vidro borossilicato ou materiais plásticos como o polipropileno, polietileno e Teflon ${ }^{\circledR}$.

A diminuição do tamanho das partículas, por processos de moagem, é feita com o objetivo de melhorar a homogeneidade e aumentar a relação entre a área superficial e o volume da amostra, o que em etapas posteriores pode facilitar a dissolução ${ }^{2}$. Entretanto, a moagem e o peneiramento podem acarretar alguns problemas relacionados com contaminação e perdas da amostra. Os procedimentos empregados dependerão, entre outros fatores, da quantidade e da diversidade de amostras a serem homogeneizadas, do tamanho das partículas e da dureza do material. Entre os materiais utilizados para moer, podem ser citados aço inoxidável, ágata, óxido de zircônio, carbeto de tungstênio, titânio e politetrafluoretileno ${ }^{2}$. Um dos procedimentos de moagem, conhecido como moagem criogênica, utiliza o princípio de congelamento da amostra com a utilização de nitrogênio líquido e posterior cominuição dessa amostra com barras de aço inoxidável. É bastante eficiente para amostras com elevado teor de água como as amostras biológicas e de alimentos $^{22}$. 
A homogeneização é necessária para se obter a representatividade da amostra coletada. Isto irá reduzir a diversidade química e biológica entre as amostras. A etapa de homogeneização é bastante crítica para a amostragem de suspensões, uma vez que as massas utilizadas para preparar as suspensões são relativamente pequenas e a quantidade de partículas que são amostradas, é muito pequena. Por exemplo, em ETAAS, para assegurar boa precisão entre as medidas é necessário garantir a introdução de pelo menos 50 partículas no interior do tubo de grafite. Um outro problema associado às análises de suspensões é a estabilidade das mesmas ${ }^{7}$.

A filtração, especialmente para as técnicas analíticas que utilizam nebulização pneumática para a introdução de amostras, torna-se necessária para a eliminação de resíduos sólidos da solução, os quais podem causar o entupimento dos nebulizadores ${ }^{24}$. Em certos casos, a filtração é usada durante a coleta das amostras, especialmente quando se trata de particulados atmosféricos.

A decomposição de amostra, ou seja, a digestão ou solubilização de amostras com o auxílio de ácidos oxidantes e em altas temperaturas, tem como objetivo a destruição macroscópica da matriz e quebra de ligações químicas de elementos com o restante desta, solubilizando dessa maneira o analito de interesse. Em geral, os elementos de interesse estão quimicamente ligados nas amostras ${ }^{25}$.

O desenvolvimento de procedimentos analíticos que simplifiquem todas as etapas do preparo de amostra de maneira que se evitem perdas e contaminação do analito e que torne os processos mais rápidos e seguros, é um desafio considerado por muitos autores como "o estado da arte do preparo de amostras" 4,27.

\subsubsection{Decomposição de Amostras - Procedimentos Convencionais}

Os procedimentos de decomposição de amostras podem ser por via seca e via úmida, referindo-se respectivamente, aos procedimentos envolvendo uma etapa de aquecimento em muflas e com a adição de reagentes ${ }^{2}$. Também serão discutidos alguns procedimentos alternativos de decomposição de amostras por via úmida ${ }^{4,11,12,14,29}$. Cabe ressaltar que serão enfocados sistemas de decomposição visando aos materiais orgânicos. 


\subsubsection{Decomposição de Amostras - Via Seca}

A decomposição de amostras por via seca envolve os mais antigos e mais simples procedimentos para a eliminação de matéria orgânica. Esses métodos baseiam-se na oxidação da matéria orgânica, obtendo-se um resíduo inorgânico na forma de cinza solúvel em soluções ácidas. Os procedimentos de decomposição por via seca ${ }^{5}$ podem ser realizados em sistemas abertos, a baixas temperaturas ${ }^{5}$ ou em sistemas fechados como o frasco de combustão com oxigênio ${ }^{2}$.

A decomposição por via seca, em sistema aberto, a qual é também chamada de decomposição clássica, foi um dos procedimentos mais populares para a destruição da matriz orgânica, visando à análise de traços em amostras de materiais biológicos ${ }^{30}$. A amostra é colocada em um cadinho (quartzo ou porcelana) e aquecida na atmosfera ambiente até que todo material orgânico seja queimado, resultando apenas um resíduo inorgânico não volátil. O oxigênio na atmosfera atua como agente oxidante e o resíduo proveniente da queima consiste de óxidos de metais, assim como sulfetos não voláteis, fosfatos, silicatos e outros.

Uma vantagem desta técnica é a possibilidade de se utilizarem quantidades relativamente grandes de amostras, além de não causar uma diluição excessiva, minimizando os problemas associados com a heterogeneidade do material analisado e também da baixa quantidade de alguns analitos. Em contrapartida, alguns elementos podem ser convertidos em uma forma volátil e perdidos parcial ou completamente, ou ainda sofrer reação com o cadinho. Esses problemas impossibilitam a aplicação desses métodos para todos os elementos, sendo aplicável somente para elementos metálicos, visto que a maioria dos semi-metais e não metais são oxidados a produtos voláteis ${ }^{20}$. Um procedimento alternativo para minimizar perdas baseia-se na oxidação da amostra em baixas temperaturas (em torno de $150^{\circ} \mathrm{C}$ ) por átomos de oxigênio excitados, radicais livres, íons e elétrons livres, gerados pela passagem de um fluxo de oxigênio à baixa pressão (1-5 torr) através de um tubo de sílica aquecido ${ }^{2}$. Dependendo da técnica utilizada para determinação, a concentração de sólidos dissolvidos na solução final pode ser problemática. Os produtos voláteis da combustão e o excesso de oxigênio são purgados em direção a um módulo de exaustão, enquanto que os constituintes não 
voláteis permanecem no resíduo, os quais podem ser posteriormente determinados. Em virtude das baixas temperaturas, as perdas por volatilização e as interações com os frascos de reação são sensivelmente diminuídas. Elementos voláteis como $\mathrm{As}, \mathrm{Cd}, \mathrm{Sb}$, $\mathrm{Pb}, \mathrm{B}$ e Ge podem ser submetidos a este procedimento de decomposição sem perdas significativas. A grande desvantagem apresentada neste procedimento é a baixa pressão do oxigênio, o que implica em uma velocidade de combustão muito lenta, levando se horas e em alguns casos até dias para queimar um grama de amostra.

Para os materiais com altos teores de cinzas onde o oxigênio excitado não consegue atingir o centro da amostra, foi proposto em 1982 por Knapp ${ }^{31}$, um equipamento denominado CPA (do inglês Cool Plasma Asher). O sistema, conforme representado na figura 1, utiliza um agitador magnético adaptado ao sistema CPA para a agitação da amostra durante o processo de decomposição a baixa temperatura.

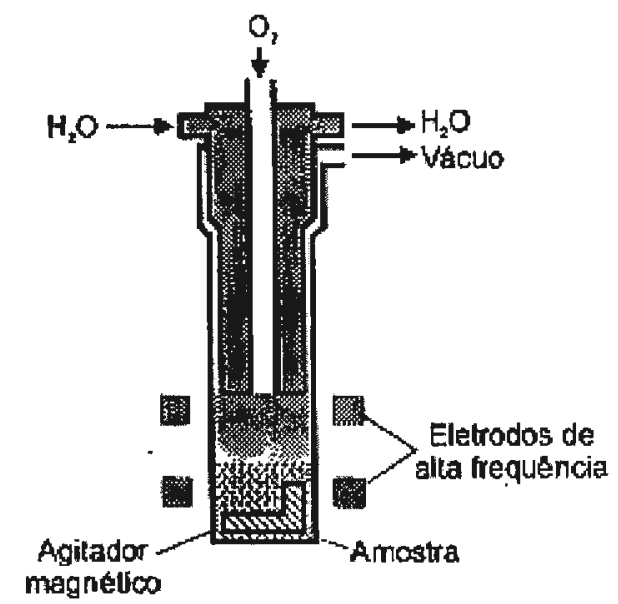

Figura 1. Sistema de decomposição com plasma de oxigênio (CPA) com agitador magnético ${ }^{31}$.

Em 1955, Schöniger desenvolveu o método do frasco de combustão com oxigênio, também conhecido como frasco de combustão de Schöniger para a decomposição de amostras orgânicas e biológicas ${ }^{2}$. O método consiste em confinar a amostra em um envoltório, normalmente papel, o qual fica suspenso em um frasco fechado com atmosfera de oxigênio e com uma solução absorvedora de íons. O envoltório é queimado e os produtos da oxidação são absorvidos pela solução. As vantagens desse método 
incluem a velocidade de decomposição das amostras, o baixo risco de perdas e contaminação, por se tratar de um sistema fechado, bem como a simplicidade do processo. As limitações do método são a oxidação incompleta da amostra (às vezes um pouco de fuligem é produzida, a qual pode interferir em algumas determinações, embora a inclusão de um aditivo possa contornar esse problema); a possível contaminação proveniente do papel utilizado ou ainda a formação de monóxido de carbono, tornando inviável para a determinação de carbono.

\subsubsection{Decomposição de Amostras - Via Úmida}

Da mesma maneira que as técnicas de decomposição por via seca, as técnicas de decomposição por via úmida podem ser realizadas em sistemas abertos ou fechados.

Em geral, os procedimentos convencionais de decomposição de materiais orgânicos ou biológicos por via úmida implicam em aquecimento da amostra em um bloco digestor, chapa metálica ou em fornos de microondas na presença de reagente ou mistura de reagentes. Estes reagentes podem ser um ácido mineral oxidante concentrado, misturas de ácidos oxidantes, misturas de ácido oxidante com peróxido de hidrogênio, ou ainda, hidrólise alcalina com o hidróxido de tetrametilamônio ${ }^{32}$.

Os ácidos com propriedades oxidantes mais usados na decomposição por via úmida são o nítrico, o sulfúrico e o perclórico. Estes ácidos podem ser usados individualmente (com exceção do ácido perclórico, devido ao perigo de explosão) ou combinados uns com os outros. Quando um determinado ácido é indispensável para a decomposição de uma amostra em particular e precisa estar presente na mistura, o mesmo, normalmente em maior proporção, não somente determina a taxa e a extensão da decomposição, como também pode afetar a escolha do método analítico ${ }^{20}$. A decomposição por via úmida é particularmente útil para a determinação de baixas concentrações de metais em vários tipos de amostras, porque muitos elementos de interesse são convertidos em cátions inorgânicos simples não voláteis, que permanecem no meio ácido.

A decomposição por via úmida em frascos abertos é uma das mais antigas e usadas técnicas para a dissolução de amostras orgânicas. Este método baseia-se na 
decomposição de amostras por ácidos aquecidos em frascos abertos à pressão atmosférica. No entanto, segundo $\mathrm{Knapp}^{33}$, a decomposição em frascos abertos está sujeita a erros sistemáticos por contaminação e perdas por volatilização. $\mathrm{O}$ uso de ácidos concentrados pode aumentar o risco de contaminação e afetar a qualidade dos brancos.

Em virtude das decomposições por via úmida em sistemas abertos serem realizadas a pressão atmosférica, a temperatura de decomposição se restringe à temperatura de ebulição do solvente ou ácido empregado. Considerando que a taxa de reação está diretamente relacionada com a temperatura, esta condição impõe um limite sobre o tempo necessário para a decomposição da amostra. Uma reação mais rápida pode ser obtida fechando-se a amostra e o ácido em um frasco resistente à pressão e à temperatura. Esse tipo de abertura, ao mesmo tempo em que proporciona uma decomposição mais rápida e eficiente, introduz um elemento de risco na sua utilização, e é necessário controlar muito bem a pressão e temperatura no interior do frasco para evitar explosões. Apesar desse fato, sistemas fechados são hoje amplamente empregados na decomposição de amostras.

Entre os materiais empregados para a decomposição em sistemas fechados, o politetrafluoretileno (PTFE), em vista a sua baixa reatividade química, possui lugar de destaque. Entretanto, a desvantagem do PTFE como material para frasco de digestão reside no fato de que para altas temperaturas e pressões, a superfície pode ser corroída por ácidos ${ }^{34} \mathrm{e}$ alguns elementos difundem-se, resultando em efeitos de memória, produzindo erros sistemáticos ${ }^{35}$. Alternativamente, alguns autores aconselham o uso de tubos de quartzo fechados ${ }^{33}$ para a decomposição de diversas substâncias em temperaturas elevadas.

Em 1984, Jackwerth \& Gomicek $^{36}$ apresentaram uma visão geral das técnicas empregadas na decomposição em alta pressão para a determinação de baixas concentrações. Segundo os autores, quando o ácido nítrico é usado, a massa e o tipo de amostra, o volume de ácido, o volume do recipiente, a temperatura e duração do aquecimento determinam a qualidade de oxidação da matéria orgânica e a segurança do procedimento. 
Um dos procedimentos de decomposição em alta pressão, denominado High Pressure Asher ${ }^{\circledR}$ (HPA) ${ }^{35}$, foi produzido comercialmente por uma empresa austríaca e consegue oxidar completamente amostras orgânicas independentemente de sua composição química. As soluções resultantes praticamente não contém carbono residual. De acordo com a figura 2, que mostra o esquema do equipamento, a pressão interna do frasco de quartzo é equilibrada por uma pressão externa maior que 100 bar de nitrogênio. É possível obter soluções livres de carbono dispensando o tratamento adicional com ácido perclórico, independente do tipo de material orgânico a ser decomposto.

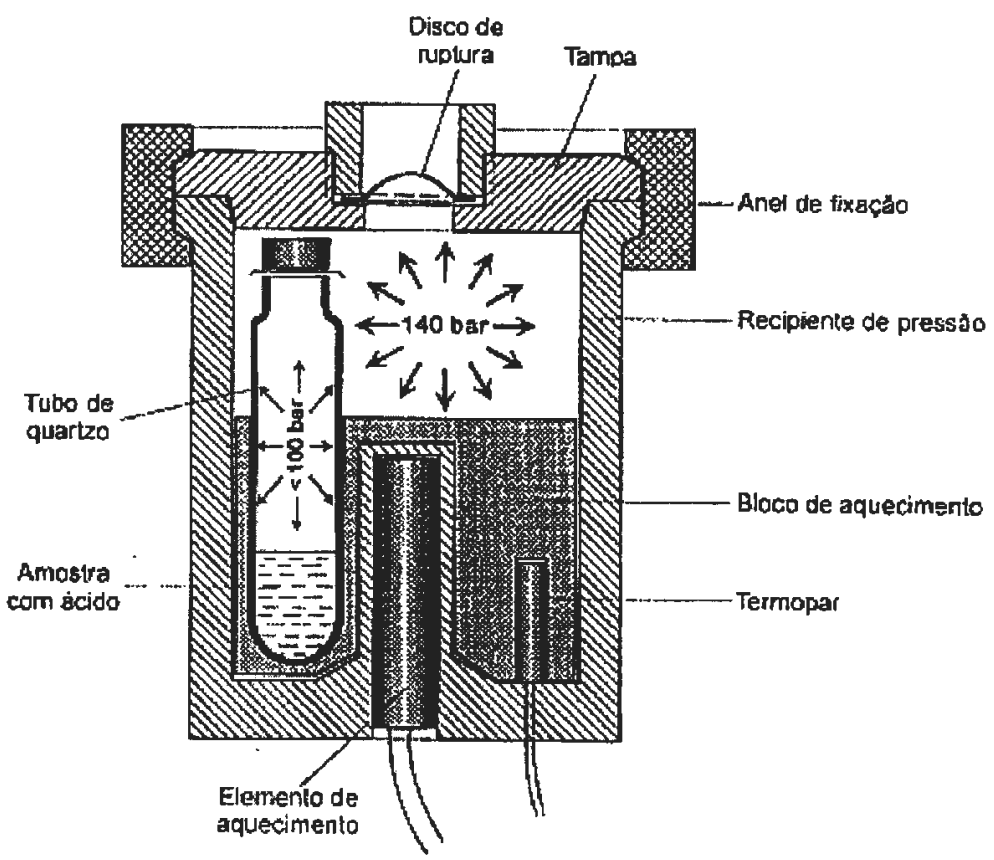

Figura 2. Sistema de decomposição de alta pressão em autoclave ${ }^{35}$

Mesmo com o emprego de altas pressões nas decomposições por métodos convencionais, o tempo continua sendo o fator mais crítico no preparo de amostras. Uma alternativa para acelerar esta etapa foi o desenvolvimento da tecnologia de aquecimento por microondas. Desde a primeira aplicação das microondas como fonte de energia para a digestão ácida por Abu-Samra et al. ${ }^{37}$, em 1975, as aplicações para o preparo de amostras têm crescido exponencialmente ${ }^{4}$. 
A freqüência de microondas situa-se na faixa de 300 a $300.000 \mathrm{MHz}$, o que equivale a comprimentos de ondas da ordem de $1 \mathrm{~m}$ a $1 \mathrm{~mm}$. Comercialmente, somente freqüências de $2450 \mathrm{MHz}$ são usadas para fins domésticos, industriais, científicos e médicos, a razão para tal é evitar possíveis interferências com outras freqüências usadas para telecomunicações, radares, etc.

Microondas são radiações eletromagnéticas não ionizantes que provocam o movimento das espécies em solução pela migração de íons e/ou rotações de dipolo, causadas pelo elevado número de vezes em que o campo eletromagnético se alterna ( $\mathrm{em}$ um forno de microondas caseiro, por exemplo, isso ocorre $4,9 \times 10^{9}$ vezes por segundo) ${ }^{32}$. Devido a esse mecanismo de "stress" induzido, ocorre o aquecimento, sendo que o mesmo não é produzido por fonte externa, mas sim pela interação entre as microondas e as moléculas da amostra. As reações que ocorrem durante a decomposição são aceleradas pela temperatura dos ácidos, enquanto que a pressão no frasco digestor é provocada pela combinação das pressões parciais dos ácidos, da água contida no ácido e amostra e dos gases gerados durante o processo de decomposição.

As vantagens oferecidas pelo aquecimento com fornos de microondas são amplamente demonstradas e muitos procedimentos têm sido descritos ${ }^{3}$. Entretanto, as condições de decomposição precisam ser estabelecidas para cada problema analítico ${ }^{38}$, ou seja, tipo de amostra, elementos a serem determinados e o tipo de sistema de microondas empregado.

Atualmente, existem no mercado dois tipos de instrumentação para a digestão com microondas com propósitos analíticos: fornos de microondas com cavidade e fornos de microondas focalizadas.

Nos fornos de microondas com cavidade (geralmente utilizados para decomposição em sistemas fechados), a radiação é produzida pelo magnetron e transportada através do guia das ondas para a cavidade, onde é distribuída em direções específicas que permitem uma maior irradiação da zona próxima ao centro da cavidade (figura 3). A bandeja rotatória permite expor a amostra a uma radiação homogênea e reprodutível, dependendo do projeto do forno. Existem fornos que operam com 2 magnetrons o que garante uma maior e mais homogênea transferência de energia para 
cada frasco de reação. O número de frascos de digestão varia de 1 a 14 , dependendo do fabricante.

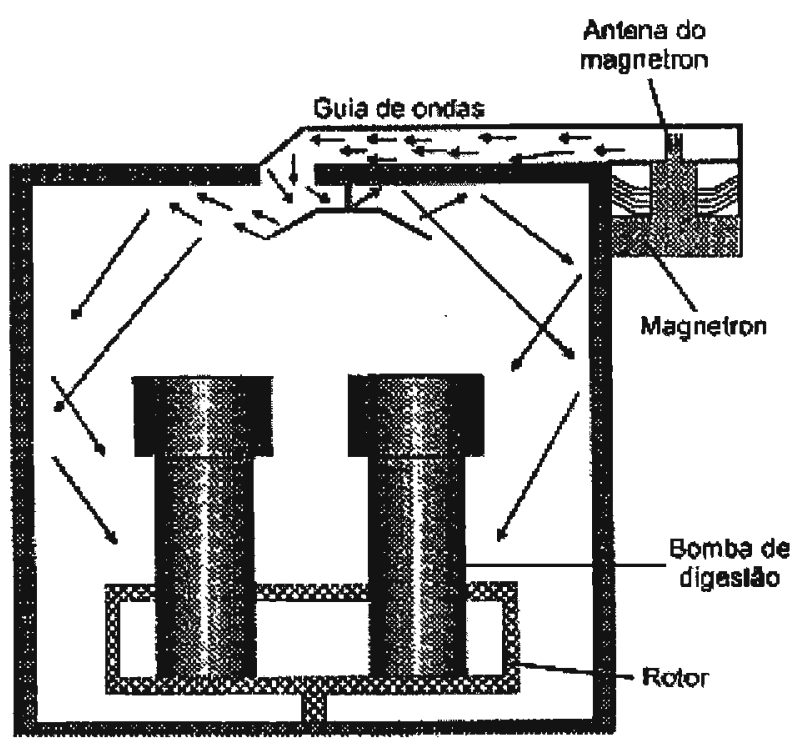

Figura 3. Desenho esquemático de um forno de microondas, mostrando os frascos de digestão fixados em um rotor, sob ação de microondas ${ }^{3}$.

Os materiais mais empregados para a fabricação dos vasos ou copos de reação são transparentes às microondas como o PTFE, PFA (perfluoroalcoxi) e TFM $^{\circledR}$ (marca registrada da Hoechst para PTFE quimicamente modificado).

A aplicação desses fornos de microondas para o preparo de amostra, reduziu o tempo de decomposição, entretanto ainda existem algumas limitações que requerem considerações, tais $\operatorname{como}^{39}$ : (i) sistemas fechados permitem uso limitado de massas de amostra (cerca de $1 \mathrm{~g}$ para materiais inorgânicos e $0,5 \mathrm{~g}$ ou menos para amostras orgânicas) para evitar altas pressões geradas dentro dos vasos, (ii) impossibilidade da adição de reagentes durante o aquecimento, (iii) necessidade de resfriamento para despressurização antes da manipulação da amostra. Em contrapartida os fornos assistidos por microondas focalizadas atuam a pressão atmosférica, possibilitando a adição de reagentes em diferentes momentos do procedimento, proporcionando evaporação até secura ou redução do excesso de solução digestora, possibilidade da utilização de grandes quantidades de amostras e ainda não há a necessidade de esperar um tempo para a despressurização ${ }^{40}$. 
Os sistemas de digestão de amostras que empregam microondas focalizadas possibilitam um grande número de aplicações. Em geral, a digestão é feita em frascos adequadamente "fechados", porém a pressão atmosférica. Estes frascos tem a forma de um tubo de 30 a $40 \mathrm{~cm}$ de altura e de 2 a $4 \mathrm{~cm}$ de diâmetro, e são denominados de tubos de digestão. Os tubos são feitos de quartzo, vidro borosilicato ou Teflon ${ }^{\circledR}$, com capacidade para 50,100 ou $250 \mathrm{ml}$. Esses tubos de digestão possuem um dispositivo que é adaptado na sua extremidade superior, construído de forma a restringir a contaminação pelo ar externo, possuindo entrada para adição contínua ou intermitente de reagentes, e proporcionando o refluxo do vapor do solvente e do(s) ácido(s), de modo a aproveitar ao máximo a capacidade de digestão e minimizar as perdas de reagentes.

O sistema utiliza gerador de microondas (magnetron), que produz um campo eletromagnético que se propaga ao longo de um guia de onda até o recipiente de amostra (figura 4).

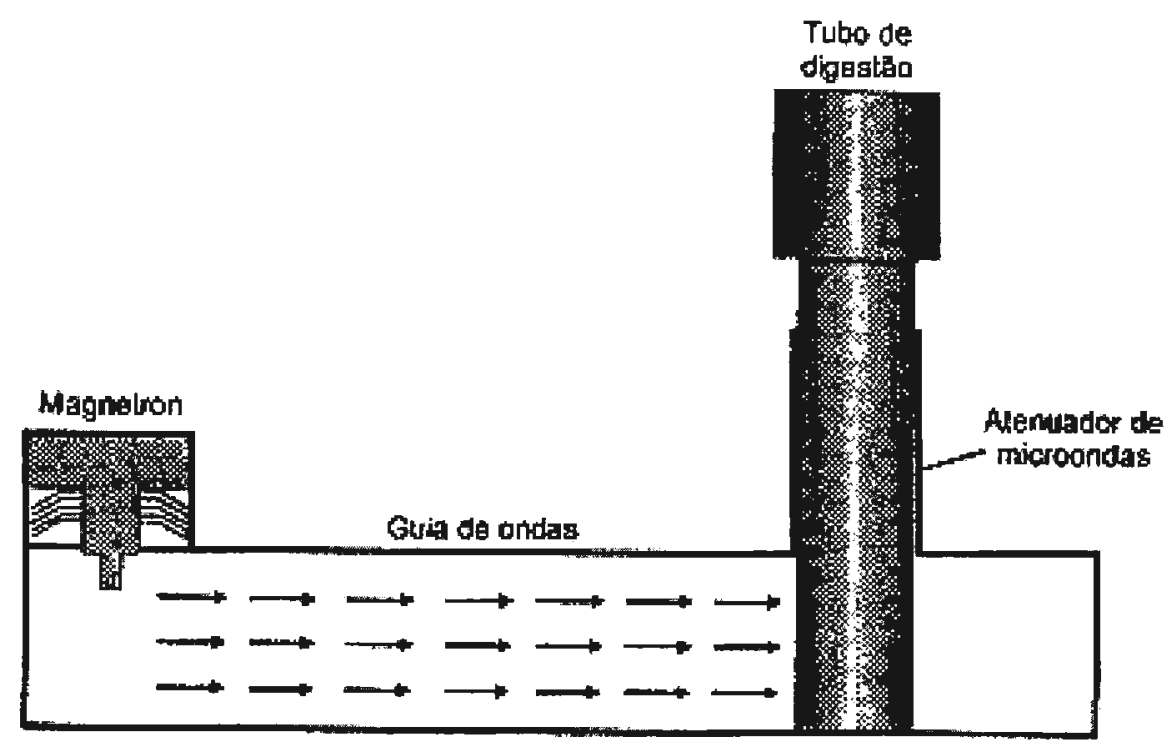

Figura 4. Esquema de um forno com microondas focalizadas equipado com um único magnetron.

Existem ainda sistemas com dois ou seis frascos de digestão. Nesses sistemas uma válvula controladora de fluxo de microondas permite a penetração das microondas no frasco de amostra, independentemente (figura 5). 


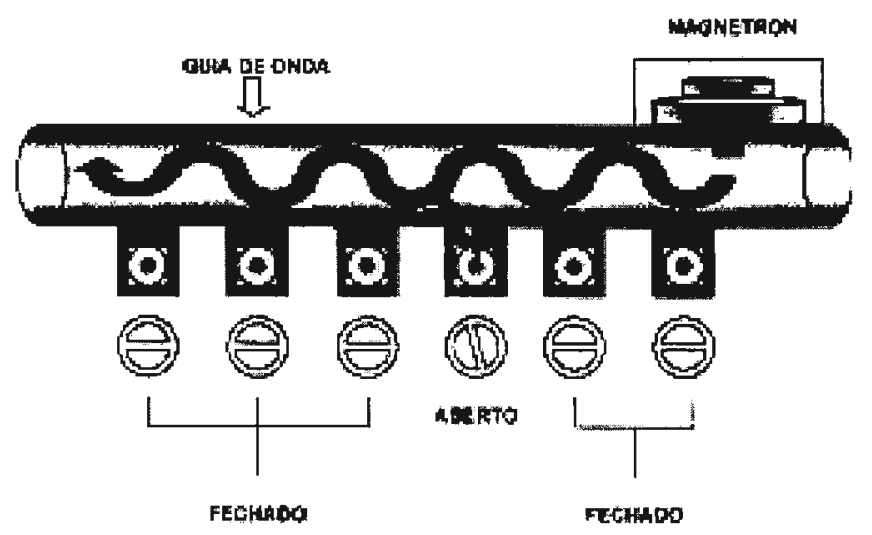

Figura 5. Esquema de microondas focalizadas equipado com 6 frascos digestores.

Contudo, os equipamentos para o preparo de amostras com aquecimento assistido por microondas a pressão atmosférica possuem alguns inconvenientes como possíveis perdas de elementos por volatilização e, com o emprego de maiores massas de amostras, o consumo de ácidos é maior, podendo ser uma fonte considerável de contaminação.

\subsubsection{Decomposição de Amostras - Procedimentos Alternativos}

\subsubsection{Acoplamento do forno de microondas a sistemas de fluxo}

A decomposição assistida por microondas como fonte de energia apresenta-se como uma alternativa efetiva aos procedimentos convencionais de digestão, pois observase redução no tempo da decomposição e nos problemas associados a perdas do analito e contaminação da amostra. Apesar destas vantagens, fatores como a transferência manual de volumes, adição de reagentes e diluições adicionais, continuam sendo fontes de erro e em algumas vezes ocasionam contaminações e perdas de material. Estes problemas podem ser minimizados ou até eliminados com o acoplamento de um sistema em fluxo a um forno de microondas para decomposição "on-line". De uma maneira geral, o sistema de fluxo para decomposição de amostras é incorporado a um forno de microondas, sendo que a amostra digerida pode ser coletada em frasco para subsequente análise (figura 6a), ou levada diretamente ao detector acoplado em linha com o equipamento de detecção (figura 6b). É interessante ressaltar que, dependendo do objetivo da análise, não é 
necessária uma completa digestão da amostra, sobretudo quando a técnica analítica selecionada, permite uma etapa de eliminação de concomitantes como é o caso do ETAAS. Para estes casos, o forno de microondas realiza somente uma extração do analito de interesse para a fase aquosa. Para esta proposta, são utilizados sistemas de fluxo que incluem um forno de microondas acoplado em linha a espectrômetros de absorção atômica com chama (FAAS), com atomização eletrotérmica (ETAAS), com espectrometria de emissão atômica com plasma induzido de argônio (ICP-AES) e com espectrofotometria (UV-Vis) ${ }^{4}$.

a)

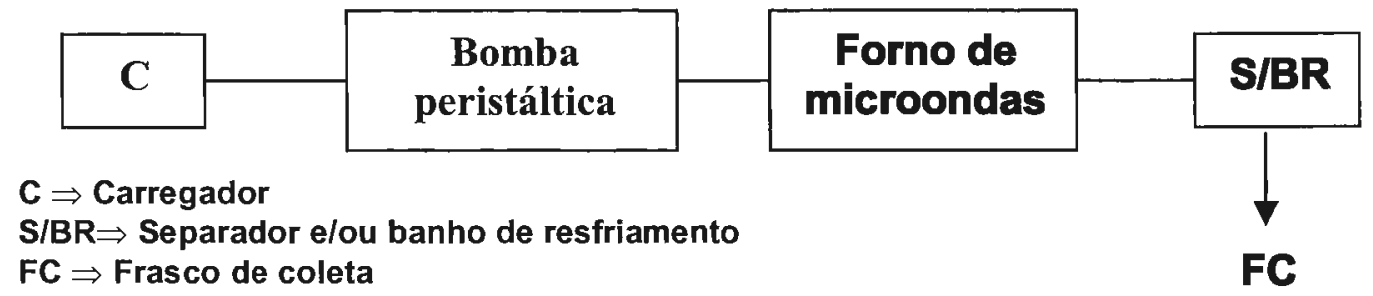

b)

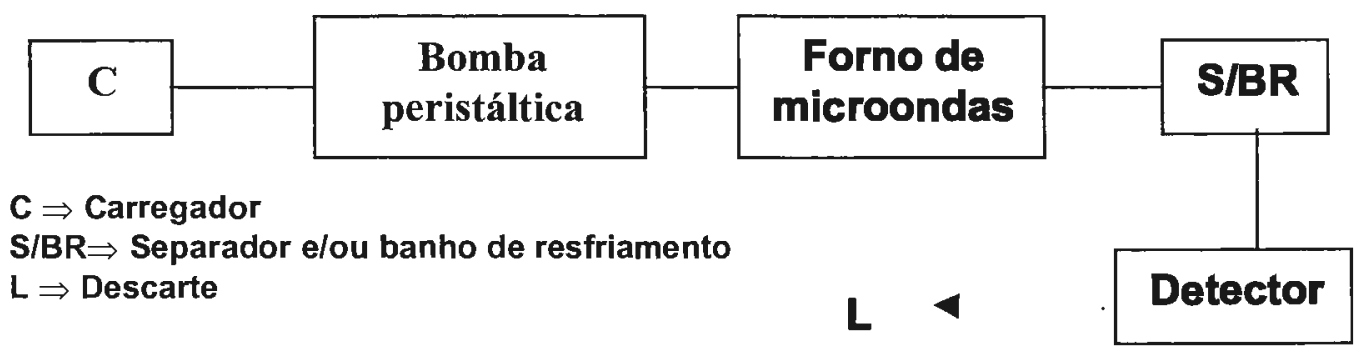

Figura 6. Diagrama de blocos representando o sistema de fluxo acoplado a um forno de microondas para o preparo de amostras : a) com coleta de amostra, b) em linha com o detector.

A técnica de decomposição de amostra em forno de microondas acoplado a um sistema de fluxo foi primeiramente sugerida e aplicada para a decomposição de amostras de soro sangüíneo por Burguera et al. $^{41}$ em 1986. O sistema foi utilizado em combinação com um espectrômetro de absorção atômica com chama para a determinação de $\mathrm{Fe}, \mathrm{Cu} \mathrm{e}$ $\mathrm{Zn}$. Deste então, o acoplamento de fornos de microondas aos sistemas de fluxo (FIA) 
para a decomposição de amostras em linha vem sendo uma das boas alternativas para a etapa de pré-tratamento de amostra ${ }^{4}$.

\subsubsection{Decomposição de amostras em microfrascos}

O uso de pequenos recipientes para a preparação de amostras apresenta algumas características favoráveis como: (i) o emprego de pequenas quantidades de reagentes (de alto grau de pureza); (ii) o uso de pequenas quantidades de amostras; (iii) pequena geração de resíduo; (iv) permite a montagem de sistemas para o processamento de grande número de amostras; e (v) a segurança. Em geral, essas são as principais características desejadas em um método analítico para preparação de amostras.

Idealmente, se todas as etapas do procedimento analítico, deste a coleta da amostra, pudessem ser feitas sempre no mesmo recipiente, os riscos de perdas e de contaminação seriam reduzidos ao mínimo. A coleta, pesagem e preservação da amostra poderiam ser feitas "in loco" e, do transporte até a análise final, os procedimentos poderiam ser feitos com maior rapidez, simplicidade e segurança. A utilização de um mesmo recipiente para a realização de todas as etapas de preparo de amostra até a análise final é conhecida como princípio do frasco único ${ }^{11}$.

Uma alternativa atraente para a decomposição de amostras ambientais, empregando os conceitos discutidos acima, foi descrita detalhadamente por Sperling ${ }^{42}$ em 1984, para a determinação de Cd por espectrometria de absorção atômica com forno de grafite (GFAAS). A decomposição era feita em frascos fechados de polipropileno (1,5 e $4 \mathrm{ml}$ de capacidade), aquecidos a $70^{\circ} \mathrm{C}$ por uma noite. $\mathrm{O}$ procedimento consistia no tratamento da amostra com mistura ácida $\left(\mathrm{H}_{2} \mathrm{SO}_{4}+\mathrm{HNO}_{3}, 1+4 \mathrm{v} / \mathrm{v}\right)$ e aferição de volume no próprio frasco usado para a decomposição; a proporção de mistura ácida era de $50 \mu \mathrm{L}$ para cada $5 \mathrm{mg}$ de amostra. Segundo o autor, com este procedimento foi possível o processamento simultâneo de um grande número de amostras com elevada sensibilidade, já que a amostra não era excessivamente diluída durante o processamento. Campos $^{43}$, em 1988, adaptou este procedimento para a decomposição de amostras vegetais para a determinação de $\mathrm{Cd}, \mathrm{Cu}$ e $\mathrm{Pb}$ por GFAAS empregando até $5 \mathrm{mg}$ de amostra, $50 \mu \mathrm{L}$ de mistura sulfonítrica $\left(\mathrm{H}_{2} \mathrm{SO}_{4}+\mathrm{HNO}_{3}, 1+3 \mathrm{v} / \mathrm{v}\right)$ e aquecimento em 
estufa a $80^{\circ} \mathrm{C}$, por 12 horas. O autor observou boa concordância entre os valores certificado.

Utilizando esse mesmo princípio, em 1995, Flores ${ }^{11}$, utilizou microfrascos de polipropileno para o pré-tratamento de amostras vegetais, fígado bovino e de águas, em sistemas fechados com ácidos inorgânicos concentrados. As amostras (cerca de $10 \mathrm{mg}$ ) foram decompostas em frasco de polipropileno fechado de $2,0 \mathrm{ml}$ de capacidade com adição seqüencial de $80 \mu \mathrm{L}$ de ácido sulfúrico e $150 \mu \mathrm{L}$ de ácido nítrico concentrado, com aquecimento em estufa ou em forno de microondas doméstico, com prévia calibração de potência. Em geral, as variações dos resultados foram de cerca de $11 \%$, atribuidas em parte, à reduzida massa de amostra empregada. $\mathrm{O}$ autor não observou contaminação devida aos frascos de polipropileno. O teor de carbono residual nas amostras, após a decomposição foi inferior a $50 \%$.

\subsubsection{Decomposição de amostras em microfrascos com vapor de ácido}

Em 1991, Matusiewicz ${ }^{44}$ et al. descreveram um sistema para a decomposição de amostras de sedimento marinho e tecido biológico a partir de ataque ácido em fase vapor com aquecimento com microondas (CEM MDS-81, 600W). A amostra (0,25 g) era colocada em um pequeno recipiente de PTFE (4,0 $\mathrm{ml}$ de capacidade), o qual era inserido em um recipiente externo de PTFE-PFA contendo $\mathrm{HNO}_{3}$ ou mistura de $\mathrm{HF}+\mathrm{HNO}_{3}$. O sistema era fechado e o aquecimento iniciado (com máxima potência de $210 \mathrm{~W}$ e tempo total de 45 ou 90 minutos, dependendo da amostra). A pressão máxima foi de $13 \mathrm{~atm}$ e a eficiência da decomposição, avaliada pelo teor de carbono residual, era de cerca de $97 \%$. Amostras de materiais de referência foram analisadas por FAAS e GFAAS para 15 elementos e os resultados apresentaram boa concordância.

Utilizando o mesmo princípio, em 2000, Araújo et al. $^{45}$ desenvolveram um procedimento de solubilização de amostras de plantas por digestão ácida em fase vapor. Em tal procedimento foi proposta uma alternativa para preparo de amostra com purificação simultânea dos reagentes utilizados. Os autores construíram um suporte de PTFE com capacidade para acomodar quatro recipientes que foi acoplado dentro do frasco do forno de microondas focalizadas. $\mathrm{O}$ sistema possibilitou a solubilização ácida 
das amostras em fase vapor, em pressão atmosférica, e ao mesmo tempo, empregando o princípio do frasco único. O sistema foi avaliado utilizando-se materiais de referência certificados com determinação de Co e Fe por GFAAS e/ou FAAS. Parâmetros como o tempo de exposição das amostras ao vapor ácido, a eficiência de solubilização em função da distância das amostras em relação ao guia de onda, a adição de água ou peróxido de hidrogênio, a granulometria das amostras, bem como as variações da acidez e da temperatura ao longo do suporte, foram avaliados. Os autores verificaram que a eficiência do sistema de solubilização é dependente da temperatura (decrescente ao longo do suporte), da presença da água ou do peróxido de hidrogênio e do tamanho de partícula. Os teores de carbono residual variaram entre 8,8 e $72,4 \%$ comparando-se com a matriz orgânica original. A utilização desse procedimento propiciou o aumento da freqüência de solubilização do forno de microondas focalizada de 6 para 24 amostras, além da purificação "in situ" do ácido, minimizando as etapas de preparo de amostras e reduzindo a contaminação.

\subsubsection{Decomposição de amostra através de hidrólise enzimática}

Em 1999, Bermejo-Barrera et al. $^{29}$ propuseram um procedimento de hidrólise enzimática baseado no uso da enzima pronase $\mathrm{E}$ para o preparo de amostras biológicas, como mexilhão e cabelo. $\mathrm{Cu}, \mathrm{Fe}, \mathrm{Mg}$ e $\mathrm{Zn}$ foram determinados por FAAS, e alguns elementos traço, como $\mathrm{As}, \mathrm{Ag}, \mathrm{Cd}$ e $\mathrm{Pb}$ foram determinados por ETAAS. O pH foi ajustado para 7,4 com uma solução de de hidroximetil em meio ácida (TRIS-HCl) e a temperatura foi fixada em $37^{\circ} \mathrm{C}$. Os parâmetros como tempo de hidrólise, concentração e volume da enzima foram estudados e otimizados. O procedimento apresentou uma recuperação de $100 \%$ para $\mathrm{As}, \mathrm{Cd}, \mathrm{Cu}$ e $\mathrm{Mg}$ nas amostras de mexilhão em comparação com o procedimento de digestão em bombas de PTFE com $\mathrm{HNO}_{3}$ e $\mathrm{H}_{2} \mathrm{O}_{2}$ assistida por microondas. Os autores verificaram que o uso da hidrólise enzimática desempenha um papel importante no estudo de especiação para determinar diferentes espécies químicas associados com diferentes proteínas. Uma grande limitação desse procedimento é o tempo elevado de extração (5 horas), no entanto a hidrólise enzimática para extração dos elementos em materiais aparece como uma alternativa para o preparo de amostras. 


\subsubsection{Decomposição a alta pressão com microondas focalizadas}

Em 1999, Henryk Matusiewicz ${ }^{46}$ desenvolveu um sistema de decomposição a altapressão com microondas focalizadas - HPA-FMs (do inglês: High-Pressure Asher Fucused Microwave). O sistema combina a eficiência de decomposição e segurança dos sistemas de decomposição à alta-pressão - HPA (do inglês: High-Pressure Asher) com a rapidez de decomposição dos fornos de microondas focalizadas. O sistema utiliza microondas de $2,45 \mathrm{GHz}$ para aumentar a potência do microondas em até $650 \mathrm{~W}$, direcionadas para seis tubos de quartzo contendo amostra com ácido nítrico. A pressão e a temperatura do sistema atingem 130 bar e $320^{\circ} \mathrm{C}$, respectivamente. Esse sistema apresentou uma decomposição efíciente e uma redução drástica no tempo de digestão (5 min) em comparação ao tempo de digestão apresentado pelo sistema de decomposição em alta-pressão (120 min). O autor sugeriu algumas melhorias futuras, como a implantação de controle simultâneo da pressão e temperatura em todos os vasos.

\subsubsection{Decomposição assistida por radiação infravermelho}

O uso da radiação infravermelho para o preparo de amostras não é muito freqüente. Essa radiação compreende a região do espectro eletromagnético entre a radiação visível e as microondas, correspondendo a faixa de comprimento de onda de 770 $\mathrm{nm}$ a $1000 \mu \mathrm{m}$, com faixas de freqüência da ordem de $1,2 \times 10^{14}$ a $6,0 \times 10^{12} \mathrm{~Hz}$. A absorção dessa radiação promove um aumento das vibrações moleculares e variações nas rotações moleculares que resultam em aquecimento e propagação do calor gerado ${ }^{47}$.

Gouveia et al. ${ }^{14}$ investigaram um procedimento de preparo de amostras com rápido aquecimento da amostra em meio ácido usando radiação infravermelho emitida por lâmpadas de tungstênio com refletor de ouro. A solução diluída do ácido era aquecida em tempo inferior a 60 s e o tempo gasto para a solubilização da amostra foi menor que 5 minutos. Os autores avaliaram a eficiência do procedimento determinando os teores de cobre, ferro, manganês e zinco em materiais de referência certificados de fígado bovino e folhas de maçã. As vantagens do procedimento proposto são a simplicidade e o baixo 
custo além da facilidade de implementação, visando a análise de baixas concentrações de elementos.

\subsubsection{Associação do forno de microondas com radiação ultra-violeta para decomposição de amostra.}

G. Knapp et. al. ${ }^{48}$ em 2001 desenvolveram um sistema de decomposição que associa o forno de microondas com a radiação UV para a decomposição de amostras líquidas com resíduo de carbono orgânico dissolvido, tais como água de superfície , águas residuais, detritos e fluidos biológicos. A técnica é baseada na utilização de um frasco de digestão de um forno de microondas, na qual é inserida uma lâmpada de cádmio de baixa pressão. A lâmpada possui uma antena que permite ser ligada pela incidência de radiações de microondas, emitindo radiações UV na região de $228 \mathrm{~nm}$. A intensidade da lâmpada depende da intensidade de radiação de microondas incidida sobre ela.

O sistema utiliza $7 \mathrm{~mL}$ de uma alíquota da solução com a amostra para $1 \mathrm{~mL}$ de $\mathrm{H}_{2} \mathrm{O}_{2}$ e $50 \mu \mathrm{L}$ de $\mathrm{HNO}_{3}$, os quais são colocados no interior da bomba de digestão de quartzo, juntamente com a lâmpada de cádmio. A amostra é digerida em um forno de microondas a pressão de 72 bar. A energia da radiação de microondas é reduzida automaticamente, quando a pressão de reação em um das bombas exceder 72 bar.

Temperaturas superiores a $280{ }^{\circ} \mathrm{C}$ podem ser atingidas, resultando em uma maior eficiência de digestão comparado com os dispositivos de digestão por UV. O tempo de digestão do sistema é reduzido em até cinco vezes e a concentração de carbono residual dissolvido diminui até 50 vezes.

O desempenho do sistema foi avaliado através da digestão e análise de material de referência CRM 151 (leite desnatado). O sistema apresentou recuperações de 96 a 112\% para os elementos analisados. 


\subsection{Aspectos morfológicos do cabelo}

O cabelo, além de ser um adorno, tem a função de proteger a cabeça dos raios solares, o que é feito através da melanina, a qual é também responsável pela sua coloração. O cabelo humano é composto por $80 \%$ de proteínas, $15 \%$ de água e pequena quantidade de lipídios e materiais inorgânicos. O conteúdo mineral do cabelo varia de 0,25 a $0,95 \%$ no conteúdo das cinzas. De aproximadamente 100.000 fios de cabelo que existem na cabeça, $10 \%$ se encontram na fase de repouso. Durante a fase de crescimento, os folículos produzem cabelo a uma velocidade de 0,2 a $0,5 \mathrm{~mm}$ por dia, o que resulta em aproximadamente $1 \mathrm{~cm}$ a cada mês ${ }^{18}$.

O cabelo humano é um filamento queratinizado que cresce a partir de cavidades em forma de sacos chamados folículos (figura 7). Estes folículos estendem-se desde a derme até a epiderme através do extrato córneo. Cada folículo é um órgão em miniatura que contém os componentes glandulares e musculares. $\mathrm{O}$ diâmetro de um fio de cabelo humano varia de 15 a $120 \mu \mathrm{m}$, dependendo da raça ${ }^{50}$. O cabelo é basicamente composto por 3 camadas: cutícula (camada externa composta por várias sub-camadas separadas por um complexo de células - endocutícula, epicutícula e exocutícula), córtex (principal componente do cabelo, formado por um conjunto de células cilíndricas denominadas matriz, local onde fica situada a queratina e outras proteínas) e medula (camada mais interna do folículo) que em alguns tipos de cabelo pode não estar presente ${ }^{50}$.

Cada folículo possui seu próprio ciclo de desenvolvimento, que corresponde às fases anágena, catágena e telógena ${ }^{50}$ :

- Anágena: É a fase do desenvolvimento e do crescimento do cabelo, sendo que a papila (situada na porção inicial da raiz do cabelo) do folículo está em íntimo contato com os vasos sangüíneos, onde substâncias presentes nos fluídos circulantes são absorvidas pelo cabelo.

- Catágena: Esta fase transitória dura apenas semanas, onde o cabelo pára de crescer e não há mais irrigação sangüínea (o cabelo morre), cerca de $1 \%$ do cabelo de um indivíduo está nesta fase.

- Telógena: Nesta fase o cabelo cai, sendo empurrado por um novo folículo que nasce no mesmo local. 


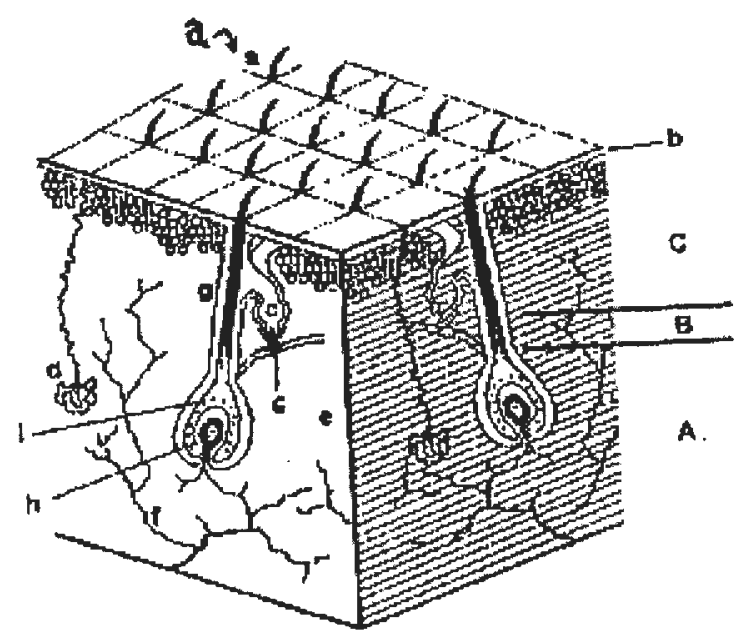

Figura 7. Representação dos folículos do cabelo: a) extrato córneo; b) epiderme; c) glândula sebácea; d) glândula ecrina; e) derme; f) vasos sangüíneos; g) folículo; h) papila; i) grânulos de melanina; A) zona de diferenciação e síntese biológica; B) zona de queratinização e C) região do cabelo permanente ${ }^{52}$

\subsubsection{Absorção de elementos pelo cabelo}

Cada folículo é um tecido em miniatura, que contém componentes musculares e glandulares. O crescimento do folículo piloso é ricamente suplementado com vasos sangüíneos e o sangue que banha esses folículos é um meio de transporte para os elementos essenciais, assim como para aqueles potencialmente tóxicos. Esses elementos são continuamente incorporados à proteína do cabelo durante $\mathrm{o}$ seu crescimento (absorção endógena). E assim, a variação da concentração de determinado elemento durante os diferentes períodos pode ser medida. A diferença dos outros tecidos ou fluídos corporais é que o cabelo é um produto de metabolismo final que incorpora elementos em sua estrutura no tempo em que está crescendo. A medida que o cabelo se aproxima da superfície da pele, ele sofre um processo de endurecimento, permitindo que a maioria dos elementos químicos fique irreversivelmente ligado aos grupos SH dos aminoácidos. Estes elementos concentrados podem refletir as concentrações em outros tecidos orgânicos.

A estrutura morfológica do cabelo e sua composição química evidenciam que é pouco provável que haja uma distribuição uniforme de elementos traços no mesmo, havendo regiões onde a incorporação é maior ${ }^{50}$. 
A absorção de elemento pelo cabelo dá-se também a partir do arraste de substâncias externas (poeira, fumaça, cosméticos, suor e sebo provindos das glândulas sebáceas que lançam seus produtos sobre a epiderme), pela água, uma vez que o cabelo é hidrófilo (absorção exógena). Os elementos traço irão fixar-se à queratina do cabelo, ou em alguns casos específicos à membrana das células ${ }^{50,51,52}$. Partículas de poeira contendo quantidades significativas de elementos traço podem ficar retidas entre as várias camadas da cutícula através de interações eletrostáticas ${ }^{50}$, principalmente quando esta estiver danificada. A estrutura da camada eletrônica externa de cada elemento determina o tipo de ligação. Os tipos de ligação em diferentes camadas do cabelo conduzem a diferentes concentrações de um determinado elemento.

\subsubsection{Determinação elementar no cabelo}

Os primeiros resultados das análises de cabelos foram publicados por Hoppe em 1858, que determinou As no cabelo de cadáveres exumados 11 anos após o sepultamento. Aproximadamente 100 anos após, em 1954, Goldblum determinou anfetamina em pêlos de cobaia. Mas, com relação à determinação de drogas no cabelo, a publicação que realmente mudou a situação foi a de Baumgartner que, em 1979, determinou a concentração de opiáceos no cabelo humano, através de extração com metanol e detecção por radioimunoensaio (RIA) $)^{53}$.

Em 1945, Flesch já havia proposto que o cabelo poderia ser usado como material de biópsia para a determinação de elementos traço presentes no corpo humano, já que o cabelo funciona como um órgão excretor ${ }^{51}$. Mas, durante as décadas seguintes as análises de sangue e urina tiveram a preferência, sendo que na década de 30 iniciou-se a era da medicina industrial ${ }^{50}$, ou seja, o diagnóstico de doenças através de exames laboratoriais. Nos anos 60, a utilidade da análise de cabelo foi redescoberta por pesquisadores da área de nutrição e, na década seguinte foram realizados vários simpósios e livros foram publicados sobre o assunto ${ }^{50}$.

A análise de cabelo é bastante utilizada em criminalística (na Europa, para identificar criminoso, através da análise do DNA e morfologia), toxicológica, ambiental, medicina do trabalho (para avaliar a exposição a metais pesados) e nutrição. Em muitos 
casos, a análise de cabelo é o único recurso para comprovar o uso de drogas no caso de pessoas já falecidas, com o objetivo de se descobrir a causa da morte, ou ainda, pode ser utilizada para avaliar o consumo de drogas em centros de reabilitação para a re-aquisição da carteira de motorista apreendida (Alemanha) e, é solicitada para candidatos a empregos importantes (USA) ${ }^{54}$.

No Brasil, atualmente, a análise de cabelo é solicitada principalmente por médicos da área da medicina ortomolecular, para avaliar o estado nutricional (elementos essenciais presentes em baixa ou alta concentração) e possíveis contaminações por elementos tóxicos ${ }^{55}$. Até o momento, a análise de cabelo não é popularmente aceita. No entanto, todos os anos grandes avanços ocorrem e cresce a demanda por esse tipo de análise ${ }^{18}$.

O cabelo, segundo alguns autores, é considerado um "dosímetro biológico", "filamento de registro" ou ainda "espelho do ambiente", devido à capacidade de absorver elementos provenientes do ambiente ao qual o indivíduo foi exposto (contaminação exógena), ou ainda através da ingestão (contaminação endógena) ${ }^{7}$.

Com o desenvolvimento e amadurecimento de novas técnicas analíticas na década de 80, principalmente ETAAS, ICP-OES e ICP-MS, surgiram novas perspectivas relacionadas à determinação de metais em cabelo ${ }^{50,56}$. Porém, ao mesmo tempo tem sido motivo de enormes controvérsias geradas principalmente pela inadequada interpretação dos resultados da análise de cabelo ${ }^{55}$.

As modificações que acontecem no cabelo são demoradas, razão pela qual esta análise elementar não identifica modificações agudas ou rápidas.

A análise elementar no cabelo é uma ferramenta de muita importância dentro da medicina ortomolecular, pois permite estabelecer os parâmetros do equilíbrio ou desequilíbrio metalomineral que acontece no organismo. Apesar de ser uma análise cuja especificidade e sensibilidade são variáveis de acordo com o elemento mensurado, ela permite identificar aqueles metais que, em elevados níveis, possam estar agindo como catalisadores de reações produtoras de estresse oxidativo, como o caso do ferro na reação de Fenton ${ }^{55}$, e determinar os minerais e metais, muito deles essenciais ao organismo, cuja deficiência pode estar associada ao quadro clínico predominante do paciente, como é o 
caso da doença de $\operatorname{Keshan}^{15}$, causada pela deficiência de selênio, que atinge mais de 10 milhões de residentes na China.

Estas análises permitem, no conjunto, estabelecer um protocolo terapêutico que possa completar e/ou suplementar uma estratégia convencionalmente estabelecida no tratamento da patologia predominante no paciente, assim como avaliar a toxicidade dos elementos para o metabolismo humano ${ }^{55}$.

\subsection{Importância nutricional dos elementos $\mathrm{Se}, \mathrm{Mn}, \mathrm{Fe}, \mathrm{Cu}$ e $\mathrm{Zn}$}

O radical superóxido e o radical hidroxil são classificados como radicais livres, que são átomos ou moléculas que apresentam um ou mais elétrons desemparelhados e, consequentemente, uma elevada reatividade. Os radicais livres gerados pela redução parcial do oxigênio podem reagir com macromoléculas biológicas oxidando-as e causando danos ao organismo ${ }^{57,58}$. Um aumento da concentração de radicais livres no organismo, devido a sua elevada reatividade, podem atacar biomoléculas como o DNA (ácido desoxirribonucleico), proteínas e membranas celulares. Os radicais livres derivados do oxigênio, como o radical superóxido e o radical hidroxil, são os responsáveis por algumas doenças como arterioesclerose, câncer e inflamações, devido a ação deletéria desses intermediários reativos dentro do organismo ${ }^{58}$. No entanto, em organismos com células eucarióticas, existe um complexo sistema de defesa contra a ação desses radicais livres. O bom funcionamento desse complexo sistema de defesa é indispensável para a manutenção da vida aeróbica, uma vez que ele garante o controle adequado da concentração de radicais livres no organismo. A eficiência do sistema de defesa controla a proliferação dos radicais livres, os quais estão relacionados com a integridade de um conjunto de enzimas (que possuem em suas estruturas, os elementos $\mathrm{Cu}, \mathrm{Mn}$, Se e $\mathrm{Zn})^{58}$. Dentre esse conjunto de elementos, o ferro é o elemento que apresenta uma importância maior dentro do organismo. O ferro está ligado a proteínas; conhecem-se cerca de 50 proteínas de $\mathrm{Fe}$ transporte, Fe armazenagem e transportadores de $\mathrm{O}_{2}$ além de exercer funções dentro de algumas enzimas. Sintomas de deficiência de ferro incluem: anemia, fraqueza, fadiga, alterações gastrointestinais, inflamações na mucosa da boca, perda do cabelo, cabelo opaco, depressão, menstruaçoes frequêntes e 
edema pulmonar. $\mathrm{O}$ aumento no nível de ferro pode aumentar o risco de ataque cardíaco e arterosclerose nos homens e nas mulheres após a menopausa. Na fase fértil, a menstruação elimina o excesso de ferro ${ }^{55}$.

A maioria dos papeis bioquímicos do zinco reflete seu envolvimento em um grande número de enzimas ou como um estabilizador da estrutura molecular dos constituintes subcelulares e membranas. O zinco participa na síntese e degradação dos carboidratos, lipídeos, proteínas e ácido nucléicos. O cabelo foi utilizado por muitos pesquisadores para determinar o armazenamento do mesmo no corpo. Baixos níveis podem levar a crescimento retardado, atividade reduzida das enzimas pancreáticas, síntese protéica e de DNA prejudicadas, demora na cicatrização de feridas, síntese de colesterol reduzida, diminuição na incorporação de aminoácidos nas proteínas do fígado e dos rins, e etc ${ }^{55}$.

O cobre é necessário para produção de hemoglobina, pois facilita a absorção do ferro. O cobre atua também na formação e manutenção óssea, assim como na síntese de DNA. As enzimas de cobre agem no metabolismo do oxigênio dos radicais livres, tendo assim ação antiinflamatória leve. A carência do cobre inclui sintomas como: anemia, calvície, diarréia, fadiga e alteração no sistema respiratório. Excesso de cobre pode levar a toxicidade que está associada à depressão, irritabilidade, náuseas, vômitos, dores musculares e artralgias ${ }^{55}$.

O manganês é considerado o menos tóxico entre os metais traços quando administrado oralmente. A forma tóxica de manganês pode ser transportada pelo ar nas minas de aço e algumas industrias químicas. O manganês faz parte do metabolismo dos ácidos graxos, das proteínas, conserva a estrutura dos nervos do sistema imunológico e regula o metabolismo dos açúcares. Sinais de deficiência de manganês incluem crescimento prejudicado, anormalidades esqueléticas, função reprodutiva alterada ou diminuída, ataxia do recém-nascido e defeitos no metabolismo dos lipídios e carbidratos $^{55}$.

O papel metabólico importante desempenhado pelo selênio é como um componente da enzima glutationa peroxidase a qual, juntamente com a vitamina $\mathrm{E}$, catalase e superóxido dismutase atuam como sitemas de defesa antioxidantes no organismo. Sintomas de carência de selênio são aumento do colesterol no plasma, 
infecções repetidas, retenção de cálcio pelas fíbras musculares, que estão associadas ao início da distrofia da nutrição muscular e deficiência no ciclo respiratório combinada com carência de vitamina E. O selênio é considerado tóxico quando sua concentração aparece como 100 a 300 vezes superior ao nível considerado normal. Sintomas de toxicidade incluem: artrite crônica, hálito de alho, irritação, desarranjos gastrointestinais, perdas de cabelo, diabetes, tumores malígnos e lesões hepáticas ${ }^{55}$.

A importância dos metais para o bom funcionamento do organismo, em geral, já é reconhecida e respaldada pela literatura, que reporta várias doenças que estão relacionadas com a falta e o excesso dos metais no organismo ${ }^{55,57,59,60,61}$. A preocupação de um órgão governamental americano relacionado com nutrição e saúde pública (USDA, do inglês U. S. Department of Agriculture), em estabelecer a quantidade mínima recomendável a ser ingerida de alguns elementos metálicos, para a manutenção do bom funcionamento do organismo, indica a relevância nutricional dos metais ${ }^{59}$. 


\section{OBJETIVO}

O objetivo do presente trabalho foi o desenvolvimento de um sistema de decomposição em microfrascos de polipropileno de 2,0 e 4,0 mL de capacidade, adaptados a um forno de microondas focalizadas, como um procedimento alternativo de pré-tratamento de amostra de cabelo para determinação dos elementos ferro, cobre, zinco, manganês e selênio por FAAS e GFAAS. 


\section{EXPERIMENTAL}

\section{1. Instrumentação}

Para o desenvolvimento do sistema de decomposição foi utilizado um forno de microondas focalizadas da SPEX (Rapid Digestion System), com potência nominal de 300 W, constituído por uma cavidade para introdução de um tubo digestor. Para a digestão das amostras, foram utilizados microfrascos de polipropileno de 2,0 $\mathrm{mL}$ de capacidade da Axygen $^{\circledR}$ Scientific e de $4,0 \mathrm{~mL}$ de capacidade da Corning.

Para a moagem das amostras foi utilizado um moinho criogênico 6800 Freezer Mill. O equipamento possui uma bobina de indução e uma cavidade para introdução de 4 tubos de policarbonato. O programa de moagem utilizado foi de 3 ciclos de 2 minutos de moagem e 2 minutos de refrigeração da amostra.

Para a determinação de ferro, cobre e zinco foi utilizado um espectrômetro de absorção atômica com chama ar/acetileno (AAS vario 6, Analytick Jena AG). O equipamento possui um queimador de titânio de $10 \mathrm{~cm}$, um monocromador com espelhos ópticos de quartzo, uma fotomultiplicadora de 9 estágios SEV (EHT) R928, corretor de radiação de fundo com lâmpada de deutério e um amostrador automático (AS 52). A vazão do gás combustível utilizados para a determinação do ferro, cobre e zinco, foram $1,11 \mathrm{~min}^{-1}$, $0,831 \mathrm{~min}^{-1}$ e $0,831 \mathrm{~min}^{-1}$, respectivamente, e a vazão de ar foi de 4,401 min ${ }^{-1}$ para todos os elementos.

Para a determinação de selênio em digeridos de cabelo foi utilizado um espectrômetro de absorção atômica com atomização eletrotérmica em forno de grafite e detecção simultânea (SIMAA-6000, Perkin-Elmer, Norwalk, CT, USA). O equipamento possui policromador tipo Echelle, detectores de estado sólido com um arranjo de 60 fotodiodos, forno de grafite com aquecimento transversal (THGA), corretor de radiação de fundo com efeito Zeeman longitudinal e amostrador automático (AS-72).

Para a determinação de manganês em digeridos de cabelo foi utilizado um espectrômetro de absorção atômica com atomização eletrotérmica em forno de grafite (AAS 
ZEEnit 60, Analytical Jena, Jena, Germany). O equipamento possui forno de grafite com aquecimento transversal (THGA), corretor de radiação de fundo baseado no efeito Zeeman inverso e transversal com possibilidade de escolha de campo (2 e 3) e intensidade de 0,5T, $0,8 \mathrm{~T}$ e 1,0T e amostrador automático (AS-51).

Durante os experimentos, foram utilizadas lâmpadas de descarga sem eletrodo (EDL) de selênio e lâmpadas de cátodo oco (HCL) de manganês, ferro, cobre e zinco. As condições instrumentais estabelecidas para cada elemento foram semelhantes àquelas recomendadas pelo fabricante e estão descritas na tabela 1.

O gás protetor do tubo de grafite e de purga utilizado foi argônio 99,999\% v/v (Air Liquide, São Paulo, SP, Brasil).

Tabela 1: Parâmetros instrumentais para determinação dos elementos por FAAS e GFAAS.

\begin{tabular}{ccccc} 
Elemento & $\begin{array}{c}\boldsymbol{\lambda}^{*} \\
(\mathbf{n m})\end{array}$ & $\begin{array}{c}\mathbf{I}^{* *} \\
(\mathbf{m A})\end{array}$ & $\begin{array}{c}\text { Largura da } \\
\text { fenda }(\mathbf{n m})\end{array}$ & $\mathbf{T i}^{* * *}(\mathbf{s})$ \\
\hline $\mathrm{Mn}$ & 279,5 & 20 & 0,7 & 5 \\
$\mathrm{Se}$ & 196,0 & 290 & 0,7 & 5 \\
$\mathrm{Fe}$ & 248,3 & 8 & 0,5 & 5 \\
$\mathrm{Cu}$ & 324,8 & 3 & 1,2 & 5 \\
$\mathrm{Zn}$ & 213,9 & 4 & 0,5 & 5 \\
\hline
\end{tabular}

$* \lambda$ : comprimento de onda de leitura.

** i: corrente elétrica aplicada à fonte de radiação.

*** Ti: tempo de integração do sinal analítico.

A análise de carbono total nas amostras de cabelo foi realizada em um analisador de carbono Elementar Analyzer 2400 CHN Perkin-Elmer. O equipamento possui um tubo de combustão N241-1264, um tubo redutor N241-1291 e um detector por condutividade térmica (TCD). Os gases utilizados nesse equipamento para a combustão e o arraste são, respectivamente, oxigênio $\left(\mathrm{O}_{2}\right) 99,9995 \%$ v/v e hidrogênio $\left(\mathrm{H}_{2}\right)$ com 99,995\% v/v de pureza. O programa de aquecimento para a combustão da amostra de cabelo foi de $1000^{\circ} \mathrm{C}$ durante $90 \mathrm{~s}$. 
Para a análise de carbono residual nos digeridos de cabelo foi utilizado um espectrômetro de emissão ótica com plasma indutivamente acoplado (ICP-OES) modelo Módula da Spectro Co. O equipamento seqüencial é composto por dois sistemas ópticos com grade de difração holográfica de 2400 linhas/mm, uma com faixa de trabalho de 165 a 230 $\mathrm{nm}$ em atmosfera de argônio e uma ótica com faixa de trabalho de 230 a $800 \mathrm{~nm}$ ao ar, sete detectores fotomultiplicadora montados no ciclo de Howland, um gerador de radio freqüência de 27,12 MHz permitindo um ajuste de potência entre 750 e $2500 \mathrm{~W}$ e uma tocha de quartzo concêntrica fixa. $O$ sistema de injeção da amostra é equipado com uma bomba peristáltica, nebulizador pneumático concêntrico (Meinhard) do tipo C (vazão de até $3 \mathrm{~L} / \mathrm{min}$ e até $1 \%$ de sólido dissolvido) e uma câmara de nebulização de duplo passo. Os parâmetros instrumentais utilizados para determinação de carbono residual estão descritas na tabela 2.

Tabela 2: Parâmetros instrumentais do ICP-OES para determinação de carbono residual.

\section{Introdução de Amostra}

\begin{tabular}{cc}
$\begin{array}{c}\text { Pré-fluxo de Introdução } \\
\text { Fluxo para a Leitura }\end{array}$ & $\begin{array}{c}10 \text { segundo com vazão de } 4 \mathrm{~mL} / \mathrm{min} \\
10 \text { segundos com vazão de } 2 \mathrm{~mL} / \mathrm{min}\end{array}$ \\
\hline Potência & $1200 \mathrm{Watts}$ \\
Gás de Refrigeração & $12 \mathrm{~L} / \mathrm{min}$ \\
Gás Auxiliar & $1,2 \mathrm{~L} / \mathrm{min}$ \\
Fluxo do nebulizador & $1,0 \mathrm{~L} / \mathrm{min}$ \\
Tempo de Integração & $3 \mathrm{~s}$ \\
Comprimento de onda & $247,9 \mathrm{~nm}$ \\
\hline
\end{tabular}

Para comparação da eficiência de decomposição foi utilizado um forno de microondas fechado (Qwave da Questron), composto por um magnetron com potência 
nominal de 1000 watts e uma bandeja giratória com capacidade para 10 frascos de digestão de Teflon ${ }^{\circledR}$. Os frascos de digestão tem volume interno de $120 \mathrm{~mL}$ e possuem membrana de ruptura, sendo um dos frascos equipado com sensores de pressão e temperatura. $\mathrm{O}$ forno de microondas tem como parâmetro de controle a potência a ser incidida, o tempo de incidência, a temperatura e a pressão no interior de um dos frascos.

\subsection{Reagentes e soluções}

A água utilizada para preparar as soluções analíticas de referência, dos modificadores químicos e para a diluição das amostras de digeridos de cabelo foi destilada e bi-deionizada, através de colunas de troca aniônica e catiônica e de um sistema de ultrapurificação Milli $Q^{\circledast}$ (Millipore, Bedford, MA, USA), permitindo obter água em elevado grau de pureza, com resistividade igual a $18,2 \mathrm{M} \Omega \mathrm{cm}^{-1}$. O ácido nítrico (Synth) empregado na preparação das soluções analíticas de referência e na decomposição das amostras de cabelo, foi destilado utilizando destilador sub-boilling de quartzo (Marconi, Piracicaba, SP, Brasil). O peróxido de hidrogênio $30 \% \mathrm{~m} / \mathrm{v}$ (MERCK) foi utilizado para decomposição das amostras de cabelo.

Toda a vidraria e frascos de polietileno para armazenagem de soluções foram lavados com detergente, preenchidos com solução de ácido nítrico $10 \% \mathrm{v} / \mathrm{v}$ durante 24 horas e enxaguados com água destilada e deionizada. Após a descontaminação, os balões volumétricos e frascos para armazenamento das soluções de referência analítica foram preenchidos com solução de ácido nítrico $10 \% \mathrm{v} / \mathrm{v}$ e, somente antes da utilização, esses materiais foram enxaguados com água bi-deionizada.

O preparo das soluções analíticas de referência, modificadores químicos e das amostras foi realizado em capela de fluxo laminar classe 100 (Veco, Campinas, SP, Brasil), para evitar contaminações do ambiente do laboratório.

Soluções estoques contendo $1000 \mathrm{mg} \mathrm{L} \mathrm{L}^{-1}$ de cobre $\left(\mathrm{CuCl}_{2}\right)$, manganês $\left[\mathrm{Mn}\left(\mathrm{NO}_{3}\right)_{2} \cdot 6 \mathrm{H}_{2} \mathrm{O}\right]$, selênio $\left(\mathrm{SeO}_{2}\right)$ e zinco $\left(\mathrm{ZnCl}_{2}\right)$ foram preparadas a partir da diluição de solução Tritisol (Merck, Darmstadt, Alemanha), seguindo as recomendações do fabricante. 
A solução analítica de referência de ferro foi preparada a partir da diluição sucessiva de solução preparada com $\mathrm{Fe}_{2} \mathrm{O}_{3}$ da Johnson Mattey de grau espectroscópico dissolvido em $\mathrm{HNO}_{3}$ p.a., para concentração final de $1000 \mathrm{mg} \mathrm{L}^{-1} \mathrm{em} 0,1 \% \mathrm{v} / \mathrm{v} \mathrm{HNO}_{3}$.

Os modificadores químicos empregados foram preparados a partir dos seguintes reagentes: $\mathrm{Pd}\left(\mathrm{NO}_{3}\right)_{2}$ (Suprapur, Merck), $\mathrm{Mg}\left(\mathrm{NO}_{3}\right)_{2}$ (Suprapur, Merck) e $\mathrm{Na}_{2} \mathrm{IrCl}_{6}$ (Merck).

$\mathrm{O}$ sal de etilenodiaminotetraacetato de sódio $\left(\mathrm{C}_{10} \mathrm{H}_{14} \mathrm{O}_{8} \mathrm{~N}_{2} \mathrm{Na}_{2} \cdot 2 \mathrm{H}_{2} \mathrm{O}\right)$ utilizado para a preparação das soluções analíticas para a calibração do ICP-OES na determinação de carbono residual foi de grau analítico de alta pureza (Mallinckrodt). A solução analítica com concentração de $2,50 \% \mathrm{~m} / \mathrm{v}$ de carbono foi preparada com a pesagem de 7,756 gramas de EDTA-disódico para a diluição final de $100 \mathrm{~mL}$. Soluções analíticas com concentrações de: $0,25,0,50$ e $1,00 \% \mathrm{~m} / \mathrm{v}$ de carbono foram preparadas a partir de diluições sucessivas da solução analítica de $2,50 \% \mathrm{~m} / \mathrm{v}$ de carbono. 


\subsection{Procedimento}

\subsubsection{Construção do sistema de decomposição com microfrascos}

Para o desenvolvimento do trabalho foi elaborado um sistema de decomposição, que envolveu a utilização de microfrascos de polipropileno adaptados a um forno de microondas focalizadas. Na figura 8 estão representados os dispositivos utilizados para a montagem do sistema de decomposição. Quatro microfrascos de $4,0 \mathrm{~mL}$ ou cinco microfrascos de 2,0mL (figura 8A) foram adaptados a suportes de Teflon ${ }^{\circledR}$ (figura $8 \mathrm{~B}$ e 8C) No centro desse sistema foi fixada uma haste de vidro de $30 \mathrm{~cm}$ de comprimento (figura 8D) para a introdução e retirada do conjunto microfrasco + suporte do interior do tubo digestor. $O$ tubo digestor modificado possui uma rosca na parte superior para o encaixe do adaptador de Teflon ${ }^{\circledR}$ (figura 8E) $\mathrm{O}$ tubo digestor foi modificado, em comparação ao tubo de digestão convencional do forno de microondas focalizadas, devido às dificuldades encontradas para a introdução do suporte com os microfrascos no tubo de digestão convencional. O tubo digestor, por sua vez, foi introduzido na cavidade do forno de microondas e adaptado a um sistema de refluxo (figura 8G-I) para a decomposição de amostras. Um desenho esquemático do sistema proposto está representado na figura 9. 


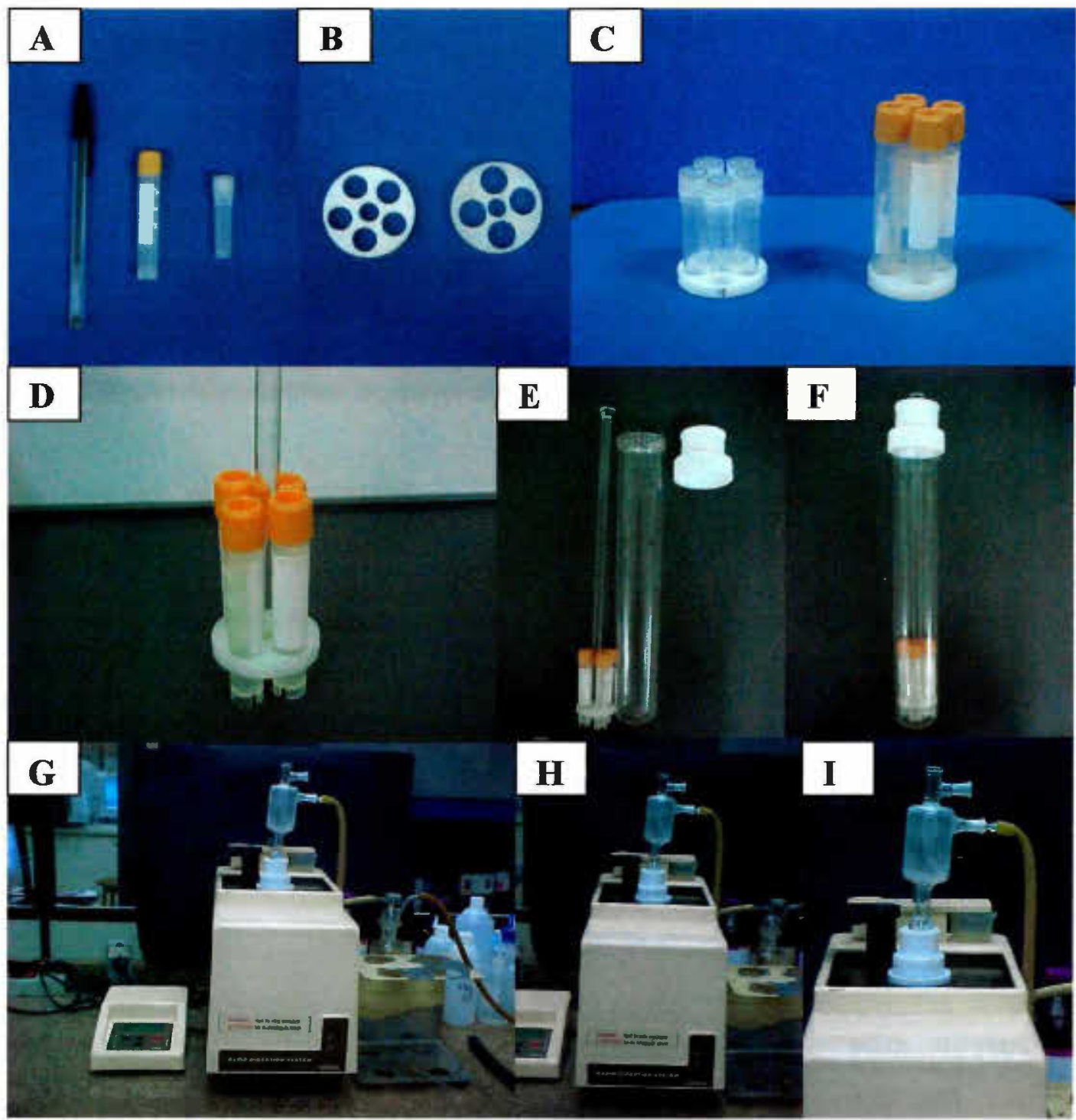

Figura 8. Sistema de decomposição proposto: A) Microfrascos de polipropileno de 4,0 e $2,0 \mathrm{~mL}$; B) Suportes de Teflon ${ }^{\circledR}$; C) Microfrascos colocados nos suportes; D) Suporte com quatro microfrascos adaptados a haste de vidro; E) Tubo digestor modificado; F) Suporte com os microfrascos no interior do tubo digestão; $\mathrm{G} \mathrm{e} \mathrm{H)} \mathrm{Tubo} \mathrm{digestor} \mathrm{na}$ cavidade do forno de microondas focalizadas; I) Sistema de refluxo adaptado ao tubo digestor. 


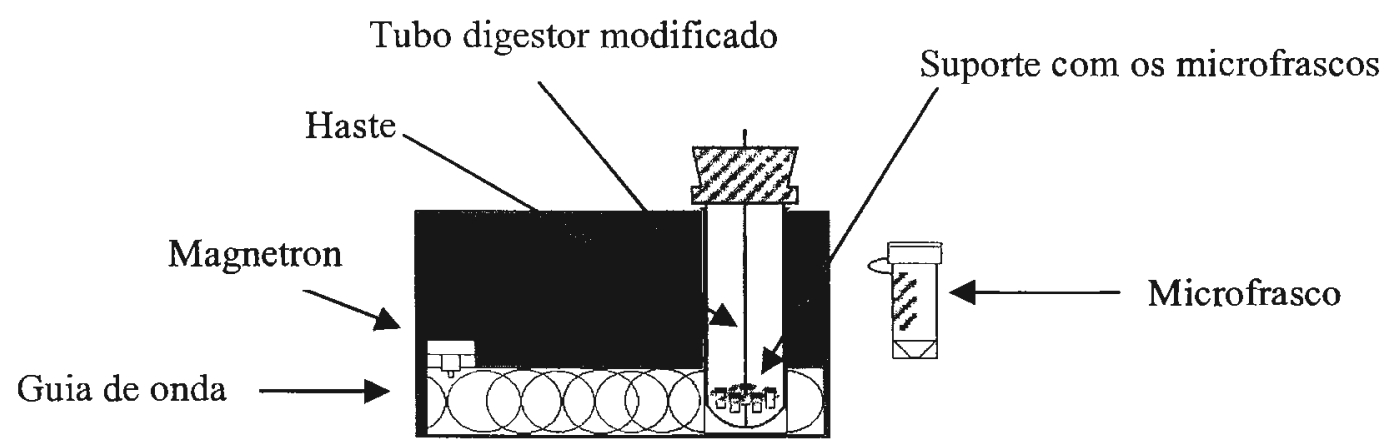

Figura 9: Desenho esquemático do sistema de decomposição proposto

\subsubsection{Calibração da potência total do forno de microondas focalizadas}

O forno de microondas focalizadas utilizado nesse estudo é constituído por uma cavidade para introdução de um tubo digestor e um magnetron para geração da radiação de microondas. O potencial total nominal do equipamento é de $300 \mathrm{~W}$. No entanto, o equipamento permite o controle da porcentagem da potência total nominal aplicada e o tempo de aplicação de microondas. Dessa maneira, pode-se selecionar deste $10 \%$ até $100 \%$ do potencial total nominal do equipamento com intervalos de $5 \%$ (tabela 3 ).

Tabela 3: Opções de aplicação de potência do forno de microondas focalizadas

\begin{tabular}{|cc|cc|}
\hline Potência $(\%)^{*}$ & Potência $(\mathbf{W})$ & Potência $(\%)^{*}$ & Potência $(\mathbf{W})$ \\
\hline--- & 30 & 55 & 165 \\
10 & 45 & 60 & 180 \\
15 & 60 & 65 & 195 \\
20 & 75 & 70 & 210 \\
25 & 90 & 75 & 225 \\
30 & 105 & 80 & 240 \\
35 & 120 & 85 & 255 \\
40 & 135 & 90 & 270 \\
45 & 150 & 95 & 285 \\
50 & 100 & 300 \\
\hline
\end{tabular}

* Porcentagem da potência total nominal (300W)

As opções selecionadas para a realização da calibração foram $10,20,30,40,50,60$, $70,80,90$ e $100 \%$ da potência total nominal do equipamento. Para isso, adotou-se um 
procedimento semelhante ao que foi descrito durante o I Workshop on Methods of Sample Decomposition, em Piracicaba, SP, $1996^{8} .120$ gramas de água destilada e deionizada (três replicada para cada potência selecionada) foram colocadas no tubo digestor do forno $(300 \mathrm{~mL})$, medindo-se a temperatura inicial. A seguir, a água foi aquecida por $60 \mathrm{~s}$ ou $120 \mathrm{~s}$ de acordo com a potência nominal selecionada $(60 \mathrm{~s}$ para potências de $60,70,80,90$ e $100 \%$ e 120 s para potências de $10,20,30,40$ e 50\%), medindo-se, imediatamente, a temperatura. A potência total foi calculada de acordo com a seguinte equação:

$$
\text { Potência }=\frac{\text { k.cp.m. } \Delta \mathrm{T}}{\mathrm{t}}
$$

Onde $\mathrm{k}$ é o fator de conversão de calorias $\mathrm{s}^{-1}$ para watts $\left(=4,184 \mathrm{~W} \mathrm{cal}^{-1} \mathrm{~s}\right) ; \mathrm{cp}$ representa o calor específico da água $\left(1 \mathrm{cal}^{-1}{ }^{\circ} \mathrm{C}^{-1}\right) ; \mathrm{m}$ é a massa de água utilizada (em gramas); $\Delta \mathrm{T}$ é a diferença entre a temperatura inicial e final da água $\left(\mathrm{em}{ }^{\circ} \mathrm{C}\right)$; e $\mathrm{t}$ é o tempo de aquecimento (em segundos).

\subsubsection{Verificação da potência absorvida pelos microfrascos no forno de microondas focalizadas}

A potência absorvida pelos quatro microfrascos de $4,0 \mathrm{~mL}$ e cinco microfrascos de 2,0 mL, colocados dentro do tubo digestor do forno de microondas utilizando uma potência nominal do forno de $10 \%$ da potência total $(30 \mathrm{~W})$ também foi investigado. $\mathrm{O}$ procedimento utilizado para estimar a potência no interior dos microfrascos foi semelhante ao utilizado para estimar a potência total irradiada sobre o tubo digestor. Para os microfrascos de 4,0 mL, foram pesadas massas de aproximadamente 3,6 $\mathrm{g}$ de água, e para os microfrascos de 2,0 mL, foram pesadas massas de aproximadamente $1,3 \mathrm{~g}$ de água. Para todos os casos mediu-se a temperatura inicial da água. O suporte com os microfrascos foi introduzido no interior do tubo digestor e o aquecimento foi realizado com uma potência nominal de $10 \%$ durante 60 segundos para os microfrascos de $2,0 \mathrm{~mL}$ e 120 segundos para os microfrascos de 4,0 mL. Imediatamente após o aquecimento, 
mediu-se a temperatura final atingida pela água no interior dos microfrascos. As medidas foram registradas com um termômetro com escalas de zero a $200^{\circ} \mathrm{C}$ e em duplicata. A potência absorvida em cada microfrasco dentro do tubo digestor foi calculada usando equação utilizada para a calibração do forno de microondas. Dessa maneira, a potência foi estimada nas 10 posições para os microfrascos de $2,0 \mathrm{~mL}$ e nas 8 posições para os microfrascos de $4,0 \mathrm{~mL}$ de acordo com as figuras 10 e 11 .
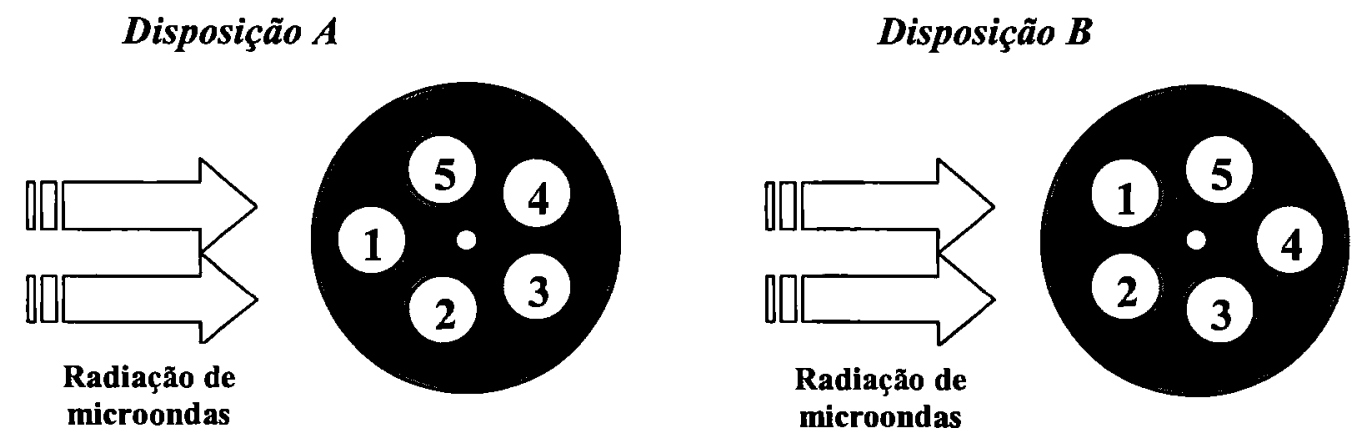

Figura 10. Posições para o suporte um (10 posições dos microfrascos de $2,0 \mathrm{ml}$ em relação ao feixe da radiação de microondas)

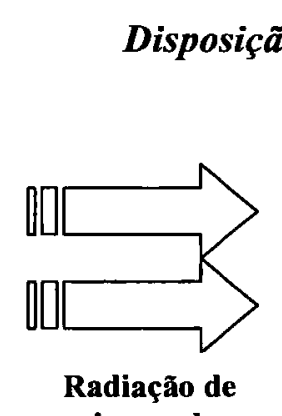
microondas

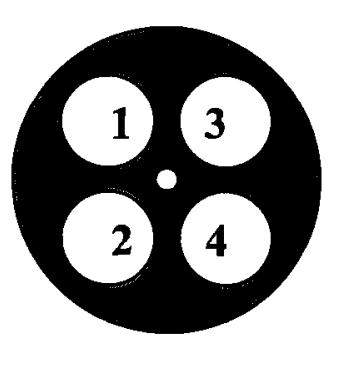

Disposição B
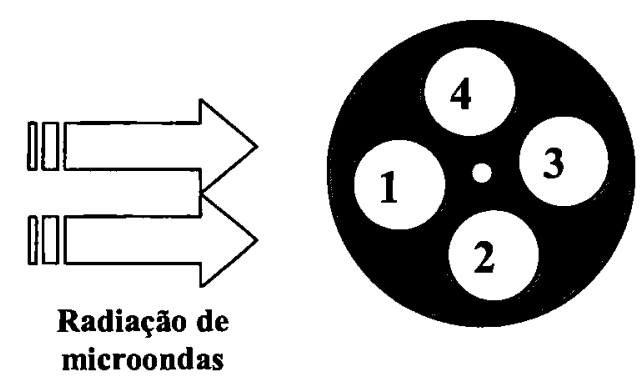

Figura 11. Posições para o suporte dois (oito posições dos microfrascos de $4,0 \mathrm{ml}$ em relação ao feixe de radiação de microondas). 


\subsubsection{Programa de aquecimento do forno de microondas focalizadas}

O estabelecimento de um programa de aquecimento para a decomposição de amostras de cabelos no forno de microondas focalizadas, com os microfrascos foi realizado com diferentes tempos de irradiação de microondas. Inicialmente, foram estudados programas com incidência durante um tempo fixo ( $3 \mathrm{~min}$ ) ou alternados, intercalando-se a incidência de microondas, com uma potência de $10 \%$ da capacidade nominal do equipamento. Cerca de $30 \mathrm{mg}$ de amostras de cabelo foram pesadas diretamente em cada um dos cinco microfrascos de polipropileno de $2,0 \mathrm{~mL}$ de capacidade e adicionados $300 \mu \mathrm{L}$ de $\mathrm{HNO}_{3}$ e, para os quatro microfrascos de $4,0 \mathrm{~mL}$ foram pesados aproximadamente $60 \mathrm{mg}$ da amostra de cabelo e adicionados $600 \mu \mathrm{L}$ de $\mathrm{HNO}_{3}$. Em seguida, os microfrascos foram fechados de maneira que não fosse totalmente rosqueada e pudesse evitar pressão excessiva no seu interior. Os microfrascos foram colocados no suporte de Teflon $^{\circledR}$ e introduzidos no tubo digestor, o qual foi colocado na cavidade do forno de microondas focalizadas para o aquecimento. Os programas de aquecimento utilizados estão apresentados na tabela 4.

Tabela 4: Programas de aquecimento do forno de microondas focalizadas para a decomposição de amostras de cabelo utilizando os microfrascos.

\begin{tabular}{|c|c|c|}
\hline \multicolumn{3}{|c|}{ Programa 1 } \\
\hline Etapas & Potência (\%)* & Tempo (min) \\
\hline 1 & 10 & 4 \\
\hline \multicolumn{3}{|c|}{ Programa 2 } \\
\hline Etapas & Potência (\%)* & Tempo (min) \\
\hline 1 & 10 & 1 \\
\hline 2 & 0 & 1 \\
\hline 3 & 10 & 1 \\
\hline 4 & 0 & 1 \\
\hline 5 & 10 & 1 \\
\hline 6 & 0 & 1 \\
\hline 7 & 10 & 1 \\
\hline
\end{tabular}

* Porcentagem da potência nominal de $300 \mathrm{~W}$ 


\subsubsection{Avaliação da quantidade de massa de amostra utilizada para decomposição nos microfrascos}

Segundo Tolg $^{64}$ (1972), a razão entre a superfície do recipiente utilizado e a massa empregada durante um procedimento de abertura de amostra deve ser a menor possível, para minimizar erros devido à adsorção e dessorção de elementos. Seguindo esse princípio, buscou-se a melhor razão entre a superfície do recipiente e a massa empregada, ou seja, utilizar a máxima quantidade de amostra possível no menor volume do recipiente (decomposição em microfrascos de polipropileno de 2,0 e 4,0 mL).

Para a realização desse estudo, foram digeridas amostras de cabelo com as seguintes massas: 5, 10, 20, 30 e $40 \mathrm{mg}$ para os microfrascos de 2,0 mL e 10, 20, 40, 60 e $80 \mathrm{mg}$ para os microfrascos de 4,0 mL. Para todas as massas adicionadas nos microfrascos de 2,0 mL, foram utilizados $300 \mu \mathrm{L}$ de $\mathrm{HNO}_{3}$ e $150 \mu \mathrm{L}$ de $\mathrm{H}_{2} \mathrm{O}_{2}$ e para os microfrascos de 4,0 mL, foram utilizados $600 \mu \mathrm{L}$ de $\mathrm{HNO}_{3}$ e $300 \mu \mathrm{L}$ de $\mathrm{H}_{2} \mathrm{O}_{2}$. Os microfrascos não foram totalmente vedados para evitar a formação de pressão no interior dos mesmos. A adição do ácido nítrico foi feita no início do programa de aquecimento, enquanto que a adição do $\mathrm{H}_{2} \mathrm{O}_{2}$ foi feita após a incidência de microondas.

\subsubsection{Verificação da variação do volume do microfrasco de polipropileno após a decomposição}

Um estudo foi realizado para verificar possíveis alterações no volume dos microfrascos após serem submetidos ao aquecimento no forno de microondas.

Inicialmente, os microfrascos de $2,0 \mathrm{~mL}$, foram aferidos para um volume de 1,35 $\mathrm{mL}$. Os microfrascos de 4,0 mL foram aferidos para um volume de 3,60 mL.

Para este estudo, pesou-se a quantidade de água destilada até a marca de aferição dos microfrascos $\left(m_{1}\right)$. Em seguida, os microfrascos foram esvaziados e secados a temperatura ambiente. Com os microfrascos totalmente secos, pesou-se aproximadamente $30 \mathrm{mg}$ de cabelo nos de 2,0 mL e $60 \mathrm{mg}$ de cabelo nos de 4,0 $\mathrm{mL}$. Os microfrascos foram colocados, respectivamente, nos suporte 2 e 1 e introduzidos no tubo digestor e o programa 2 (tabela 4) foi executado para a decomposição das amostras. Após 
o aquecimento, os digeridos foram descartados e os frascos foram lavados e secos a temperatura ambiente. Em seguida, adicionou-se uma quantidade de água até a marca de aferição dos microfrascos. Novamente os frascos foram pesados para obtenção das massas de água $\left(\mathrm{m}_{2}\right)$. O cálculo da variação de volume dos microfrascos (VV) foi realizado de acordo com a seguinte equação: $\mathrm{VV}=\left(\mathrm{m}_{2}-\mathrm{m}_{1}\right) \cdot 100 / \mathrm{d}_{\mathrm{H} 2 \mathrm{O}} \cdot \mathrm{m}_{1}$. Este procedimento foi realizado em triplicata.

\subsubsection{Avaliação da temperatura do sistema de decomposição proposto}

A temperatura de decomposição do sistema proposto foi medida, com auxílio de uma termômetro, na solução no interior dos microfrascos ao longo do processo de decomposição de amostras de cabelo. As medidas foram executadas após o primeiro, o segundo, o terceiro e o quarto minuto de aplicação de microondas (entre um minuto e outro de aplicação de microondas, intercalado por um minuto sem a aplicação das microondas). Imediatamente após a paralisação da aplicação da radiação de microondas, o termômetro era introduzido em cada um dos quatro microfrascos de 4,0 mL ou dos 5 microfrascos de 2,0 mL, seqüencialmente, e dessa forma, a temperatura nos microfrascos foi medida.

\subsubsection{Avaliação da eficiência de decomposição do sistema proposto}

Para avaliar a eficiência de eliminação da matéria orgânica do sistema de decomposição proposto para amostras de cabelo, foram realizadas determinações de carbono residual nas soluções resultantes do procedimento de decomposição proposto. Estas soluções foram deixadas em uma chapa a uma temperatura de aproximadamente $120^{\circ} \mathrm{C}$ para evaporação de carbono voláteis dissolvido na solução ${ }^{40}$.

Para a determinação de carbono residual nas soluções de digerido de cabelo, foi necessário ter o conhecimento da quantidade de carbono total presente em uma amostra de cabelo. Para isso, foi realizada a determinação da concentração de carbono total em uma amostra (uma mistura de cabelo de 7 pessoas). A amostra de cabelo utilizada para esta análise foi previamente moída em um moinho criogênico e determinado o carbono 
total com a utilização de um analisador de carbono CNH. Estas análises foram realizadas pelo laboratório da Central Analítica do IQ-USP.

Para efeitos de comparação, fez-se a determinação do teor de carbono residual em soluções de digeridos de cabelo utilizando-se procedimentos de decomposição descritas nos manuais de instrução dos fornos de microondas convencional e focalizadas.

Outro parâmetro avaliado neste estudo foi a influência da moagem do cabelo sobre a eficiência de decomposição, em comparação com a eficiência de decomposição em amostras não moídas. Para isso, foram realizadas as decomposições das amostras de cabelo não moídas e moídas pelo moinho criogênico e avaliado o teor de carbono residual nestas soluções.

Todas as determinações de carbono residual foram realizadas por ICP-OES. A calibração do equipamento foi feita com soluções analíticas de EDTA com as seguintes concentrações: $0,00-0,25-0,50-1,00-2,50 \% \mathrm{~m} / \mathrm{v}$.

O cálculo da porcentagem de carbono residual em relação à quantidade de carbono original nas amostras (antes da decomposição) foi realizada de acordo com a equação abaixo:

$$
\mathrm{RC}=\frac{\mathrm{CR} \cdot \mathrm{V} \cdot 10000}{\mathrm{C} \cdot \mathrm{m}}
$$

Onde:

- $\mathrm{RC}=$ Porcentagem de carbono residual em relação à quantidade de carbono original da amostra

- $\quad \mathrm{CR}=$ Porcentagem de carbono residual na solução de digerido da amostra

- $\mathrm{V}=$ Volume de aferição da solução de digerido da amostra

- $\mathrm{C}=$ Concentração de carbono original da amostra $(\% \mathrm{~m} / \mathrm{m})$

- $\mathrm{m}=$ Massa de amostra utilizada para a decomposição 


\subsubsection{Decomposição de amostras de cabelo em forno de microondas fechado (FMfec)}

Para a decomposição das amostras de cabelo no forno de microondas fechado, seguiu-se o procedimento de decomposição descrito no manual de instrução da Milestone (Cookbook of microwave application notes- Method 102, field clinical pharmaceutical):

- Carrossel com 10 frascos (2 frascos com amostras)

- $\cong 250 \mathrm{mg}$ de cabelo $+3,0 \mathrm{~mL}$ de $\mathrm{HNO}_{3}(65 \% \mathrm{v} / \mathrm{v})+0,25 \mathrm{~mL}$ de $\mathrm{H}_{2} \mathrm{O}_{2}(30 \%$ $\mathrm{m} / \mathrm{v})$. Após a adição do reagente esperou-se a reação inicial, com intensa liberação de gases ocorrer e, posteriormente, fechou-se o frasco digestor.

- Programa do forno de microondas fechado:

$\checkmark$ Pressão máxima: 180 psi

$\checkmark$ Temperatura máxima: $180{ }^{\circ} \mathrm{C}$

$\checkmark$ Tempo de aplicação de microondas: 7 minutos

$\checkmark$ Potência: $250 \mathrm{~W}$

Após a digestão, os digeridos foram transferido para béqueres de $10 \mathrm{~mL}$ e colocados sobre a chapa elétrica à temperatura de $120^{\circ} \mathrm{C}$ para remoção de compostos de carbono voláteis $^{40}$. Em seguida, os digeridos foram transferidos para balões, diluídos para 25,0 $\mathrm{mL}$ e armazenados em frascos de polietileno.

\subsubsection{Decomposição de amostras de cabelo em forno de microondas focalizadas - método convencional (FMfoc)}

Para a decomposição das amostras de cabelo no forno de microondas focalizadas, seguiu-se o procedimento de decomposição descrito no manual de instrução da Spex (Digestion/Application file - Record Number 291):

- Quantidade de amostras: $\cong 200 \mathrm{mg}+2,0 \mathrm{~mL} \mathrm{HNO}_{3}+0,5 \mathrm{~mL} \mathrm{H}_{2} \mathrm{O}_{2}$

- Programa de aquecimento do forno de microondas focalizadas de acordo com a (tabela 5) 
Tabela 5: Programa de aquecimento do forno de microondas focalizadas

\begin{tabular}{|c|c|c|c|c|}
\hline Etapas & Reagentes & Volume(mL) & \%Potência & Tempo(min) \\
\hline $\mathbf{1}$ & $\mathrm{HNO}_{3}$ & 2,0 & 10 & 10 \\
\hline $\mathbf{2}$ & ---- & ---- & 25 & 10 \\
\hline $\mathbf{3}$ & $\mathrm{H}_{2} \mathrm{O}_{2}$ & 0,5 & ---- & -- \\
\hline
\end{tabular}

Após a digestão, a solução foi transferida para um béquer de $10 \mathrm{~mL}$ e colocada sobre a chapa elétrica à temperatura de $120^{\circ} \mathrm{C}$ para remoção dos compostos de carbono voláteis $^{40}$. Em seguida, a solução foi transferida para um balão e diluída para $25,0 \mathrm{~mL}$ e armazenada em frasco de polietileno. Este procedimento foi realizado em triplicata.

\subsubsection{Decomposição de amostras de cabelo pelo procedimento proposto}

As decomposições das amostras de cabelo foram realizadas nos microfrascos de 2,0 $\mathrm{mL}$ (Vial 2) e 4,0 mL (Vial 4).

No sistema de decomposição utilizando os microfrascos de $2,0 \mathrm{~mL}$, foram utilizados 5 microfrascos, nos quais foram introduzidos aproximadamente $30 \mathrm{mg}$ de cabelo. $\mathrm{O}$ programa de aquecimento do forno de microondas e a adição de $300 \mu \mathrm{L}$ de $\mathrm{HNO}_{3}(65 \%$ v/v) e $150 \mu \mathrm{L}$ de $\mathrm{H}_{2} \mathrm{O}_{2} 30 \% \mathrm{~m} / \mathrm{v}$ foi realizada de acordo com a tabela 6 .

No sistema de decomposição utilizando os microfrascos de $4,0 \mathrm{~mL}$, foram utilizados 4 microfrascos, nos quais foram introduzidos aproximadamente $60 \mathrm{mg}$ de cabelo. $\mathrm{O}$ programa de aquecimento e a adição de $600 \mu \mathrm{L}$ de $\mathrm{HNO}_{3}(65 \%)$ e $300 \mu \mathrm{L}$ de $\mathrm{H}_{2} \mathrm{O}_{2} 30 \%$ $\mathrm{m} / \mathrm{v}$ foram os mesmos apresentados na tabela 6 . 
Tabela 6: Programa de aquecimento do forno de microondas focalizadas usando microfrascos

\begin{tabular}{|c|c|c|c|}
\hline Etapas & Reagentes & \%Potência & Tempo (min) \\
\hline $\mathbf{1}$ & $\mathrm{HNO}_{3}$ & 10 & 1 \\
\hline $\mathbf{2}$ & $-\cdots$ & 0 & 1 \\
\hline $\mathbf{3}$ & $-\cdots$ & 10 & 1 \\
\hline $\mathbf{4}$ & $-\cdots$ & 0 & 1 \\
\hline $\mathbf{5}$ & $-\cdots$ & 10 & 1 \\
\hline $\mathbf{6}$ & $-\cdots$ & 0 & 1 \\
\hline $\mathbf{7}$ & $-\cdots$ & 10 & 1 \\
\hline $\mathbf{8}$ & $-\cdots-----\cdots$ & 1 \\
\hline
\end{tabular}

Os digeridos dos microfrascos de $2,0 \mathrm{~mL}$ e $4,0 \mathrm{~mL}$, foram transferidos para um béquer de $10 \mathrm{~mL}$ e colocados sobre a chapa elétrica a temperatura de $120^{\circ} \mathrm{C}$ para remoção de compostos de carbono voláteis. Após esta etapa, o digerido foi transferido para um balão e diluído para $25,0 \mathrm{~mL}$. A solução final foi transferida para um frasco de polietileno. Este procedimento foi realizado em duplicata.

\subsubsection{Otimização do programa de aquecimento para determinação de Mn em digeridos de cabelo por GFAAS}

Para a verificação do comportamento térmico de $\mathrm{Mn}$ foram obtidas curvas de temperatura de pirólise e de atomização utilizando-se soluções analíticas de referência contendo $5 \mathrm{ng} \mathrm{Mn}^{2+} \mathrm{mL}^{-1}$ em $0,1 \% \mathrm{v} / \mathrm{v} \mathrm{HNO}_{3}$ na presença do modificador químico universal ( $5 \mu \mathrm{g}$ Pd e $3 \mu \mathrm{g} \mathrm{Mg}$ ). A escolha do modificador químico foi baseada em estudos prévios envolvendo determinação de manganês por GFAAS ${ }^{6}$. O mesmo procedimento foi utilizado em solução de digerido de cabelo, visando conhecer o comportamento térmico do elemento na presença da matriz.

Neste estudo foram dispensados no interior do tubo de grafite $10 \mu \mathrm{L}$ da solução analítica de referência e $10 \mu \mathrm{L}$ da solução do modificador químico. O programa de aquecimento utilizado durante esse estudo está apresentado na tabela 7. As medições experimentais foram baseadas em absorbância integrada e, durante todo estudo foram feitas medições em triplicatas. 
Tabela 7: Programa de aquecimento para estudar o comportamento térmico do manganês

\begin{tabular}{llllll}
\multicolumn{1}{c}{ Etapa } & \multicolumn{1}{c}{$\begin{array}{c}\mathbf{T} \\
\left({ }^{\mathbf{C}} \mathbf{C}\right)\end{array}$} & $\begin{array}{c}\text { Taxa } \\
\left({ }^{\mathbf{C}} \mathbf{C} / \mathbf{s}\right)\end{array}$ & \multicolumn{1}{c}{$\begin{array}{c}\text { Patamar } \\
(\mathbf{s})\end{array}$} & $\begin{array}{c}\text { Tempo } \\
(\mathbf{s})\end{array}$ & Leitura \\
\hline Secagem & 100 & 20 & 15 & 19 & Não \\
Secagem & 130 & 10 & 10 & 13 & Não \\
Pirólise & $\mathrm{Tp}^{*}$ & 100 & 5 & 16,7 & Não \\
$\mathrm{AZ}$ & $\mathrm{Tp}^{*}$ & 0 & 6 & 6 & Não \\
Atomização & $\mathrm{Ta}^{* *}$ & $\mathrm{Ta}^{* *}$ & 5 & 5,3 & Sim \\
Limpeza & 2600 & 1000 & 2 & 2,5 & Não \\
\hline
\end{tabular}

AZ: Auto-zero

* Temperatura de pirólise

** Temperatura de atomização

As curvas de temperatura de pirólise foram obtidas fixando-se a temperatura de atomização em $1900^{\circ} \mathrm{C}$ e variando-se a temperatura de pirólise entre $900^{\circ} \mathrm{C}$ e $1500^{\circ} \mathrm{C}$. As curvas de temperatura de atomização foram obtidas fixando-se a temperatura de pirólise a $1300^{\circ} \mathrm{C}$ e variando-se a temperatura de atomização de $1400^{\circ} \mathrm{C}$ a $2200^{\circ} \mathrm{C}$.

\subsubsection{Otimização do programa de aquecimento para a determinação de Se em digeridos de cabelos por GFAAS}

\subsubsection{Verificação do comportamento térmico do selênio frente a diferentes tipos de modificadores químicos}

Nesse estudo, verificou-se o comportamento térmico do selênio na ausência e presença de diferentes modificadores químicos.

O comportamento térmico do selênio foi verificado através da obtenção das curvas de temperatura de pirólise e de atomização, utilizando-se soluções analíticas de referência contendo $100 \mathrm{ng} \mathrm{Se}^{4+} \mathrm{mL}^{-1}$ em $0,1 \% \mathrm{HNO}_{3}$ na ausência e na presença dos modificadores químicos: mistura de paládio e magnésio $(5 \mu \mathrm{g} \mathrm{Pd}$ e $3 \mu \mathrm{g} \mathrm{Mg})$, irídio $(5 \mu \mathrm{g})$ e a mistura de irídio e magnésio ( $5 \mu \mathrm{g} \operatorname{Ir}$ e $3 \mu \mathrm{g} \mathrm{Mg})$.

Foram dispensados no interior do tubo de grafite $10 \mu \mathrm{L}$ da solução analítica de referência e $10 \mu \mathrm{L}$ da solução do modificador químico. O programa de aquecimento utilizado durante esse estudo está apresentado na tabela 8. As medições experimentais 
foram baseadas em absorbância integrada e durante todo estudo foram feitas medidas em triplicatas.

As curvas de temperatura de pirólise foram obtidas fixando-se a temperatura de atomização em $2200^{\circ} \mathrm{C}$ e variando-se a temperatura de pirólise entre $150^{\circ} \mathrm{C}$ e $1800^{\circ} \mathrm{C}$. As curvas de temperatura de atomização foram obtidas fixando-se a melhor temperatura de pirólise em $1300^{\circ} \mathrm{C}$ e variando-se a temperatura de atomização de $1500^{\circ} \mathrm{C}$ a $2300^{\circ} \mathrm{C}$.

Tabela 8: Programa de aquecimento para a determinação de selênio por GFAAS

\begin{tabular}{cccccc}
\hline Etapa & $\begin{array}{c}\text { T } \\
\left({ }^{\mathbf{C}} \mathbf{C}\right)\end{array}$ & $\begin{array}{c}\text { Rampa } \\
(\mathbf{s})\end{array}$ & $\begin{array}{c}\text { Patamar } \\
(\mathbf{s})\end{array}$ & $\begin{array}{c}\text { Vazão Ar } \\
\left(\mathbf{m I ~ m i n}^{-\mathbf{1}}\right)\end{array}$ & Leitura \\
\hline Secagem & 100 & 5 & 15 & 250 & Não \\
Secagem & 130 & 2 & 5 & 250 & Não \\
Pirólise & $\mathrm{Tp}^{*}$ & 5 & 15 & 250 & Não \\
Atomização & $\mathrm{Ta}^{* *}$ & 0 & 5 & 0 & Sim \\
Limpeza & 2500 & 1 & 2 & 250 & Não \\
\hline
\end{tabular}

* Temperatura de pirólise

** Temperatura de atomização

\subsubsection{Avaliação da concentração dos modificadores químicos}

Depois de verificado o comportamento térmico do selênio frente a diferentes modificadores químicos, selecionou-se dois modificadores químicos que apresentaram melhores estabilidades térmicas para um estudo da avaliação da concentração do mesmo sobre a estabilidade térmica. Os modificadores selecionados para este estudo foram as misturas Pd + Mg e Ir + Mg.

Para a elaboração desse estudo, foram preparados os modificadores químicos de Ir $+\mathrm{Mg}$ e $\mathrm{Pd}+\mathrm{Mg}$ com diferentes concentrações de acordo com a tabela 9. Estes modificadores químicos foram utilizados para a aquisição do sinal analítico de uma alíquota de $10 \mu \mathrm{L}$ da solução analítica de referência de $20 \mu \mathrm{g} \mathrm{L}^{-1}$ de selênio no GFAAS.

As temperaturas de pirólise e de atomização do GFAAS utilizados neste estudo foram de $1300^{\circ} \mathrm{C}$ e $1900^{\circ} \mathrm{C}$, respectivamente. 
Tabela 9: Modificadores químicos com diferentes concentrações avaliados para determinação de selênio.

\begin{tabular}{|c|c|c|}
\hline Concentração MQ & Modificador Químico & Quantidade do MQ* \\
\hline \multirow{2}{*}{1} & $500 \mathrm{mg} \mathrm{L}^{-1} \mathrm{Ir}+300 \mathrm{mg} \mathrm{L}^{-1} \mathrm{Mg}$ & $5 \mu \mathrm{gr}+3 \mu \mathrm{g} \mathrm{Mg}$ \\
\cline { 2 - 3 } & $500 \mathrm{mg} \mathrm{L}^{-1} \mathrm{Pd}+300 \mathrm{mg} \mathrm{L}^{-1} \mathrm{Mg}$ & $5 \mu \mathrm{g} \mathrm{Pd}+3 \mu \mathrm{g} \mathrm{Mg}$ \\
\hline \multirow{2}{*}{2} & $1000 \mathrm{mg} \mathrm{L}^{-1} \mathrm{Ir}+600 \mathrm{mg} \mathrm{L}^{-1} \mathrm{Mg}$ & $10 \mu \mathrm{g} \mathrm{Ir}+6 \mu \mathrm{gg}$ \\
\cline { 2 - 4 } & $1000 \mathrm{mg} \mathrm{L}^{-1} \mathrm{Pd}+600 \mathrm{mg} \mathrm{L}^{-1} \mathrm{Mg}$ & $10 \mu \mathrm{gd}+6 \mu \mathrm{gg}$ \\
\hline \multirow{3}{*}{3} & $2000 \mathrm{mg} \mathrm{L}^{-1} \mathrm{Ir}+1200 \mathrm{mg} \mathrm{L}^{-1} \mathrm{Mg}$ & $20 \mu \mathrm{gr}+12 \mu \mathrm{gg}$ \\
\cline { 2 - 4 } & $2000 \mathrm{mg} \mathrm{L}^{-1} \mathrm{Pd}+1200 \mathrm{mg} \mathrm{L}^{-1} \mathrm{Mg}$ & $20 \mu \mathrm{g} \mathrm{Pd}+10 \mu \mathrm{g} \mathrm{Mg}$ \\
\hline \multirow{3}{*}{4} & $4000 \mathrm{mg} \mathrm{L}^{-1} \mathrm{Ir}+2400 \mathrm{mg} \mathrm{L}^{-1} \mathrm{Mg}$ & $40 \mu \mathrm{gr}+24 \mu \mathrm{gg}$ \\
\cline { 2 - 3 } & $4000 \mathrm{mg} \mathrm{L}^{-1} \mathrm{Pd}+2400 \mathrm{mg} \mathrm{L}^{-1} \mathrm{Mg}$ & $40 \mu \mathrm{gd}+20 \mu \mathrm{gg}$ \\
\hline
\end{tabular}

* Quantidade de modificador químico introduzido no tubo de grafite $(10 \mu \mathrm{L})$

\subsubsection{Estudo da Interferência de Sulfato na determinação de Se por GFAAS}

No estudo preliminar da otimização de temperatura de pirólise e de atomização, utilizando o modificador químico $5 \mu \mathrm{g} \operatorname{Ir}+3 \mu \mathrm{g} \mathrm{Mg}$, verificou-se uma atenuação do sinal analítico de selênio em meio da matriz de cabelo. Segundo Ni Zhe-Ming ${ }^{70}$, a presença de sulfato provoca um efeito de supressão superior a $75 \%$ do sinal, dependendo da concentração do sulfato. De acordo com estudos realizados pelo autor, o efeito de supressão do sinal de selênio causado pela presença de sulfato pode ser minimizado significativamente com a utilização do modificador químico paládio e com paládio associado com íons bário e estrôncio. Com essas informações, foram realizados estudos para verificar a interferência causada por sulfato na determinação de selênio por GFAAS, utilizando-se os modificadores químicos $\mathrm{Ir}+\mathrm{Mg}$ e $\mathrm{Pd}+\mathrm{Mg}$ na ausência e na presença de íons bário e estrôncio.

Para a realização desse estudo, foi feita a aquisição do sinal analítico do selênio empregando $10 \mu \mathrm{L}$ das seguintes soluções: solução analítica de referência de $20 \mu \mathrm{g} / \mathrm{L} \mathrm{Se}$, solução analítica de referência de $20 \mu \mathrm{g} / \mathrm{L}$ Se na presença de $25 \mu \mathrm{g}$ de sulfato, solução analítica de referência de $20 \mu \mathrm{g} / \mathrm{L}$ Se na presença de $25 \mu \mathrm{g}$ de sulfato e $5 \mu \mathrm{g}$ de $\mathrm{Ba}^{2+}$ e 20 $\mu \mathrm{g} / \mathrm{L}$ Se na presença de $25 \mu \mathrm{g}$ de sulfato e $5 \mu \mathrm{g} \mathrm{de} \mathrm{Sr}^{2+}$. 
As temperaturas de pirólise e de atomização do GFAAS utilizados neste estudo foram de $1300^{\circ} \mathrm{C}$ e $1900^{\circ} \mathrm{C}$, respectivamente.

\subsubsection{Programa de aquecimento na presença do melhor modificador químico}

A otimização do programa de aquecimento para determinação de Se por GFAAS, foi realizada com a utilização do melhor modificador químico apresentado nos estudos anteriores para soluções analíticas de referência de $20 \mu \mathrm{g} / \mathrm{L} \mathrm{Se}$ e digerido de cabelo com adição de $20 \mu \mathrm{g} / \mathrm{L} \mathrm{Se}$.

As curvas de temperatura de pirólise foram obtidas fixando-se a temperatura de atomização $\left(1900^{\circ} \mathrm{C}\right)$ e variando-se a temperatura de pirólise entre $700^{\circ} \mathrm{C}$ e $1700^{\circ} \mathrm{C}$. As curvas de temperatura de atomização foram obtidas fixando-se a melhor temperatura de pirólise $\left(1300^{\circ} \mathrm{C}\right)$ e variando-se a temperatura de atomização de $1500^{\circ} \mathrm{C}$ a $2300^{\circ} \mathrm{C}$.

Foram dispensados no interior do tubo de grafite $10 \mu \mathrm{L}$ da solução analítica de referência e $10 \mu \mathrm{L}$ da solução do modificador químico. O programa de aquecimento utilizado durante esse estudo está apresentado na tabela 8. As medições experimentais foram baseadas em absorbância integrada e durante todo estudo foram feitas medições em triplicata.

\subsubsection{Avaliação de perda dos elementos utilizando o sistema de digestão proposto}

Este estudo foi realizado para verificar perdas dos elementos analisados $(\mathrm{Cu}, \mathrm{Fe}, \mathrm{Zn}$, $\mathrm{Mn}$ e Se) por volatilização durante o processo de digestão. Para a realização desse estudo, as amostras de cabelo foram digeridas, utilizando-se o sistema proposto para os microfrascos de 2,0 e 4,0 $\mathrm{mL}$ de capacidade.

Foram utilizados cinco microfrascos para a decomposição das amostras utilizadas nesse estudo.

Em três dos cinco microfrascos foram colocadas quantidades iguais de amostras de cabelo, sendo que em dois dos três microfrascos foi feita adição de uma quantidade conhecida de solução analítica de referência do elemento de interesse (tabela 10). No 
primeiro, a adição foi feita antes do processo de aquecimento por microondas e no segundo, a adição foi feita após o aquecimento.

Os dois microfrascos restantes foram utilizados um como branco e o outro para a adição de uma quantidade conhecida dos analitos sem a presença da matriz antes do processo de aquecimento por microondas (figura 12).

Após o procedimento de digestão, os microfrascos foram preenchidos com água destilada e bi-deionizada até a marca de aferição e a solução analisada pelo FAAS ou GFAAS com ou sem diluição de acordo com elemento de interesse (tabela 10).

Dessa forma, foi possível avaliar a recuperação do elemento de interesse após sofrer o processo de decomposição utilizando o sistema proposto e verificar uma possível perda desses elementos por volatilidade.

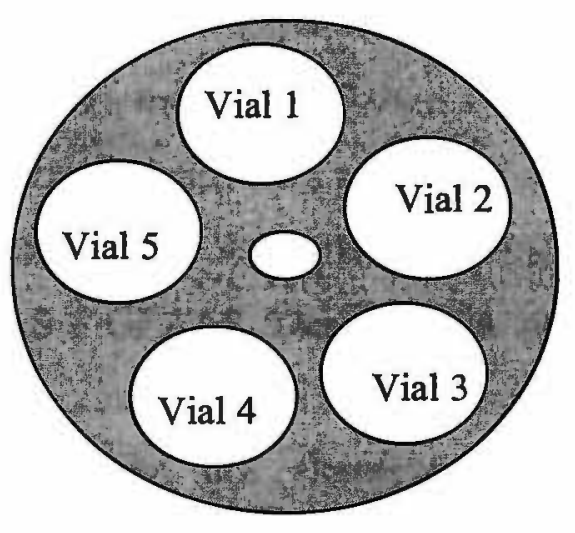

Microfrasco 1: Branco

Microfrasco 2: Branco + (A)*

Microfrasco 3: Amostra

Microfrasco 4: Amostra + (A)*

Microfrasco 5: Amostra + (B)**

* (A): Adição do analito antes do aquecimento

**(B): Adição do analito após o aquecimento

Figura 12. Distribuição das amostras para a avaliação de perdas de elementos por volatilidade. 
Tabela 10: Parâmetros utilizados para avaliação de perda de elementos por volatilidade.

\begin{tabular}{|c|c|c|c|c|c|c|c|}
\hline \multirow[t]{2}{*}{ Elementos } & \multicolumn{2}{|c|}{ Massa(mg) } & \multicolumn{2}{|c|}{$\mathbf{V}(\mathbf{m L})$} & \multirow{2}{*}{$\begin{array}{l}\text { Adição } \\
\text { mg L L }^{-1}\end{array}$} & \multirow{2}{*}{$\begin{array}{l}\text { Diluição } \\
n^{0} \text { vezes }\end{array}$} & \multirow[t]{2}{*}{ Detecção } \\
\hline & Vial 1* & Vial 2* & Vial 1* & Vial 2* & & & \\
\hline $\mathrm{Zn}$ & --- & 60 & --- & 3,60 & 2,0 & 10 & FAAS \\
\hline $\mathrm{Fe}$ & --- & 60 & --- & 3,60 & 0,2 & --- & FAAS \\
\hline $\mathrm{Cu}$ & -- & 60 & -- & 3,60 & 0,2 & --- & FAAS \\
\hline $\mathrm{Mn}$ & 30 & -- & 1,35 & --- & $2,0 * *$ & 10 & GFAAS \\
\hline $\mathrm{Se}$ & 30 & --- & 1,35 & --- & $20,0^{* *}$ & --- & GFAAS \\
\hline
\end{tabular}

* Vial 1 e 2 = respectivamente microfrascos de 2,0 e $4,0 \mathrm{~mL}$

$* * \mu \mathrm{g} / \mathrm{L}$

\subsubsection{Determinação dos elementos em amostra de referência certificada de cabelo e avaliação de adição e recuperação de analitos}

Devido aos intervalos de concentração dos elementos encontrados no cabelo ${ }^{18}$ : serem muito discrepantes [cobre $(6,0-293 \mu \mathrm{g} / \mathrm{g})$, ferro $(10-900 \mu \mathrm{g} / \mathrm{g})$, zinco $(53,7$ $327 \mu \mathrm{g} / \mathrm{g})$, manganês $(0,04-24 \mu \mathrm{g} / \mathrm{g})$ e selênio $\left.(0,002-6,6 \mu \mathrm{g} / \mathrm{g})^{18}\right]$ e da quantidade de amostra utilizada para a decomposição nos microfrascos $(\cong 30 \mathrm{mg}$ de cabelo e $\cong 60 \mathrm{mg}$ de cabelo diluídas respectivamente para $1,35 \mathrm{~mL}$ e 3,6 mL), fez-se necessária a utilização da FAAS e GFAAS. Dessa forma, para a determinação dos elementos do grupo 1 (cobre, ferro e zinco), foi utilizado um espectrômetro de absorção atômica com chama, e para a determinação dos elementos do grupo 2 (manganês e selênio), foi utilizado um espectrômetro de absorção atômica com atomização eletrotérmica em forno de grafite.

Para a validação do sistema de digestão proposto, foi realizada a análise de $\mathrm{Fe}$ e $\mathrm{Zn}$ (elementos certificados) em amostra de material de referência certificado de cabelo IAEA e determinação dos elementos $\mathrm{Fe}, \mathrm{Zn}, \mathrm{Cu}, \mathrm{Mn}$ e $\mathrm{Se}$ na amostra de cabelo digerido avaliando a adição e recuperação dos analitos.

Para verificar o sistema de digestão proposto, foi feita a determinação de $\mathrm{Fe}, \mathrm{Zn}$, $\mathrm{Cu}, \mathrm{Mn}$ e Se em oito amostras distintas.

O procedimento adotado para a decomposição da amostra de referência e das amostras de cabelo seguiu o princípio do sistema de decomposição proposto. 
O material de referência utilizado foi previamente seco em um dessecador durante 48 horas e pesado diretamente nos microfrascos de 4,0 mL. As amostras de cabelo foram cortadas em pequenos pedaços (aproximadamente de $1 \mathrm{~cm}$ ), lavadas com água deionizada de acordo com o procedimento adotado pelo Borella et al. ${ }^{19}$, seca a temperatura ambiente e, em seguida pesadas diretamente nos microfrascos de 2,0 e 4,0 $\mathrm{mL}$. Todas as amostras foram digeridas pelo sistema proposto de acordo com a tabela 6.

$\mathrm{O}$ volume final, a adição de analito e a diluição utilizada para a determinação dos elementos estão descritos na tabela 11.

Tabela 11: Parâmetros analíticos para determinação dos elementos no material de referência de cabelo e na amostra de cabelo

\begin{tabular}{|c|c|c|}
\hline \multicolumn{3}{|c|}{ Material de Referência Certificada } \\
\hline Elementos & Volume Final & Adição (mg.. ${ }^{-1}$ ) \\
\hline $\mathrm{Fe}$ & 3,6 & 0 \\
\hline $\mathrm{Zn}{ }^{*}$ & 3,6 & 0 \\
\hline \multicolumn{3}{|c|}{ Amostra de Cabelo } \\
\hline $\mathrm{Fe}$ & 3,6 & 0,1 \\
\hline $\mathrm{Zn} *$ & 3,6 & 0,1 \\
\hline $\mathrm{Cu}$ & 3,6 & 0,1 \\
\hline $\mathrm{Mn} *$ & 1,35 & $2,0^{* *}$ \\
\hline $\mathrm{Se}$ & 1,35 & $20,0^{* *}$ \\
\hline
\end{tabular}

* Diluição (1:10)

$* * \mu \mathrm{g} . \mathrm{L}^{-1}$

Para a determinação dos elementos $\mathrm{Fe}, \mathrm{Zn}$ e $\mathrm{Cu}$, as amostras foram digeridas em microfrascos de 4,0 $\mathrm{mL}$ aferidas para $3,60 \mathrm{~mL}$ enquanto que para determinação dos elementos $\mathrm{Mn}$ e Se, as amostras foram digeridas em microfrascos de 2,0 mL, aferidas para 1,35 mL. Devido a alta sensibilidade para os elementos $\mathrm{Zn}$ e $\mathrm{Mn}$ nos equipamentos, foi necessária a realização de uma diluição de dez vezes nos digeridos de cabelo.

As curvas de calibração do ferro e zinco foram obtidas, utilizando soluções analíticas de referência de 0,0 (Branco), 1,0, 2,0 e 3,0 $\mathrm{mg} \mathrm{L}^{-1}$, preparadas de acordo com o item 4.2 . 
A curva de calibração do cobre foi obtida, utilizando soluções analíticas de referência de 0,00 (Branco), 0,25, 0,50 e 1,00 $\mathrm{mg} \mathrm{L}^{-1}$.

A curva de calibração do manganês foi obtida, utilizando soluções analíticas de referência de 0,0 (Branco), 5,0, 10,0 e 20,0 $\mu \mathrm{g} \mathrm{L}^{-1}$.

A curva de calibração do selênio foi obtida, utilizando soluções analíticas de referência de 0 (Branco), 50, 100 e $200 \mu \mathrm{g} \mathrm{L^{-1 }}$.

\subsubsection{Decomposição de diferentes matrizes utilizando o sistema proposto}

Para verificar a ampla aplicação do sistema de decomposição proposto, realizou-se a digestão do material de referência certificada de fígado bovino (NIST 1577b) e subseqüente determinação dos elementos: ferro, cobre e zinco (elementos certificados) por FAAS. O material de referência utilizado foi previamente seco em um dessecador durante 48 horas, pesado diretamente no microfrasco de $4,0 \mathrm{~mL}$, digerido pelo sistema proposto de acordo com a tabela 6 .

A massa do material de referência utilizada e a diluição utilizada para a determinação dos elementos estão descritos na tabela 12 .

Tabela 12: Parâmetros analíticos para determinação dos elementos no material de referência de figado bovino

\begin{tabular}{|c|c|c|c|}
\hline Elementos & Massa (mg) & Volume Final & Diluição \\
\hline $\mathrm{Fe}$ & 58,4 & 3,6 & $1: 2$ \\
\hline $\mathrm{Cu}$ & 61,6 & 3,6 & $1: 4$ \\
\hline $\mathrm{Zn}$ & 60,8 & 3,6 & $1: 10$ \\
\hline
\end{tabular}




\section{RESULTADOS E DISCUSSÃO}

\subsection{Microfrascos de polipropileno e a escolha dos reagentes}

Atualmente, diversos materiais poliméricos, principalmente PTFE e PTFE-PFA, têm tido muita aceitação como recipientes para decomposição de amostras. Isto se deve às suas elevadas temperaturas de fusão, excelente resistência física a ácidos inorgânicos concentrados e ao baixo nível de impurezas em sua constituição. Entretanto, o custo destes materiais é razoavelmente elevado e nem sempre são disponíveis em tamanhos e formatos adequados para procedimentos de decomposição. Em vista disso, para alguns procedimentos, outros polímeros podem ser empregados, tais como polietileno e policarbonato recomendados por Adeloju, em $1989^{74}$.

Outra alternativa é o uso de recipientes de polipropileno, disponíveis em diversos tipos e tamanhos, com algumas vantagens sobre outros materiais como polietileno. $\mathrm{O}$ polipropileno tem custo equivalente ao do polietileno, entretanto o ponto de fusão do polipropileno é de $176^{\circ} \mathrm{C}$ superior a do polietileno $\left(138^{\circ} \mathrm{C}\right)$. Além disso, o polipropileno é um pouco mais resistente ao ataque de ácidos concentrados que o polietileno ${ }^{11}$.

O polipropileno, assim como os outros materiais poliméricos (PTFE, poliestileno e polietileno) é transparente às microondas e mal condutor de calor. Sob estes aspectos, o polipropileno pode ser recomendado, com algumas vantagens frente a outros polímeros, como recipiente em procedimentos de decomposição.

O sistema apresentado neste trabalho, que propõe a introdução de microfrascos de polipropileno de 2,0 e $4,0 \mathrm{~mL}$ de capacidade para decomposição em fornos de microondas focalizadas, apresenta claramente algumas vantagens com relação a procedimentos convencionais, tais como:

$\checkmark$ Maior facilidade de processamento e adequado para análises de rotina;

$\checkmark$ Emprego de pequenas quantidades de amostras e reagentes e pouco manuseio, propiciando baixo risco de contaminação e geração de pequenas quantidades de resíduos;

$\checkmark$ Processamento simultâneo de um número maior de amostras, aumentando assim, a freqüência de decomposição do forno de microondas; 
$\checkmark$ Eliminação de risco de contaminação por adsorção nas paredes do recipiente devido ao fato dos microfrascos de polipropileno serem descartáveis;

$\checkmark$ A não necessidade de limpeza prévia dos microfrascos, uma vez que os mesmos já são adquiridos de forma esterizado e fechados em sacos plásticos;

Rotineiramente, quando se faz a decomposição em sistemas fechados e com pressão, normalmente são feitas apenas duas replicadas (o procedimento é trabalhoso e é necessário, com freqüência, quantidades superiores a $0,1 \mathrm{~g}$ de amostra), cada amostra é medida três vezes e o desvio padrão obtido serve mais para estimar a incerteza nas medições sendo pouco para uma estimativa do desvio para o procedimento total. Fazendo-se a decomposição em microfrascos de polipropileno pode-se fazer um maior número de replicadas de cada amostra sem um gasto excessivo desta, o que permite uma melhor avaliação da variação no procedimento total ${ }^{11}$.

Uma das considerações importantes no desenvolvimento do procedimento de preparo de amostras é a escolha dos reagentes utilizados para a decomposição da matéria orgânica. A maioria dos procedimentos de decomposição por via úmida necessita de uma mistura de ácidos e/ou oxidantes, dos quais os mais comuns são $\mathrm{HNO}_{3}, \mathrm{H}_{2} \mathrm{SO}_{4}, \mathrm{HClO}_{4} \mathrm{e}$ $\mathrm{H}_{2} \mathrm{O}_{2}$. Dentre estes, destacam-se a mistura $\mathrm{HNO}_{3}$ e $\mathrm{H}_{2} \mathrm{O}_{2}$ para o preparo de amostras orgânicas ${ }^{50,65}$. Alguns dos motivos para a ampla aplicação dessa mistura na preparação de amostras orgânicas são a pureza com que são encontrados, a facilidade de purificação do ácido nítrico, o poder oxidante elevado dessa mistura e a solubilidade dos nitratos em água. Para o desenvolvimento do procedimento de preparo de amostras proposto, optouse pela utilização da mistura de $\mathrm{HNO}_{3}$ e $\mathrm{H}_{2} \mathrm{O}_{2}$ para a decomposição de amostras de cabelo pelo alto poder oxidante dessa mistura e pela segurança que o ácido nítrico oferece em comparação aos outros ácidos oxidantes. 


\subsection{Calibração do forno de microondas focalizadas}

A calibração do forno de microondas focalizadas foi realizada, visando à determinação da potência real que está sendo fornecida pelo forno de microondas. Para a determinação da potência fornecida pelo forno de microondas, foi feita inicialmente, sua calibração, calculando-se a potência com base no aquecimento de uma massa conhecida de água colocada no interior do tubo digestor, aplicando uma potência nominal de 10, 20, $30,40,50,60,70,80,90$ e $100 \%$ da potência total do equipamento (ver item 4.3.2). A potência total foi calculada (tabela 13) de acordo com a equação apresentada no item 4.3.2 e mostrou concordância entre $90,1 \%$ e $95,7 \%$ com a potência nominal do equipamento.

Tabela 13: Potência real calculada através da calibração do forno de microondas focalizada

\begin{tabular}{|c|c|c|}
\hline $\begin{array}{c}\text { Potência Nominal } \\
(\mathbf{W})\end{array}$ & $\begin{array}{c}\text { Potência Calculada } \\
(\mathbf{W})^{*}\end{array}$ & $\begin{array}{c}\text { [Pcal/Pnom].100 } \\
(\mathbf{\%})\end{array}$ \\
\hline 30 & $28,7 \pm 0,2$ & 95,7 \\
60 & $55,0 \pm 0,6$ & 91,7 \\
90 & $84,3 \pm 0,1$ & 93,7 \\
120 & $110,5 \pm 0,8$ & 92,1 \\
150 & $135,1 \pm 0,4$ & 90,1 \\
180 & $165,0 \pm 1,5$ & 91,7 \\
210 & $199,3 \pm 0,9$ & 94,9 \\
240 & $227,4 \pm 0,6$ & 94,8 \\
270 & $254,4 \pm 1,0$ & 94,2 \\
300 & $283,4 \pm 0,8$ & 94,5 \\
\hline
\end{tabular}

$* \mathrm{n}=2$

\subsection{Verificação da potência absorvida pelos microfrascos no forno de microondas} focalizadas

Um dos possíveis problemas da decomposição utilizando o sistema proposto é a homogeneidade de distribuição da potência irradiada nas diferentes posições dos microfrascos no interior do tubo digestor. Quando empregado o tubo digestor para o 
procedimento de digestão no forno de microondas focalizados, este problema é inexistente, pois um possível aquecimento localizado em determinada região pode ser dissipado para os arredores da amostra. Entretanto, ao se trabalhar com pequenos volumes, esse fato poderá tornar-se importante, pois pequenas variações na posição onde a amostra é colocada poderão implicar em diferenças na potência absorvida, influenciando a taxa de aquecimento e, por conseguinte, o tempo e a eficiência da decomposição ${ }^{66}$. Assim, foi necessária uma investigação prévia da absorção da potência nas diferentes posições dos microfrascos dentro do tubo digestor do forno de microondas focalizadas.

A potência absorvida nas diferentes posições dos microfrascos dentro do tubo digestor foi estimada utilizando-se a equação apresentada no item 4.3.2, para calcular a potência total do forno de microondas focalizadas. Nas tabelas 14 e 15 estão apresentadas as estimativas das potências locais calculadas, respectivamente para os microfrascos de 2,0 e $4,0 \mathrm{~mL}$.

Tabela 14: Potência estimada nas posições utilizando microfrascos de 2,0 mL

\begin{tabular}{|c|c|c|c|}
\hline Disposição & Posição & $\begin{array}{c}\text { Potência local } \\
(\mathbf{W})\end{array}$ & $\begin{array}{c}\text { Potencia total } \\
(\mathbf{W})^{*}\end{array}$ \\
\hline & 1 & $2,50 \pm 0,00$ & \\
$\mathrm{~A}$ & 2 & $2,60 \pm 0,14$ & \\
& 3 & $2,55 \pm 0,07$ & $13,10 \pm 0,25$ \\
& 4 & $2,70 \pm 0,14$ & \\
& 1 & $2,70 \pm 0,14$ & \\
\hline \multirow{3}{*}{ B } & 2 & $2,60 \pm 0,00$ & \\
& 3 & $2,90 \pm 0,00$ & \\
& 4 & $2,55 \pm 0,07$ & $13,20 \pm 0,12$ \\
& 5 & $2,50 \pm 0,07$ & \\
\hline
\end{tabular}

* Somatória das potências absorvidas em todos os microfrascos do suporte 
Tabela 15: Potência estimada nas posições utilizando microfrascos de 4,0 mL

\begin{tabular}{|c|c|c|c|}
\hline Disposição & Posição & $\begin{array}{c}\text { Potência local } \\
(\mathbf{W})\end{array}$ & $\begin{array}{c}\text { Potencial total } \\
(\mathbf{W})^{*}\end{array}$ \\
\hline \multirow{3}{*}{ A } & 1 & $4,90 \pm 0,14$ & \\
& 2 & $5,35 \pm 0,35$ & \multirow{2}{*}{$20,80 \pm 0,41$} \\
& 3 & $5,50 \pm 0,14$ & \\
& 1 & $5,05 \pm 0,07$ & \\
\hline \multirow{3}{*}{ B } & 2 & $5,00 \pm 0,41$ & \\
& 3 & $5,00 \pm 0,28$ & $20,95 \pm 0,53$ \\
& 4 & $5,60 \pm 0,00$ & \\
\hline
\end{tabular}

* Somatória das potências absorvidas em todos os microfrascos do suporte

De acordo com os resultados apresentados, a potência nas posições dentro do tubo digestor variou entre 4,9 a 5,6 W (tabela 14) e 2,5 a 2,9 W (tabela 15), Assim, é possível ter uma diferença de até $10 \%$ de absorção para os microfrascos de $4,0 \mathrm{~mL}$ e de $9 \%$ para os microfrascos de $2,0 \mathrm{~mL}$ de um microfrasco para outro dentro do tubo digestor, podendo, dessa maneira, gerar uma pequena diferença na taxa de aquecimento. Entretanto, essa pequena diferença não ocasionou uma diferença significativa na eficiência de decomposição entre os microfrascos. A pequena variação verificada se deve à aleatoriedade de incidência da radiação dentro do tubo digestor, fato este verificado pelo desvio padrão das medições em uma mesma posição.

Outro fator importante verificado neste estudo é a somatória das potências absorvidas dos microfrascos serem menores do que a potência real incidida sobre o sistema, mostrando assim, que $10 \%$ da potência nominal do forno de microondas são suficientes para a decomposição, uma vez que o excesso da radiação não será absorvido devido à pequena quantidade de massa utilizada nos microfrascos. A soma das potências absorvidas dos 4 microfrascos de 4,0 $\mathrm{mL}$ dentro do tubo digestor foi de $20,88 \pm 0,10 \mathrm{~W}$ e dos 5 microfrascos de 2,0 $\mathrm{mL}$ foi de $13,15 \pm 0,05 \mathrm{~W}$, sendo inferiores a potencial total mínima $(10 \%$ do total ou $28,7 \mathrm{~W})$ incidida pelo forno de microondas focalizadas. 


\subsection{Programa de aquecimento do forno de microondas focalizadas}

Para a decomposição de amostras de cabelo, utilizando-se o sistema proposto, foram avaliados dois programas de aquecimento de acordo com a tabela 4. Em ambos os programas foram aplicados $30 \mathrm{~W}(10 \%)$ de potência durante 4 min. No programa 1 , a aplicação dos 4 min de microondas foi de maneira contínua, enquanto que no programa 2, a aplicação de microondas foi alternada, com $1 \mathrm{~min}$ de repouso entre as aplicações de 1 min de microondas.

O programa 1 mostrou-se inadequado para a decomposição das amostras de cabelo, pois a aplicação contínua de microondas sobre os microfrascos de $4 \mathrm{~min}$, provocou um super aquecimento e intensa geração de gases no interior dos mesmos, causando o transbordamento da solução. Com o programa 2, o aquecimento foi mais brando, não se observando intensa geração de gases e nem super aquecimento. Apesar de ser mais longo, o aumento de 3 minutos na etapa de decomposição da amostra do programa 2 não diminuiu significativamente a freqüência de decomposição, uma vez que no método proposto o número de amostra digeridas por vez no forno de microondas focalizadas foi ampliado em 4 ou 5 vezes.

\subsection{Avaliação da quantidade de massa de amostra utilizada para a decomposição nos microfrascos}

A massa de amostra utilizada para decomposição foi verificada para os microfrascos de 2,0 e de 4,0 mL de capacidade. Para os microfrascos de 2,0 mL, as quantidades de 5, 10,20 e $30 \mathrm{mg}$ de amostra de cabelo utilizadas para a decomposição apresentaram soluções resultantes totalmente límpidas, com uma coloração amarelada. Visualmente, não apresentou nenhum resíduo sólido. No entanto, as decomposições realizadas com 40 mg de amostra foram mais problemáticas, pois nesta quantidade de massa ocorreu grande geração de gases, fazendo com que a solução transbordasse para fora do microfrasco. Para os microfrascos de $4,0 \mathrm{~mL}$, verificou-se o mesmo comportamento. As soluções provenientes das decomposições realizadas com $60 \mathrm{mg}$ de amostras ou menos, não apresentaram nenhum resíduo sólido. Tendo as mesmas características das soluções 
adquiridas nas decomposições até $30 \mathrm{mg}$ de amostras nos microfrascos de 2,0 mL. Entretanto, para as decomposições de $80 \mathrm{mg}$ ou acima dessa massa de cabelo nos microfrascos de $4,0 \mathrm{~mL}$, verificou-se grande geração de gases provocando o mesmo efeito de transbordamento ocorrido nos microfrascos de $2,0 \mathrm{~mL}$ para quantidades de amostras superiores a $40 \mathrm{mg}$.

\subsection{Verificação da variação do volume do microfrasco de polipropileno após a decomposição}

No desenvolvimento do presente trabalho, as soluções decompostas foram aferidas nos próprios microfrascos. Por esta razão, foi necessário assegurar-se da exatidão desta calibração.

Os microfrascos de 2,0 $\mathrm{mL}$ foram aferidos apara um volume de 1,35 mL e a variação mostrou-se inferior a $1 \%(\mathrm{n}=20)$. Os microfrascos de $4,0 \mathrm{~mL}$ possuíam escala graduada original. Com base nessa escala, foi feita a aferição desses microfrascos com água, e verificou-se que a aferição era de $3,6 \mathrm{~mL}$ com uma variação inferior a $1 \%$ ( $\mathrm{n}=$ 20). Estas aferições foram realizadas antes do aquecimento.

O polipropileno é relativamente transparente às microondas e mal condutor de calor. Assim, mesmo que a solução em seu interior atinja valores elevados de temperatura, a parede externa dos frascos não fica excessivamente aquecida (suportável ao tato). Tanto para os microfrascos de $2,0 \mathrm{~mL}$ quanto para os microfrascos de $4,0 \mathrm{~mL}$ foram verificadas variações negativas e positivas em relação ao volume aferido após o aquecimento com o programa de decomposição. $\mathrm{O}$ volume interno dos microfrascos de $2,0 \mathrm{~mL}$ variou de $-1,4 \%$ a $1,0 \%$ (figura 13 ). No caso dos microfrascos de $4,0 \mathrm{~mL}$, houve uma variação menor do que $\pm 1,0 \%$ (figura 14). As pequenas variações nos volumes apresentadas para ambos os microfrascos, não foram significativas no volume total dos microfrascos. Essas pequenas variações nos volumes podem estar associadas a erros sistemáticos de pesagem da massa de água e medição de volume, uma vez que a água foi introduzida no interior dos microfrascos manualmente, com auxílio de uma micropipeta Eppendorf. 
De acordo com estes resultados, podemos concluir que não houve uma variação significativa no volume dos microfrascos.

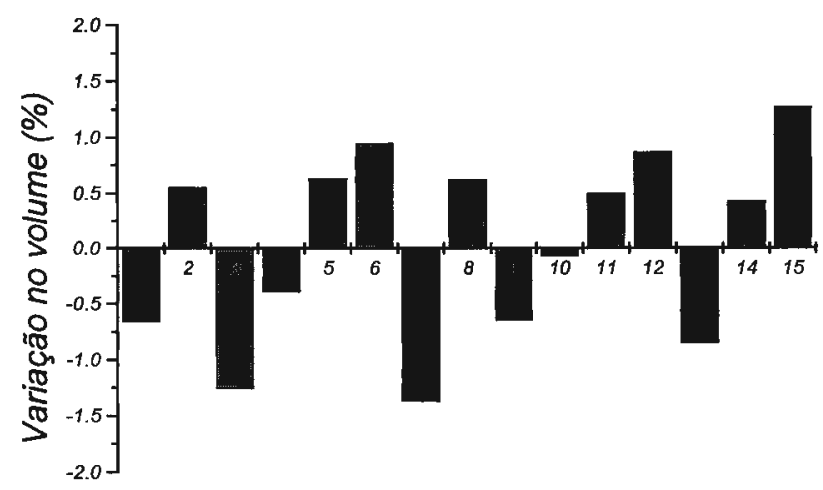

Microfrascos de $2,0 \mathrm{ml}$

Figura 13. Variação do volume dos microfrascos de $2,0 \mathrm{ml}$, verificada após aquecimento com o programa 2 de decomposição da tabela 4 .

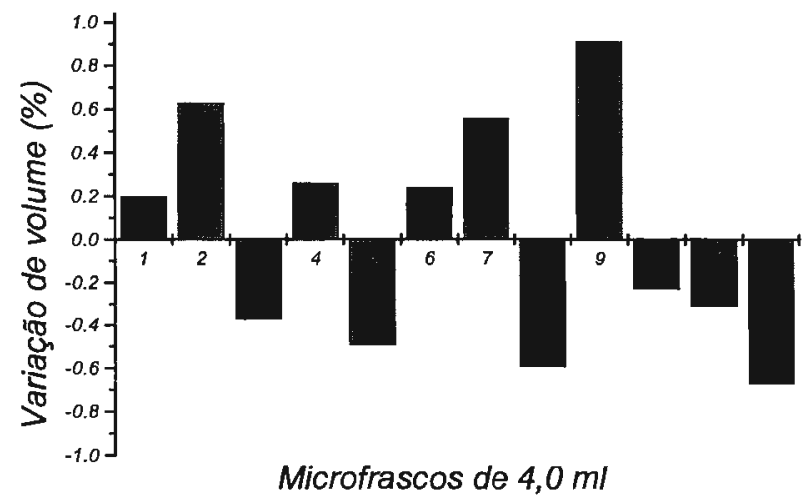

Figura 14. Variação do volume dos microfrascos de $4,0 \mathrm{ml}$, verificada após aquecimento com o programa 2 de decomposição da tabela 4.

\subsection{Avaliação da temperatura do sistema de decomposição proposto}

Em ambos os sistemas de decomposição (com suporte para os microfrascos de 4,0 $\mathrm{mL}$ e $2,0 \mathrm{~mL}$ ) houve um aumento gradativo na temperatura no interior dos microfrascos entre o primeiro minuto até o último minuto de aplicação de microondas. As temperaturas máximas obtidas no sistema de decomposição proposto, utilizando - se os 
microfrascos de 4,0 e $2,0 \mathrm{~mL}$, foram de $102 \pm 5^{\circ} \mathrm{C}$ e $89 \pm 5^{\circ} \mathrm{C}$ respectivamente (figura 15).

As temperaturas obtidas no sistema de decomposição proposto são inferiores às necessárias para uma decomposição completa de materiais biológicos, como cabelo e ou fígado bovino, pois para uma decomposição completa desses materiais é necessário atingir uma temperatura de aproximadamente $160-170^{\circ} \mathrm{C}^{2}$. Essas temperaturas são impossíveis de serem obtidas utilizando o sistema e a mistura ácida proposta. Dependendo da mistura é possível atingir temperaturas superiores, por exemplo, $\mathrm{HNO}_{3}+$ $\mathrm{H}_{2} \mathrm{SO}_{4}$. No sistema proposto, a temperatura é dependente do ponto de ebulição do ácido nítrico $\left(121^{\circ} \mathrm{C} \text { a pressão atmosférica }\right)^{2}$. Para a decomposição completa de diversas amostras orgânicas, são necessárias condições drásticas de decomposição. Um exemplo é os sistemas de decomposições utilizando alta pressão denominado High Pressure Asher ${ }^{\circledR}$ $(\mathrm{HPA})^{35}$. Nesses sistemas utilizam-se ácidos com ponto de ebulição baixo $\left(121^{\circ} \mathrm{C}\right)$, entretanto consegue-se obter decomposições completas devido a elevadas temperaturas atingidas $\left(300^{\circ} \mathrm{C}\right)$ provocadas pela alta pressão.

No caso dos microfrascos de polipropileno, a decomposição não é total, em virtude das baixas temperaturas atingidas pelo sistema. Entretanto, é questionável se decomposições incompletas sejam um fator limitante da exatidão das medições feita por $\mathrm{AAS}^{14}$. Alguns autores comentam que, quando uma amostra é tratada com ácidos, alguns elementos são extraídos para a fase líquida, mesmo sem uma decomposição completa ${ }^{67}$, 68 . 


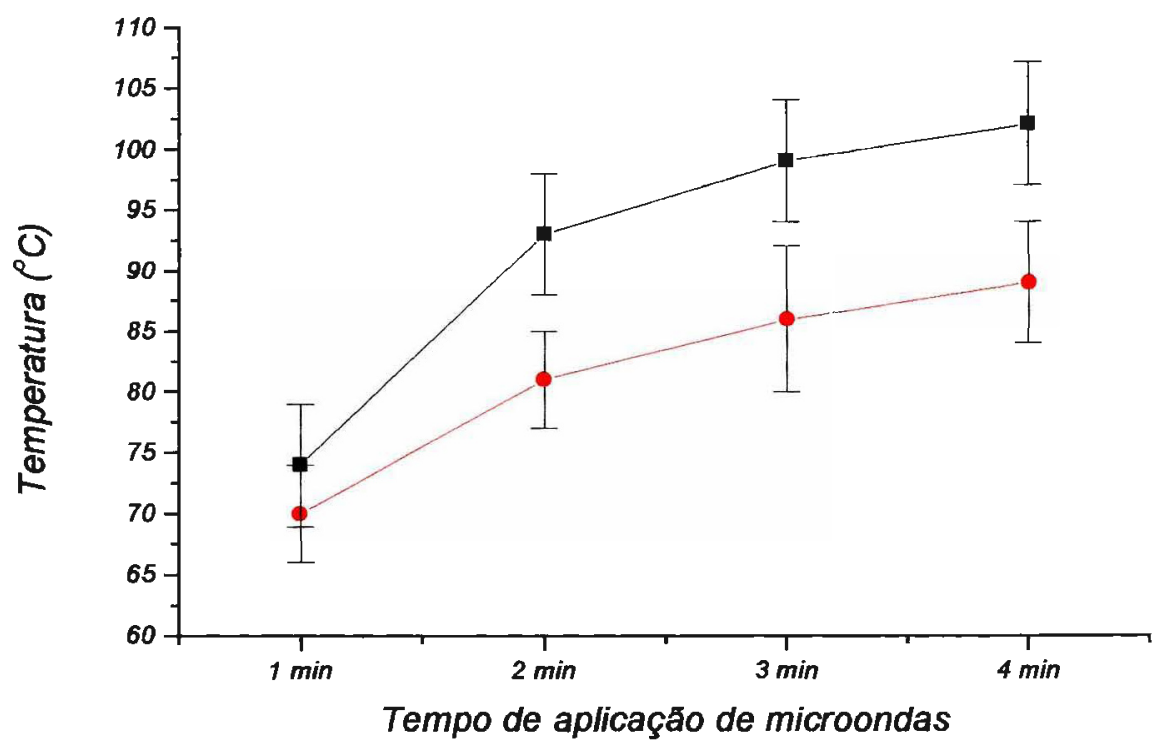

Figura 15. Temperaturas da solução contida nos microfrascos de $4,0 \mathrm{~mL}$ (preta) e $2,0 \mathrm{~mL}$ (vermelha) após a aplicação alternada de 4 minutos de microondas para a decomposição de amostras de cabelo.

\subsection{Avaliação da eficiência do sistema de decomposição proposto}

O teor de carbono remanescente na solução após a decomposição permitiu uma avaliação quantitativa da eficiência do ataque à amostra, representando uma ferramenta de grande utilidade para o desenvolvimento de sistemas de decomposição ${ }^{69}$. Assim, a eficiência de eliminação da matéria orgânica do sistema de decomposição proposto foi avaliada através da determinação de carbono residual nas soluções resultantes da digestão de amostras de cabelo. Apesar da incompleta decomposição da amostra, devido as baixas temperaturas atingidas pelo sistema, os resultados mostraram uma eficiência de eliminação da matéria orgânica comparável à obtida pelos procedimentos convencionais, descritos nos manuais dos fornos de microondas fechados e focalizados (tabela 16). 
Tabela 16: Teor de carbono residual de diferentes procedimentos de digestão

\begin{tabular}{c|c}
\hline Procedimento de decomposição & Carbono residual (\%)* \\
\hline Microondas fechado & $34,7 \pm 1,6^{* *}$ \\
Microondas focalizadas & $35,0 \pm 2,2^{* *}$ \\
Vial 2 & $30,7 \pm 2,3^{* *}$ \\
Vial 4 & $30,2 \pm 0,7^{* *}$ \\
\hline
\end{tabular}

* Porcentagem de carbono residual em relação à quantidade de carbono total $(\% \mathrm{~m} / \mathrm{m})$ $* * \mathrm{n}=2$

Com relação ao parâmetro moagem do cabelo para a decomposição no sistema proposto, verificou-se que a moagem não alterou a eficiência de decomposição. Os teores de carbono residual nas amostras moídas foram semelhantes aos apresentados pelas amostras de cabelos não moídas (tabela 17).

Tabela 17: Teor de carbono residual de diferentes amostras de cabelo

\begin{tabular}{c|c} 
Tipo de amostragem & Carbono residual (\%)* \\
\hline Amostra não moída & $30,7 \pm 2,3^{* *}$ \\
Amostra moída criogenicamente & $31,5 \pm 0,8^{* *}$ \\
\hline
\end{tabular}

* Porcentagem de carbono residual em relação à quantidade de carbono total $(\% \mathrm{~m} / \mathrm{m})$

$* * \mathrm{n}=4$

\subsection{Programa de aquecimento para determinação de Mn em digeridos de cabelo por GFAAS}

Para a otimização do programa de aquecimento visando a determinação de manganês em amostras de digerido de cabelo, realizou-se um estudo do comportamento térmico do manganês na presença do modificador químico $5 \mu \mathrm{g} \mathrm{Pd}+3 \mu \mathrm{g} \mathrm{Mg}$, em uma solução de 5,0 $\mu \mathrm{g} / \mathrm{L}$ de manganês, em uma solução de digerido de cabelo sem adição de analito e em uma solução de digerido de cabelo com adição de 5,0 $\mu \mathrm{g} / \mathrm{L}$ do analito.

O comportamento térmico do manganês, nas duas primeiras soluções foi semelhante, assim, verificou-se que a estabilidade térmica do manganês com o modificador químico não foi alterada na presença da matriz (Figura 16). Tanto na solução analítica quanto na solução de digerido de cabelo, a estabilidade térmica do manganês se manteve até $1300^{\circ} \mathrm{C}$, ocorrendo uma pequena perda de sinal do analito até $1500^{\circ} \mathrm{C}$, e 
acima dessa temperatura, ocorre uma drástica perda de sinal. Na solução de digerido de cabelo com adição de analito, a queda drástica do sinal ocorreu acima de $1300^{\circ} \mathrm{C}$ (figura 16).

Neste estudo, pôde-se verificar a recuperação do analito adicionado na solução de digerido de cabelo. Até a temperatura de $1300^{\circ} \mathrm{C}$, a absorbância integrada medida a partir da solução de digerido de cabelo + adição de $5 \mu \mathrm{g} / \mathrm{L}$ de Mn é próxima à soma algébrica da absorbância da solução de digerido de cabelo mais a absorbância da solução de $5 \mu \mathrm{g} / \mathrm{L}$ de Mn. Isto mostra claramente que a matriz de cabelo não apresenta nenhuma interferência sobre a determinação de manganês por GFAAS, nas condições estudadas.

Considerando este estudo, selecionou-se a temperatura de $1300^{\circ} \mathrm{C}$ como a temperatura de pirólise para determinação do manganês por GFAAS. Verificou-se também que a melhor temperatura de atomização para o manganês foi de $1900^{\circ} \mathrm{C}$ (figura 16). A partir dos dados obtidos adotou-se o programa de aquecimento para determinação de manganês por GFAAS (tabela 18).

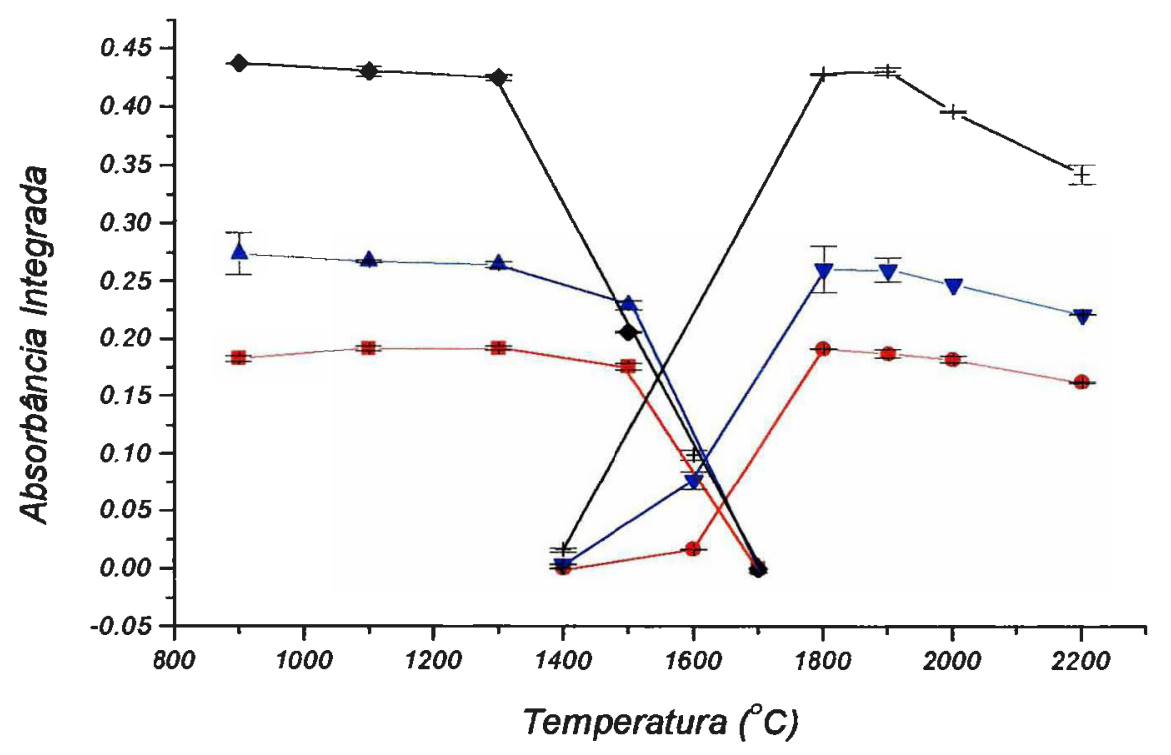

Figura 16. Curvas de temperaturas de pirólise e atomização na presença do modificador químico universal para solução analítica de referência de $5,0 \mu \mathrm{g} / \mathrm{L}$ de manganês (azul), solução de digerido de cabelo (vermelho) e solução de digerido de cabelo + adição de 5,0 $\mu \mathrm{g} / \mathrm{L}$ de $\mathrm{Mn}$ (preta). 
Tabela 18: Programa de aquecimento otimizado para a determinação de manganês

\begin{tabular}{cccccc}
\hline Etapa & $\mathbf{T}$ & Taxa & Patamar & Tempo & Leitura \\
& $\left({ }^{\mathbf{0}} \mathbf{C}\right)$ & $\left({ }^{\mathbf{C}} \mathbf{C} / \mathbf{s}\right)$ & $(\mathbf{s})$ & $(\mathbf{s})$ & \\
\hline Secagem & 100 & 20 & 15 & 19 & Não \\
Secagem & 130 & 10 & 10 & 13 & Não \\
Pirólise & 1300 & 100 & 5 & 16,7 & Não \\
AZ* & 1300 & 0 & 6 & 6 & Não \\
Atomização & 1900 & 1900 & 5 & 5,3 & Sim \\
Limpeza & 2600 & 1000 & 2 & 2,5 & Não \\
*AZ: Auto-zero & & &
\end{tabular}

5.10 Programa de aquecimento para a determinação de Se em digeridos de cabelos por GFAAS

\subsubsection{Verificação do comportamento térmico do selênio frente a diferentes tipos de modificadores químicos}

A utilização de modificador químico é importante para se determinar selênio por espectrometria de absorção atômica com atomização eletrotérmica, visto que a temperatura máxima de pirólise obtida na ausência do modificador químico é de aproximadamente $200^{\circ} \mathrm{C}$. Nessa situação, as espécies $\mathrm{SeO}_{(\mathrm{g})}$ e $\mathrm{SeO}_{2}$, as quais são os principais precursores atômicos de selênio, iniciam a volatilização, provocando a perda de selênio antes da etapa de atomização ${ }^{73}$. Na ausência de modificador químico esse processo inicia-se em $130^{\circ} \mathrm{C}$.

Na presença de modificadores químicos, nota-se o aumento da estabilidade térmica do selênio de até $1400^{\circ} \mathrm{C}$ para $\mathrm{Pd}+\mathrm{Mg}\left(\mathrm{NO}_{3}\right)_{2}$ e de até $1500^{\circ} \mathrm{C}$ para $\mathrm{Na}_{2} \mathrm{IrCl}_{6}+\mathrm{Mg}\left(\mathrm{NO}_{3}\right)_{2}$ (figura 17). Logo, com a utilização desses modificadores, é possível trabalhar com maiores temperaturas de pirólise favorecendo a eliminação de concomitantes indesejáveis e minimizando interferências durante a atomização, 
Quando se utilizou apenas $\mathrm{Na}_{2} \mathrm{IrCl}_{6}$ como modificador químico observou-se uma queda do sinal de absorbância em torno de $400^{\circ} \mathrm{C}$, provavelmente devido à presença de $\mathrm{Cl}^{-}$proveniente do modificador químico, formando espécies voláteis com o selênio, porém a partir de $750^{\circ} \mathrm{C}$ o sinal permaneceu constante até $1500^{\circ} \mathrm{C}$. O patamar na curva de pirólise, verificado acima de $750^{\circ} \mathrm{C}$, pode ser atribuído à formação de alguma espécie termicamente estável, formada entre selênio e irídio. Com a utilização de $\mathrm{Na}_{2} \mathrm{IrCl}_{6}+$ $\mathrm{Mg}\left(\mathrm{NO}_{3}\right)_{2}$, não se observou a queda do sinal analítico até a temperatura de $1500^{\circ} \mathrm{C}$. A estabilização térmica do selênio ocorreu até $1500^{\circ} \mathrm{C}$. Uma das explicações possíveis para esse fato é que o Ir $+\mathrm{Mg}\left(\mathrm{NO}_{3}\right)_{2}$ se comportaria como o $\mathrm{Pd}+\mathrm{Mg}\left(\mathrm{NO}_{3}\right)_{2}$, onde o $\mathrm{Mg}\left(\mathrm{NO}_{3}\right)_{2}$ promove uma distribuição mais uniforme do paládio sobre a superfície do tubo de grafite, durante a secagem e pirólise, gerando microgotículas facilitando a difusão e volatilização do analito durante a atomização ${ }^{21}$.

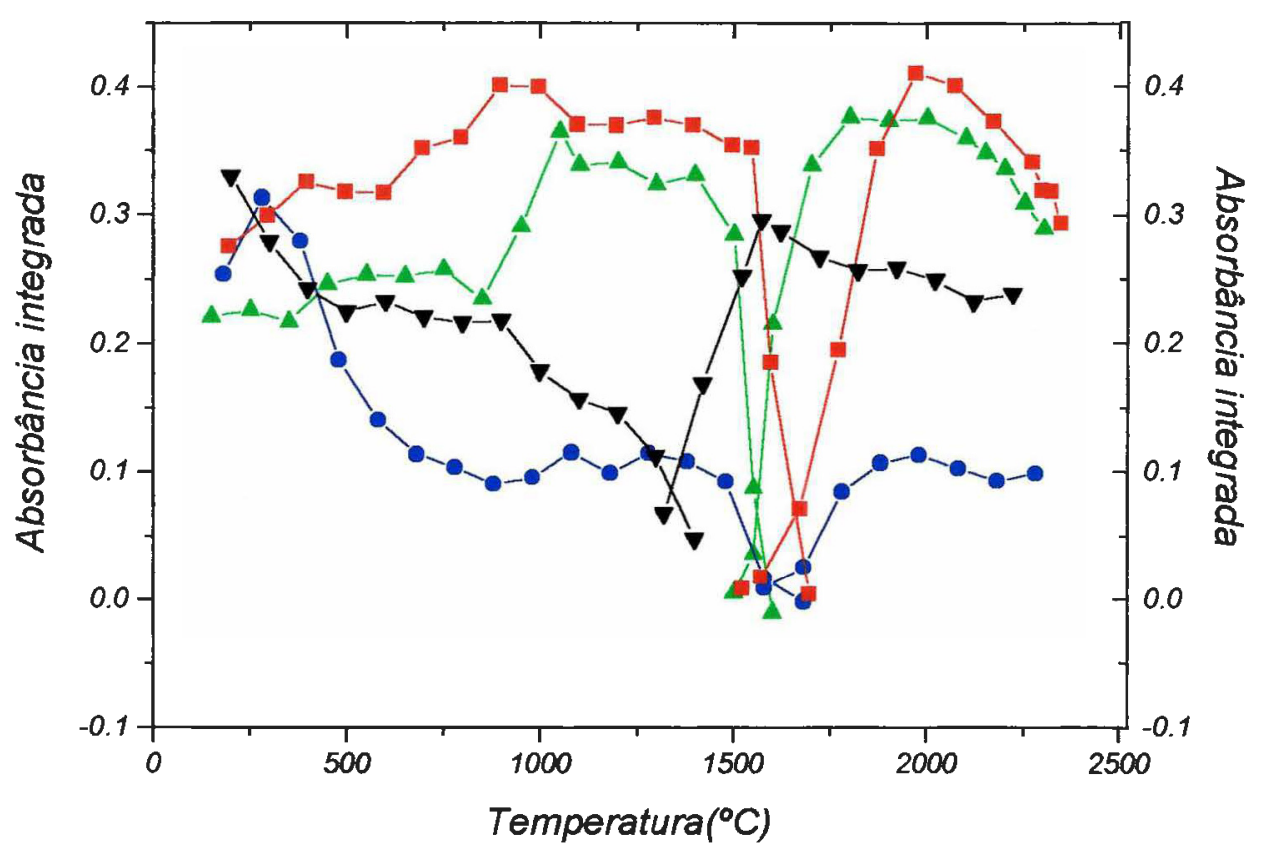

Figura 17. Curvas de temperatura de pirólise e atomização utilizando solução analítica de referência de $100 \mu \mathrm{g} / \mathrm{L}$ de selênio na ausência (preta) e presença de modificadores auímicos: $\mathrm{Pd}+\mathrm{Mg}$ (verde). Ir (azul) e Ir $+\mathrm{Mg}$ (vermelha)

A princípio, a elaboração do programa de aquecimento para a determinação de selênio em amostras de digerido de cabelo por GFAAS e a avaliação da recuperação do 
analito na presença da matriz, foram realizadas através do estudo do comportamento térmico do selênio, utilizando como modificador químico, a mistura irídio e magnésio (5 $\mu \mathrm{g} \operatorname{Ir}+3 \mu \mathrm{g} \mathrm{Mg})$.

Entretanto a estabilidade térmica do selênio na presença da matriz, utilizando a mistura irídio e magnésio como modificador químico, apresentou um decréscimo em relação ao que foi observado para a solução analítica de referência. Na solução analítica de referência, a estabilidade térmica do selênio se manteve até $1500^{\circ} \mathrm{C}$ (figura 17 ), e acima dessa temperatura ocorreu uma drástica perda na sensibilidade. Para a solução de digerido de cabelo com adição do analito, não pode ser avaliado a estabilidade do selênio, pois os sinais analíticos obtidos nas diferentes temperaturas de pirólise apresentaram-se muito pequenos (inferiores ao que foi apresentado na solução analítica de referência) e não tiveram decréscimos significativos com o aumento da temperatura de pirólise (figura 18). A diminuição no sinal analítico na presença da matriz indica a ocorrência de interferência na determinação de selênio utilizando o modificador químico $5 \mu \mathrm{g} \operatorname{Ir}+3 \mu \mathrm{g}$ Mg.

A interferência verificada pode ser atribuída a duas causas distintas: a presença de enxofre nas amostras de digerido de cabelo, pois o selênio pode formar ligação estável com o enxofre presente na amostra, dificultando a atomização do mesmo ${ }^{72}$, ou ainda, a quantidade do modificador químico utilizado não ser o suficiente para estabilizar todo selênio presente na amostra ${ }^{71}$. 


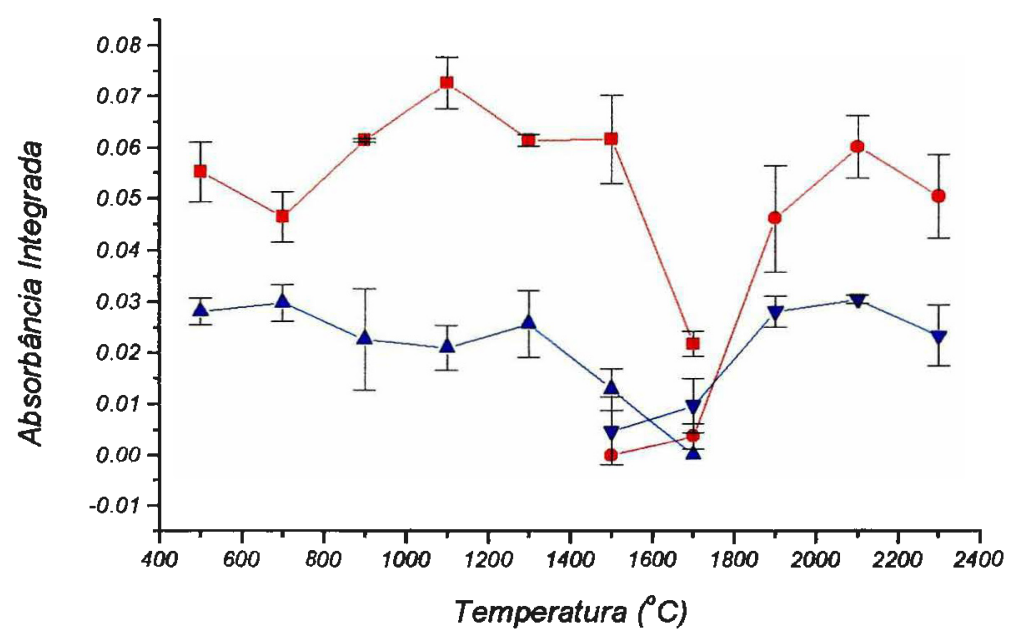

Figura 18. Curvas de temperaturas de pirólise e atomização para a solução analítica de referência de $20 \mu \mathrm{g} / \mathrm{L}$ de selênio (vermelha) e para a solução de digerido de cabelo com adição de $20 \mu \mathrm{g} / \mathrm{L}$ de selênio (azul) utilizando o modificador químico $5 \mu \mathrm{g} \mathrm{Ir}+3 \mu \mathrm{g} \mathrm{Mg}$.

\subsubsection{Avaliação da concentração dos modificadores químicos}

Nos estudos sobre o efeito da concentração do modificador químico $\mathrm{Ir}+\mathrm{Mg}$, observou-se um aumento no sinal analítico de selênio com o aumento da concentração do modificador químico até a solução de concentração $20 \mu \mathrm{g} \mathrm{Ir}+12 \mu \mathrm{g} \mathrm{Mg}$. Acima dessa concentração ocorre uma diminuição do sinal analítico do selênio (figura 19).

Nos estudos envolvendo a concentração do modificador químico $\mathrm{Pd}+\mathrm{Mg}$, o sinal analítico do selênio aumentou conforme aumenta a concentração do modificador químico (figura 19). Entretanto verificou-se também, o aumento da radiação de fundo (BG) ao se utilizar concentrações crescentes do modificador químico $\mathrm{Pd}+\mathrm{Mg}$ (figura 20).

Após a análise dos resultados obtidos neste estudo, foram selecionados os modificadores químicos de concentração $20 \cdot \mu \mathrm{g} \mathrm{Ir}+12 \cdot \mu \mathrm{g} \mathrm{Mg}$ devido ao maior sinal analítico de selênio, e $20 \cdot \mu \mathrm{g} \mathrm{Pd}+10 \cdot \mu \mathrm{g} \mathrm{Mg}$ devido a melhor relação entre sinal analítico e BG. 


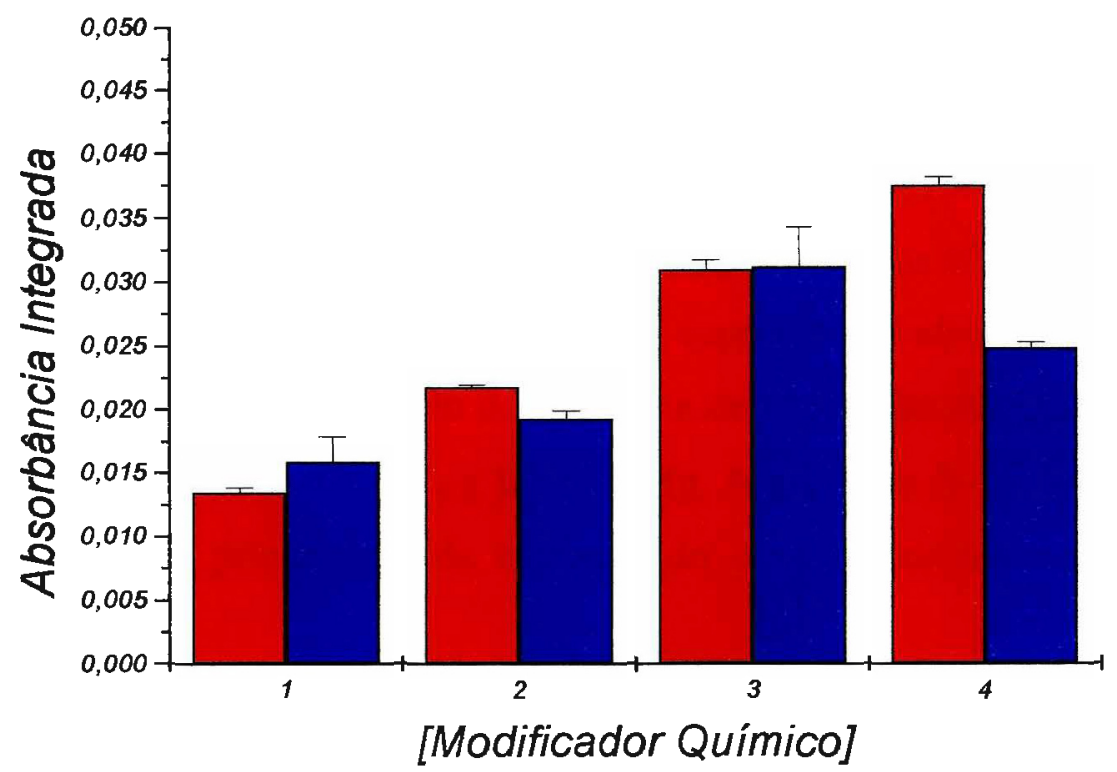

Figura 19 Sinal analítico de $20 \mu \mathrm{g} / \mathrm{L}$ de Se utilizando modificadores químicos $\mathrm{Pd}+\mathrm{Mg}$ (Vermelho) e Ir $+\mathrm{Mg}$ (Azul) com as seguintes concentrações: $1=5 \mu \mathrm{g}$ Ir ou Pd+3 $\mu \mathrm{g} \mathrm{Mg}$, 2=10 $\mu \mathrm{g}$ Ir ou Pd+6 $\mu \mathrm{g} \mathrm{Mg}, 3=20 \mu \mathrm{g} \mathrm{Ir}+12 \mu \mathrm{g} \mathrm{Mg}$ ou $20 \mu \mathrm{g} \mathrm{Pd}+10 \mu \mathrm{g} \mathrm{Mg}, 4=40 \mu \mathrm{g} \mathrm{Ir}+$ $24 \mu \mathrm{g} \mathrm{Mg}$ ou $40 \mu \mathrm{g} \mathrm{Pd}+20 \mu \mathrm{g} \mathrm{Mg}$.

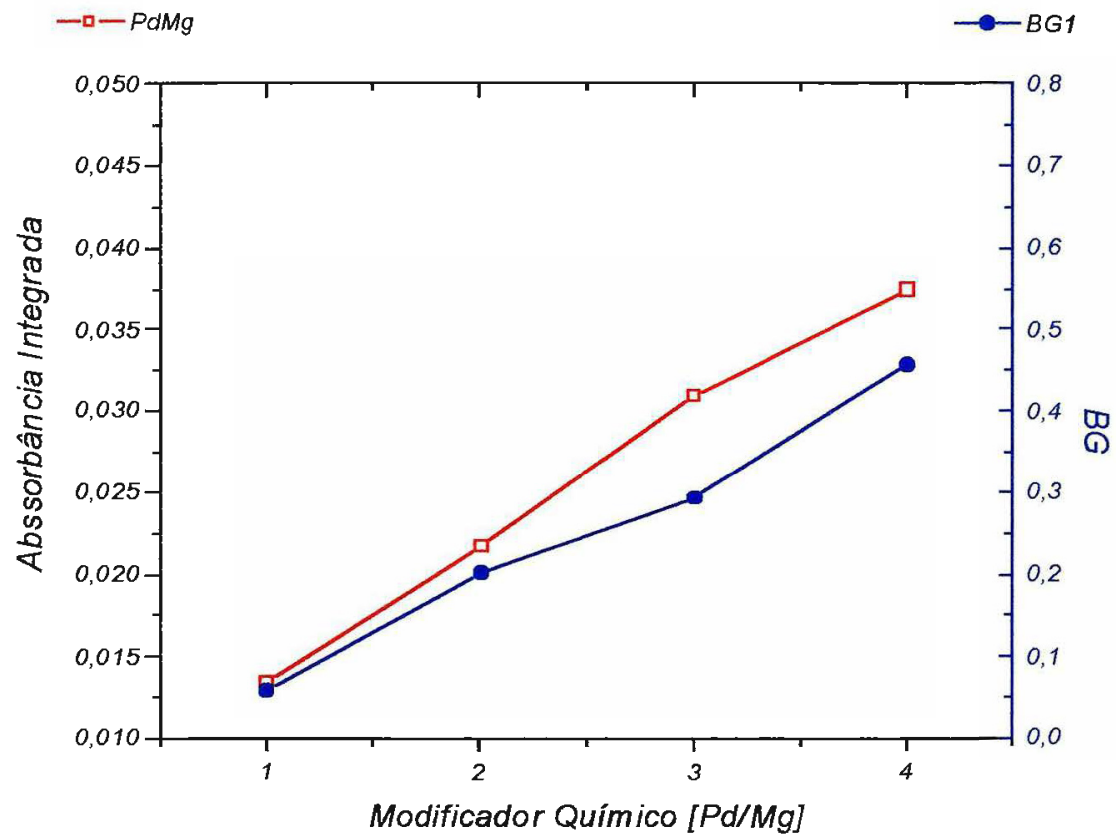

Figura 20. Sinal analítico de selênio (Vermelho) e do BG (Azul) de uma solução analítica de referência de $20 \mu \mathrm{g} / \mathrm{L}$ de selênio utilizando modificador químico $\mathrm{Pd}+\mathrm{Mg}$ com as concentrações: $\mathbf{1}=5 \mu \mathrm{g} \mathrm{Pd}+3 \mu \mathrm{g} \mathrm{Mg}, 2=10 \mu \mathrm{g} \mathrm{Pd}+6 \mu \mathrm{g} \mathrm{Mg}, 3=20 \mu \mathrm{g} \mathrm{Pd}+10$ $\mu \mathrm{g} \mathrm{Mg} \mathrm{e} 4=40 \mu \mathrm{g} \mathrm{Pd}+20 \mu \mathrm{g} \mathrm{Mg}$. 


\subsubsection{Interferência de sulfato na determinação de Se por GFAAS}

Outra hipótese para a atenuação do sinal analítico do selênio na presença da matriz seria a presença de enxofre na amostra, dificultando a atomização do mesmo. Segundo Ni Zhe-Ming $^{72}$, a presença de $5 \mu \mathrm{g}$ de sulfato ou mais provoca um efeito de supressão em valores superiores a $75 \%$ do sinal. Esse efeito de supressão do sinal analítico de selênio foi verificado em amostra de digerido de cabelo na determinação de selênio por GFAAS utilizando o modificador químico $5 \mu \mathrm{g} \operatorname{Ir}+3 \mu \mathrm{g} \mathrm{Mg}$. A presença de sulfato na solução de digerido de cabelo é proveniente da oxidação do enxofre presentes na queratina do cabelo.

Para avaliar a quantidade de enxofre total presente na amostras de cabelo, foi realizada uma análise de enxofre em uma amostra de cabelo utilizando um analisador de enxofre (esta análise foi realizada na Central Analítica do Instituto de Química da USP). $\mathrm{O}$ teor de enxofre encontrado nesta amostra foi de $4,28 \% \mathrm{~m} / \mathrm{m}$. Considerando que todo enxofre presente em $30 \mathrm{mg}$ de amostra de cabelo (quantidade utilizada para decomposição no microfrasco de $2,0 \mathrm{~mL}$ ) fosse oxidado a sulfato e a introdução de $10 \mu \mathrm{L}$ da solução de digerido de cabelo no interior do tubo de grafite para a análise, estaríamos introduzindo $29 \mu \mathrm{g}$ de sulfato. Esta quantidade, provavelmente acarretou o efeito de supressão no sinal analítico de selênio verificado para as amostras de digerido de cabelo.

Nos estudos envolvendo a minimização do efeito de supressão do sinal analítico de selênio utilizando soluções contendo íons bário e estrôncio associada ao uso dos modificadores químicos $20 \mu \mathrm{g} \operatorname{Ir}+12 \mu \mathrm{g} \mathrm{Mg}$ e $20 \mu \mathrm{g} \mathrm{Pd}+10 \mu \mathrm{g} \mathrm{Mg}$, mostraram que ao se utilizar o modificador químico Ir $+\mathrm{Mg}$, mesmo com auxílio dos ânions bário e estrôncio não foi possível a minimização desse efeito. Entretanto, ao se utilizar o modificador químico $\mathrm{Pd}+\mathrm{Mg}$, conseguiu-se eliminar completamente o efeito de supressão, mesmo sem a presença dos ânions bário ou estrôncio (figura 21) 


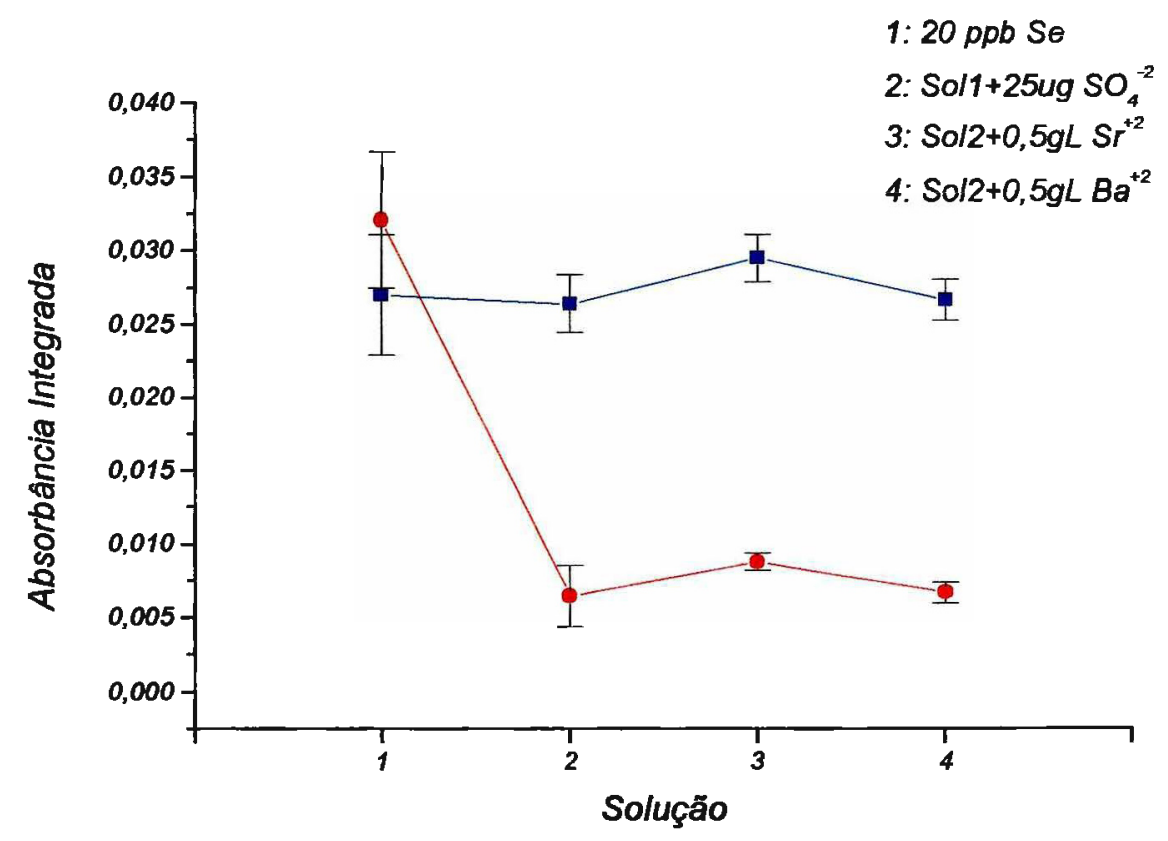

Figura 21. Supressão do sinal analítico de selênio pela presença de $25 \mu \mathrm{g}$ de $\mathrm{SO}_{4}{ }^{2-}$ utilizando os modificadores químicos: $20 \mu \mathrm{g} \mathrm{Pd}+10 \mu \mathrm{g} \mathrm{Mg}$ (Azul) e $20 \mu \mathrm{g} \mathrm{Ir}+12 \mu \mathrm{g} \mathrm{Mg}$ (Vermelho)

Após estes estudos, concluiu-se que o modificador químico $20 \mu \mathrm{g} \mathrm{Pd}+10 \mu \mathrm{g} \mathrm{Mg}$ mostrou-se mais eficiente para determinação de selênio em amostras de digerido de cabelo por GFAAS.

\subsubsection{Programa de aquecimento utilizando o melhor modificador químico}

A otimização do programa de aquecimento, visando à determinação de selênio em amostras de digerido de cabelo foi realizada através do estudo do comportamento térmico

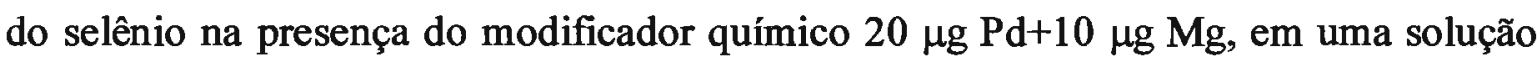
analítica de referência de $20,0 \mu \mathrm{g} / \mathrm{L}$ de selênio e em uma solução de digerido de cabelo com adição de $20,0 \mu \mathrm{g} / \mathrm{L}$ do analito.

Com a eliminação do efeito de supressão do sinal de selênio provocado pelo sulfato, o comportamento térmico do selênio, em ambas as soluções foi semelhante. Tanto na solução analítica de $20 \mu \mathrm{g} / \mathrm{L}$ Se quanto na solução de digerido de cabelo com adição de 
$20 \mu \mathrm{g} / \mathrm{L} \mathrm{Se}$, a estabilidade térmica do selênio se manteve até $1200^{\circ} \mathrm{C}$, ocorrendo perda de sinal do analito acima dessa temperatura (figura 22).

Considerando-se este estudo, selecionou-se a temperatura de $1200^{\circ} \mathrm{C}$ como a temperatura de pirólise para determinação do selênio por GFAAS. Verificou-se também que a melhor temperatura de atomização foi de $1900^{\circ} \mathrm{C}$ (figura 22). A partir dos dados obtidos adotou-se o programa de aquecimento para determinação de selênio por GFAAS (tabela 19).

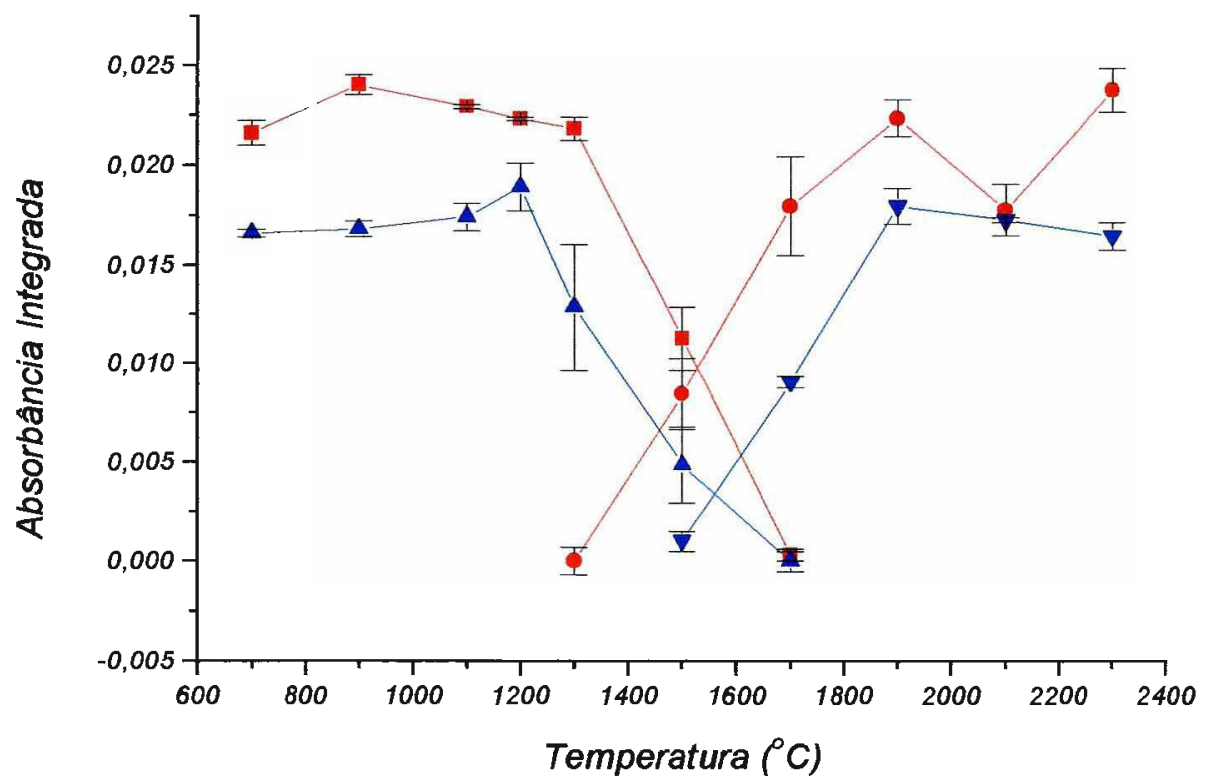

Figura 22: Comportamento térmico do selênio com a utilização do modificador químico $20 \mu \mathrm{g} \mathrm{Pd}+10 \mu \mathrm{g} \mathrm{Mg}$ na solução analítica de referência de $20 \mu \mathrm{g} / \mathrm{L}$ Se (Azul) e na solução de digerido de cabelo com adição de $20 \mu \mathrm{g} / \mathrm{L}$ Se (Vermelho) 
Tabela 19: Programa de aquecimento para a determinação de selênio por GFAAS

\begin{tabular}{llllll}
\hline Etapa & $\begin{array}{l}\mathrm{T} \\
\left({ }^{\mathrm{o}} \mathrm{C}\right)\end{array}$ & $\begin{array}{l}\text { Rampa } \\
(\mathrm{s})\end{array}$ & $\begin{array}{l}\text { Patamar } \\
(\mathrm{s})\end{array}$ & $\begin{array}{l}\text { Vazão Ar } \\
(\mathrm{mL} \text { min-1) }\end{array}$ & Leitura \\
\hline Secagem & 100 & 5 & 15 & 250 & Não \\
Secagem & 130 & 2 & 5 & 250 & Não \\
Pirólise & 1200 & 5 & 15 & 250 & Não \\
Atomização & 1900 & 0 & 5 & 0 & Sim \\
Limpeza & 2500 & 1 & 2 & 250 & Não \\
\hline
\end{tabular}

\subsection{Avaliação de perda dos elementos utilizando o sistema proposto}

O sistema de decomposição proposto envolveu a utilização de microfrascos de polipropileno fixado dentro do tubo digestor para a decomposição de amostras com a tampa do microfrasco semi-rosqueada (sistema "quasi fechado") para alívio de pressão, evitando dessa maneira, problemas relacionadas com explosões dos microfrascos. $\mathrm{O}$ sistema de decomposição "quasi fechado" é também uma forma de se evitar possíveis perdas de elementos por volatilidade, sem a necessidade de se trabalhar em sistemas a altas pressões.

Nesse estudo, verificou-se recuperações similares dos analitos adicionados antes e após a digestão (tabela 20). Os valores obtidos mostraram que no sistema proposto não houve perdas significativas desses elementos durante o processo de decomposição.

Tabela 20: Recuperação dos elementos após o procedimento de digestão

\begin{tabular}{c|ccc}
\hline Analitos & $\begin{array}{c}\text { Rec-Bco* } \\
(\mathbf{\%})\end{array}$ & $\begin{array}{c}\text { Rec-Amostra 1* } \\
\text { (\%) }\end{array}$ & $\begin{array}{c}\text { Rec-Amostra 2** } \\
\text { (\%) }\end{array}$ \\
\hline $\mathrm{Zn}$ & $101 \pm 2$ & $98 \pm 4$ & $99 \pm 4$ \\
$\mathrm{Cu}$ & $96 \pm 3$ & $103 \pm 5$ & $98 \pm 6$ \\
$\mathrm{Fe}$ & $107 \pm 3$ & $96 \pm 3$ & $100 \pm 3$ \\
$\mathrm{Mn}$ & $99 \pm 1$ & $102 \pm 4$ & $113 \pm 7$ \\
$\mathrm{Se}$ & $105 \pm 2$ & $99 \pm 5$ & $93 \pm 4$ \\
\hline
\end{tabular}

* Adição de analito antes do aquecimento por microondas

** Adição de analito após o aquecimento por microondas 


\subsection{Determinação dos elementos em amostra de referência certificada de cabelo e avaliação de adição e recuperação de analitos}

Todos os parâmetros de calibração instrumental para determinação dos elementos em questão estão descritos na tabela 21.

Tabela 21: Parâmetros das calibrações para determinações dos elementos

\begin{tabular}{|c|c|c|c|c|c|}
\hline Parâmetros $^{*}$ & Fe & Cu & Zn & Mn & Se \\
\hline $\mathrm{K}_{1}$ & 0,0081 & 0,0023 & 0,0158 & 0,0113 & 0,0043 \\
\hline $\mathrm{K}_{2}$ & 0,0547 & 0,0650 & 0,2164 & 0,0179 & 0,0015 \\
\hline $\mathrm{R}^{2}$ & 0,999 & 0,995 & 0,999 & 0,998 & 0,973 \\
\hline $\mathrm{CC}$ & 0,08 & 0,07 & 0,02 & $0,24 \mu \mathrm{g} \cdot \mathrm{L}^{-1}$ & $4,40 \mu \mathrm{g} . \mathrm{L}^{-1}$ \\
\hline $\mathrm{LD}$ & $0,11 \mathrm{mg} \cdot \mathrm{L}^{-1}$ & $0,04 \mathrm{mg} \cdot \mathrm{L}^{-1}$ & $0,08 \mathrm{mg} \cdot \mathrm{L}^{-1}$ & $0,14 \mu \mathrm{g} \cdot \mathrm{L}^{-1}$ & $4,42 \mu \mathrm{g} \cdot \mathrm{L}^{-1}$ \\
\hline
\end{tabular}

* $\mathrm{K}_{1}, \overline{\mathrm{K}}_{2}=$ Constantes da equação da reta de calibração: $A b s=K_{1}+K_{2}$ Conc.;

$\mathrm{R}^{2}=$ Coeficiente de correlação; $\mathrm{CC}=$ Concentração característica (mg. $\left.\mathrm{L}^{-1}\right) / 1 \% \mathrm{~A}$

$\mathrm{LD}=$ Limite de deteç̧ão

Devido à diferença de volume requerida pelas duas técnicas analíticas, as digestões das amostras de cabelo para determinações dos elementos $\mathrm{Zn}, \mathrm{Fe}$ e $\mathrm{Cu}$ por FAAS, foram feitas em microfrascos de polipropileno de $4,0 \mathrm{~mL}$, enquanto que para determinações de selênio e manganês por GFAAS, as amostras de cabelo foram digeridas em microfrascos de polipropileno de 2,0 $\mathrm{mL}$ de capacidade.

Devido à pequena quantidade de material de referência disponível, não foi possível realizar essa decomposição em replicada. Os resultados apresentados na tabela 22 foram obtidos para uma única amostra. Os resultados obtidos para o ferro $(116 \mu \mathrm{g} / \mathrm{g})$ e para o zinco $(163 \mu \mathrm{g} / \mathrm{g})$ ficaram dentro do intervalo de confiança certificado.

A tabela 23 apresenta os resultados obtidos para avaliação da adição e recuperação dos elementos zinco, ferro, cobre, manganês e selênio em uma amostra de cabelo, submetida ao procedimento desenvolvido de decomposição após o estabelecimento das melhores condições de trabalho. As recuperações para os elementos avaliados variaram-se entre 90 a $103 \%$. 
Tabela 22: Resultados obtidos em amostra de material de referência IAEA-086

\begin{tabular}{|c|c|c|c|}
\hline Elem & $\begin{array}{c}\text { Valor certificado } \\
(\boldsymbol{\mu g} / \mathbf{g})\end{array}$ & $\begin{array}{c}\text { I.C.C.*} \\
(\boldsymbol{\mu g} / \mathbf{g})\end{array}$ & $\begin{array}{c}\text { Valor Encontrado } \\
(\boldsymbol{\mu g} / \mathbf{g})\end{array}$ \\
\hline $\mathrm{Fe}$ & 123 & $110-136$ & 116 \\
\hline $\mathrm{Zn}$ & 167 & $159-174$ & 163 \\
\hline
\end{tabular}

* Intervalo de confiança certificado

Tabela 23: Resultados obtidos em amostra de cabelo

\begin{tabular}{|c|c|c|}
\hline Elemento & $\begin{array}{c}\text { Adição } \\
(\boldsymbol{\mu g} / \mathbf{g})\end{array}$ & $\begin{array}{c}\text { Recuperação } \\
\mathbf{( \% )}\end{array}$ \\
\hline $\mathrm{Zn}$ & 2000 & 103 \\
\hline $\mathrm{Fe}$ & 200 & 101 \\
\hline $\mathrm{Cu}$ & 200 & 98 \\
\hline $\mathrm{Mn}$ & 2 & 90 \\
\hline $\mathrm{Se}$ & 20 & 93 \\
\hline
\end{tabular}

As amostras analisadas foram cedidas por pessoas saudáveis (não fazem ou não fizeram nenhum tratamento com medicamentos que apresentassem, $\mathrm{Fe}, \mathrm{Cu}, \mathrm{Zn}, \mathrm{Mn}$ e $\mathrm{Se}$ na sua formulação, nos últimos dois anos) e eram pessoas que não utilizavam produtos para tingimento de cabelo.

Os resultados dos elementos avaliados nas amostras de cabelo das oito pessoas apresentaram-se dentro da faixa de concentração considerado normal, segundo a OMS (Órgão Mundial da saúde). Estes resultados mostram-se bastante coerentes, uma vez que, as amostras foram provenientes de pessoas que não apresentavam nenhum indício de contaminação por ingestão de medicamentos ou pelo consumo de produtos de tingimento de cabelo. Além disso, os locais de freqüência das pessoas que cederam as amostras para este estudo, não possuíam fontes de contaminação exógena.

Avaliando-se estes resultados, verifica-se que o sistema proposto para a decomposição das amostras de cabelo adotado neste estudo apresentou-se bastante adequado, preciso e, sobretudo eficiente. 
Tabela 24: Resultados obtidos nas análises dos elementos das amostras de cabelo

\begin{tabular}{|c|c|c|c|c|c|}
\hline Indivíduo & $\mathrm{Fe}\left(\mu \mathrm{g} \cdot \mathrm{g}^{-1}\right)$ & $\mathrm{Cu}\left(\mu \mathrm{g} \cdot \mathrm{g}^{-1}\right)$ & $\mathrm{Zn}\left(\mu \mathrm{g} \cdot \mathrm{g}^{-1}\right)$ & $\operatorname{Mn}\left(\mu \mathrm{g} \cdot \mathrm{g}^{-1}\right)$ & $\operatorname{Se}\left(\mu \mathrm{g} \cdot \mathrm{g}^{-1}\right)$ \\
\hline $\mathrm{A}$ & $39,6 \pm 1,5$ & $20,3 \pm 0,6$ & $274 \pm 18$ & $0,66 \pm 0,08$ & $<\mathrm{LD}^{*}$ \\
\hline B & $30,9 \pm 0,7$ & $25,3 \pm 0,5$ & $174 \pm 8$ & $0,74 \pm 0,06$ & $<\mathrm{LD}^{*}$ \\
\hline $\mathrm{C}$ & $37,3 \pm 1,8$ & $27,4 \pm 1,5$ & $206 \pm 1$ & $1,03 \pm 0,04$ & $<\mathrm{LD}^{*}$ \\
\hline $\mathrm{D}$ & $46,0 \pm 0,7$ & $17,1 \pm 0,7$ & $256 \pm 11$ & $0,44 \pm 0,07$ & $0,52 \pm 0,11$ \\
\hline $\mathrm{E}$ & $47,8 \pm 0,4$ & $15,4 \pm 0,4$ & $217 \pm 3$ & $1,38 \pm 0,06$ & $0,22 \pm 0,14$ \\
\hline $\mathrm{F}$ & $25,7 \pm 1,8$ & $13,7 \pm 1,1$ & $147 \pm 13$ & $0,99 \pm 0,10$ & $<\mathrm{LD}^{*}$ \\
\hline G & $43,3 \pm 1,4$ & $19,8 \pm 0,5$ & $147 \pm 20$ & $1,52 \pm 0,08$ & $0,34 \pm 0,18$ \\
\hline $\mathrm{H}$ & $21,1 \pm 1,6$ & $26,2 \pm 0,4$ & $214 \pm 9$ & $0,69 \pm 0,08$ & $<\mathrm{LD}^{*}$ \\
\hline $\mathrm{FCN}^{* *}$ & $30-60$ & $15-25$ & $150-250$ & $0,5-1,5$ & $0,5-1,0$ \\
\hline
\end{tabular}

* Abaixo do limite de detecção do GFAAS

** Faixa de concentração dos elementos considerada normal para os padrões do Órgão Mundial da Saúde

\subsection{Decomposição de diferentes matrizes utilizando o sistema proposto}

As soluções provenientes da decomposição do material de referência certificado de fígado bovino, com o sistema de decomposição proposto, apresentaram-se límpidas, sem a presença de nenhum resíduo sólido.

As recuperações dos elementos ferro, zinco e cobre na amostra de material de referência certificado de fígado bovino ficaram entre $82 \%$ e $120 \%$ (tabela 25 ), o que mostra uma boa eficiência de decomposição utilizando o sistema de decomposição proposto para diferentes matrizes.

Tabela 25: Recuperações dos elementos $\mathrm{Fe}, \mathrm{Cu}$ e $\mathrm{Zn}$ na amostra de fígado bovino

\begin{tabular}{|c|c|c|c|}
\hline NIST 1577b & V.C $(\mu \mathrm{g} / \mathbf{g})^{*}$ & V.E $(\mu \mathrm{g} / \mathbf{g})^{* *}$ & Recuperação (\%) \\
\hline $\mathbf{F e}$ & $160 \pm 8$ & $192,3 \pm 0,8$ & 120 \\
\hline $\mathbf{C u}$ & $127 \pm 16$ & $104,1 \pm 3,7$ & 82 \\
\hline $\mathbf{Z n}$ & $184 \pm 15$ & $192,5 \pm 10,4$ & 105 \\
\hline * Valores certificados & $* *$ Valores encontrados \\
\hline
\end{tabular}




\section{CONCLUSÕES}

O sistema proposto apresentou-se viável para ser empregado na decomposição de amostras de cabelo para determinações elementares por técnicas espectrométricas devido a sua facilidade de manuseio, simplicidade e eficiência de decomposição ser comparável com procedimentos convencionais em fornos de microondas fechados e focalizados.

$\mathrm{O}$ procedimento aqui mostrado presta-se adequadamente para o pré-tratamento de um número maior de amostras simultaneamente em um forno de microondas focalizadas, com grande economia de reagentes e facilidade de processamento, além da mínima diluição da amostra. Mesmo a etapa de diluição e de aferição de volume são realizadas no próprio microfrasco, com bons resultados para os elementos avaliados. Os valores dos brancos foram sempre muitos pequenos, demonstrando a qualidade dos microfrascos, que não necessitam de limpeza prévia para os elementos investigados. Além disso, os microfrascos foram descartados após o uso para prevenir a contaminação de analitos adsorvidos em sua paredes, devido ao seu baixo custo e facilidade de aquisição, ao contrário de outros recipientes que precisam ser especialmente fabricados para tal, como é o caso de tubos de quartzo, Teflon ${ }^{\circledR}$, e etc.

Outra vantagem apresentada nesse procedimento é a miniaturização dos processos de decomposição, ou seja, o sistema proposto utiliza pequenos volumes de reagentes, produzindo assim, pequenas quantidades de resíduos e aumentando a segurança do analista.

O sistema "quasi fechado" evita o acúmulo de gases causando a alteração do volume, ou ainda, a explosão dos microfrascos, ao mesmo tempo em que este sistema não apresentou perdas dos elementos por volatilização.

O procedimento de decomposição proposto envolveu a utilização de microfrascos de polipropileno de 2,0 e 4,0 ml de capacidade. A escolha dos volumes dos microfrascos foi baseada nas diferentes formas de introdução de amostras das diferentes técnicas espectroanalíticas que estão sendo utilizados no desenvolvimento desse trabalho. As decomposições que estão sendo realizadas nos microfrascos de $2,0 \mathrm{ml}$ visam às determinações por ETAAS, que é uma técnica cuja característica principal é o pequeno 
volume de amostra requerido $(<50 \mu \mathrm{L})$. Entretanto, outras técnicas espectroanalíticas como FAAS, ICP-OES e ICP-MS, necessitam de maiores volumes de amostra, sobretudo quando o sistema de introdução de amostras for a nebulização pneumática. Para estas técnicas, o sistema propõe a utilização dos microfrascos de $4,0 \mathrm{ml}$ para a decomposição de amostras.

A utilização dos microfrascos de polipropileno possibilita a aplicação do princípio do frasco único, ou seja, todas as etapas do procedimento analítico são realizadas no próprio recipiente, deste a coleta da amostra, o armazenamento, o preparo até a análise final, evitando-se dessa maneira, contaminações provenientes do manuseio da amostra.

Apesar das condições relativamente brandas e da decomposição não ser completa (restam em média $30 \%$ de carbono residual), isto não interferiu na determinação de $\mathrm{Fe}, \mathrm{Cu}$ e Zn por FAAS, e principalmente a determinação de Mn e Se por GFAAS, que possibilita etapas de pirólise e utilização de modificadores químicos que minimizam e até eliminam qualquer interferência provocada pela matriz residual.

$\mathrm{Na}$ decomposição em microfrascos, principalmente para microfrascos de $2,0 \mathrm{~mL}$, onde a quantidade de massa utilizada é limitada de no máximo $50 \mathrm{mg}$, é um fator desvantajoso do ponto de vista de certificação dos resultados, ao se levar em conta a não disponibilidade de materiais de referência com certificado de garantia para massas tão pequenas de amostras. Entretanto essa limitação não é tão severa, uma vez que o grande objetivo do sistema proposto é a aumento de processamento de decomposição do microondas focalizadas. $\mathrm{O}$ problema relacionado à representatividade do uso de massas reduzidas pode ser contornado com uma homogeneização adequada da amostra (como por exemplo, a moagem criogênica mostrou-se bastante eficiente para homogeneização da amostra de cabelo) e um número maior de repetições.

O sistema proposto apresenta-se potencialmente aplicável a outros elementos e outras matrizes assim como outras técnicas analíticas, o que pôde ser confirmado com a decomposição de amostras de fígado bovino e em estudos preliminares que envolveram determinações por ICP-OES e ICP-MS. 


\section{REFERÊNCIAS}

1. Iyengar G. V, Subramanian K. S., Woittiez J. R. W., Element Analysis of Biological Samples Principles and Practice, CRC Press, Boca Raton, New York, 1997

2. Krug F. J., Apostila: Pré-tratamento de amostras, III Workshop on Sample Decomposition, 2000

3. Kingston H. M., Haswell S. J., Microwave-enhanced Chemistry. Fundamentals, Sample Preparation and Applications, ACS Professional Reference Book, Washington, 1997.

4. Arruda M. A. Z., Santelli R. E., Química Nova, 20(6) (1997) 638.

5. Britt E., Anal. Chem. News \& Features, 1 (1998) 467A.

6. Tsalev D. L., Sperling M., Welz, B., Analyst, 117 (1992) p.1735.

7. Magalhães C. E. C., Arruda M. A. Z., Química Nova, 21(4) (1998) 459.

8. Pereira E. R., Rohwedder J. J., Arruda M. A. Z., Analyst, 123 (1998) 1023.

9. Burguera J. L., Burguera M., Rondon C. E., Anal. Chim. Acta., 366 (1998) 295.

10. Flores E. M. M., Mortari S. R., and Martins, A. F. J Anal At Spectrom., 12 (1997) p. 379.

11. Flores E. M. M., Tese de Doutoramento em Engenharia "Procedimento combinado para decomposição e determinação de elementos traços por espectrometria de absorção atômica e desenvolvimento de gerador de hidretos em microescala", UFSM, Santa Maria (1997)

12. Araújo G. C. L., Nogueira A. R. A., Nóbrega J. A., Analyst 125 (2000) 1861.

13. Araújo G. C. L., Dissertação de Mestrado "Solubilização de amostras de plantas por digestão ácida em fase vapor", UFSCar, São Carlos (2000).

14. Gouveia S. T., Fatibello-Filho O., Nóbrega J. A., J. Braz. Chem. Soc. 11/3 (2000) 261.

15. Smith F. E., Arsenault E. A., Talanta 43 (1996) 1207.

16. www.sampleprep.duq.udu/sampleprep/

17. Subramanian K. S., Spectrochim. Acta, 51B (1996) 291. 
18. Pozebon D., Dressler V. L., Curtius A. J., Química Nova 22(6) (1999) 838.

19. Borella P., Rovesti S., Caselgrandi E., Bargellini A., Mikrochim. Acta 123 (1996) 271.

20. Sulcek Z., Povondra P., "Methods of Decomposition in Inorganic Analysis", CRC Press, Boca Raton, USA, (1989)

21. Qiao H., Jackson K. W., Spectrochim. Acta. 46B 14 (1991) 1841

22. Gonzalez M. H., Silva F. V., Carrilho E. N., Nóbrega J. A., Nogueira A. R. A., “TA-3 $11^{\circ}$ Encontro Nacional de Química analítica" Livros de resumos

23. Madjidi V., Robertson. J. D., Spectrochim. Acta, 46B (1991) 1723.

24. Brwner R. F., Boorn A. W., Anal. Chem., 56 (7) (1984) 786.

25. Yang J. Y., Yang M. H., Lins S. M., Anal. Chem., 57 (1985) 472.

26. Adeloju S. B., Bond A. M., Briggs M. H., Anal. Chem. 56 (1984) 2397.

27. Avila V. L., Crit. Rev. in Anal. Chem, 29(3) 195.

28. Correia P. R. M., "Determinação simultânea de Manganês/Selênio e Cobre/Zinco em soro sangüíneo por espectrometria de absorção atômica com atomização eletrotérmica”, Dissertação de mestrado, USP/SP São Paulo/SP 2001.

29. Barrera P. B., Nocelo S. F., Piñeiro A. M., J. Anal. At. Spectrom., 14 (1999) 1893.

30. . Mader J., Szaková E., Talanta 43 (1995) 521.

31.Knapp G., Methoden zum Aufschlub organischer Materialien fur die Elementpurenanaluse, in. B. Welz, Atomspecktrometrische, Verlag Chemie, Weinhein/Bergstrabe 1982.

32. Zhou C. Y., Wong M. K., Koh L. L., Wee Y. C., Talanta 43 (1996) 1061.

33. Knapp G., Mikrochim. Acta [Wien] II (1991) 445.

34. Matusiewiec H., Barnes R. M., Anal Chem 57 (1985) 406.

35. Knapp G., Fresenius Z. Anal. Chem, 317 (1984) 213.

36. Jackwerth E., Gomiscek S., Pure \& Appl. chem, 56 (1984) 479.

37. Abu-Samra A., Morris J. S., Koirtyohann S. R., Anal. Chem. 47 (1975) 1475.

38. Zunk B., Anal. Chim. Acta 236 (1990) 337.

39. Chakranorti D., Burguera M., Burguera J. L, Fresenius'J. Anal. Chem., 347, (1993) 
233.

40. Krushevska A., et al. Analyst, 118 (1993) 1175.

41. Burguera M., Burguera J. L., Alarcon O. M., Anal. Chim Acta 179 (1986) 351.

42. Sperling K. R., "Fortschritte in der Atomspektrometrischen Spurenanalytik", Band 2, ed. B. Welz, VCH, Veinheim (1984) 385.

43. Campos R. C., "Estudo de uma nova técnica de introdução de amostras sólidas combustíveis para determinação de elementos voláteis por espectrometria de absorção atômica com chama", Tese de doutorado, Pontifícia Universidade Católica, Rio de janeiro/RJ 1988 p 202

44. Matusiewiec H., Sturgeon R. E., Berman S.S., J. Anal. At. Spectrom., 6 (1991) 283.

45. G. C. L. Araújo, A. R. A. Nogueira, J. A. Nóbrega, Analyst 125 (2000) 1861.

46. Matusiewicz H., Anal Chem 71 (1999) 3145.

47. Ingle J. D. J., Crouch S. R., “Spectrochemical Analysis”, $1^{\mathrm{a}}$ ed. New York, PrenticeHall, 1988

48. Florian D., Knapp G., Anal. Chem. 73 (2001) 1515.

49. Ming Z., Bin H., Bin H. H., Spectrochim. Acta, 49B 10 (1994) 947.

50. Beneze K., Fresenius, J. Anal. Chem. 337 (1990), 867.

51. Chatt, A., Katz S. A, "Hair Analysis, Applications in the Biomedical and Environmental Sciences", VCH Publishers, New York, 1988.

52. Caroli S., Senofonte O., Violante N., Fornarelli L., Microchem. J. 46 (1992) 159.

53. Sachs H., Forensic Sci. Int. (1997), 84, 7.

54. Arnold W., Sachs H., Fresenius'J. Anal. Chem. 348 (1994) 484.

55. Olszerwer E., Smith B., Laganá S., "Manual de Interpretação do mineralograma: Exame do Cabelo" São Paulo: Tecnopress, 1998.

56. Caroli S., Spectrochim Acta 43(B), (1988), 371.

57. Grisham M. B., "Reactive Metalolites of Oxygen and Nitrogen in biology and medicine" R. G. Landes. Co, Austin / Georgetown, (1992).

58. Hiramatsu M., Yoshikawa T. Y., Inoue M., "Food and Free Radicals", Plenum, Press New-York, (1997). 
59. Johnson P. E., J. Nutr, 126 (1996) 2309S.

60.Zhou C. Y., Wong M. K., Koh L. L., Wee Y. C., Talanta 43 (1996) 1061.

61. J. Savory, M. R. Wills, Clin. Chem. 38/8 (1992) 1565.

62. Matusiewicz H., R. E. Sturgeon R. E., Fresenius'J. Anal. Chem. 349 (1994) 428.

63. Hiramatsu M., Yoshikawa T., Inoue M., "Food and Free Radicals", Plenum, Press New-York, (1997).

64. Tolg G., Talanta 19 (1972) 1489.

65. Smith F. E., Arsenault E. A., Talanta 43 (1996) 1207.

66. Fuente M. A., Juárez M; Analyst 120 (1995) 107.

67. Carbonell V., J. Anal. At. Spectrom. 7 (1992) 1085.

68. Morales A., et al.; J. Anal. At. Spectrom. 4 (1989) 329.

69. Krushevska A., Barnes R. M., Amarasiwaradena C. J., Foner H., Martines L., J. Anal. At. Spectrom. 7 (1992) 845. 